Prepared in cooperation with the International Joint Commission, North Dakota Department of Environmental Quality, and Minnesota Pollution Control Agency

\title{
Time-Series Model, Statistical Methods, and Software Documentation for R-OWTREND—An R Package for Analyzing Trends in Stream-Water Quality
}

Open-File Report 2020-1014 Version 1.2, March 2023 



\section{Time-Series Model, Statistical Methods, and Software Documentation for R- OWTREND—An R Package for Analyzing Trends in Stream-Water Quality}

By Aldo V. Vecchia and Rochelle A. Nustad

Prepared in cooperation with the International Joint Commission, North Dakota Department of Environmental Quality, and Minnesota Pollution Control Agency

Open-File Report 2020-1014

Version 1.2, March 2023 


\title{
U.S. Department of the Interior \\ DAVID BERNHARDT, Secretary
}

\section{U.S. Geological Survey James F. Reilly II, Director}

\author{
U.S. Geological Survey, Reston, Virginia: 2020 \\ First Release: 2020 \\ Revised: November 2021 (ver. 1.1) \\ Revised: March 2023 (ver. 1.2)
}

\begin{abstract}
For more information on the USGS - the Federal source for science about the Earth, its natural and living resources, natural hazards, and the environment—visit https://www.usgs.gov or call 1-888-ASK-USGS.

For an overview of USGS information products, including maps, imagery, and publications, visit https://store.usgs.gov/.

Any use of trade, firm, or product names is for descriptive purposes only and does not imply endorsement by the U.S. Government.

Although this information product, for the most part, is in the public domain, it also may contain copyrighted materials as noted in the text. Permission to reproduce copyrighted items must be secured from the copyright owner.

Suggested citation:

Vecchia, A.V., and Nustad, R.A., 2020, Time-series model, statistical methods, and software documentation for ROWTREND-An R package for analyzing trends in stream-water quality (ver. 1.2, March 2023): U.S. Geological Survey Open-File Report 2020-1014, 51 p., https://doi.org/10.3133/ofr20201014.
\end{abstract}

Associated data for this publication:

U.S. Geological Survey, 2019, USGS water data for the Nation: U.S. Geological Survey National Water Information System database, https://doi.org/10.5066/F7P55KJN.

ISSN 2331-1258 (online) 


\section{Acknowledgments}

The authors thank Joseph Nett with the North Dakota Department of Environmental Quality and Hong Wang with the Metropolitan Council for valuable input in developing the R-OWTREND software package.

Thanks also to Chris Ellison and Steve Sando with the U.S. Geological Survey for many years of invaluable technical guidance and encouragement throughout the process of developing the methodology and software behind R-QWTREND. 



\section{Contents}

Acknowledgments ……...................................................................................................................

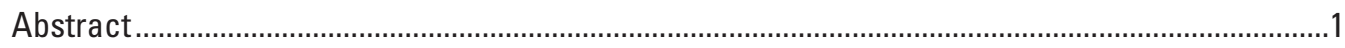

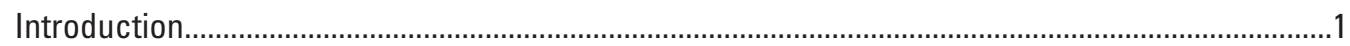

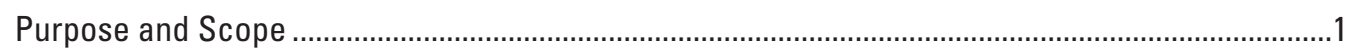

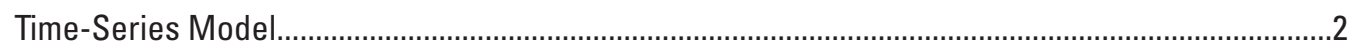

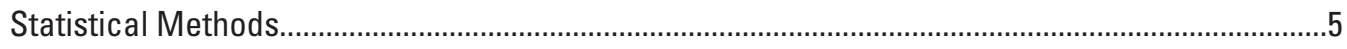

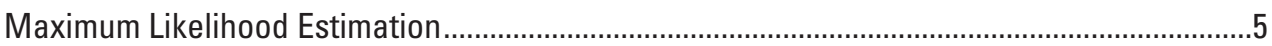

Trend Coefficients and Probability Values.......................................................................

Selecting the Best Trend Model from Several Alternatives ..............................................6

Annual Geometric Mean Concentration ........................................................................

Annual Flow-Weighted Mean Concentration ..................................................................

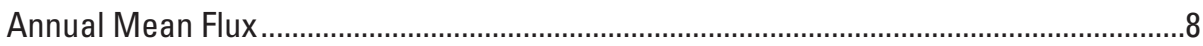

Flow-Averaged Exceedance Probability............................................................................

Annual Flow-Averaged Exceedance Frequency ……………......................................

Censored Concentration Data ......................................................................................

Flagging Potential Outliers ……................................................................................

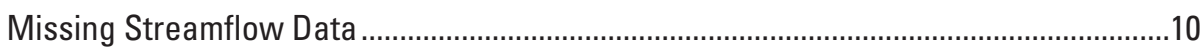

Recommended Minimum Data Requirements ..............................................................11

R-QWTREND Software Documentation ............................................................................

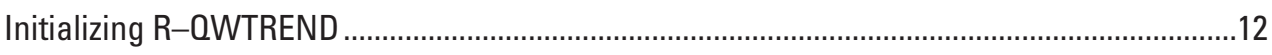

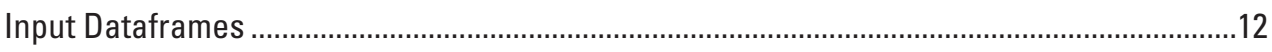

Preparing Data for Time-Series Analysis Using PrepQWdata ..............................................16

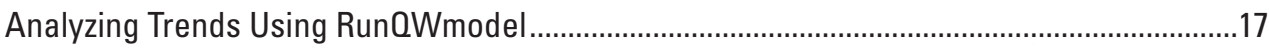

Example 1-Parameter NpnN for RRFargoOWP..................................................24

Example 2-Parameter PTot for RRFargo QWP ……………………….................38

Example 3 -Parameter PTot for RRHalstadQWP ..................................................42

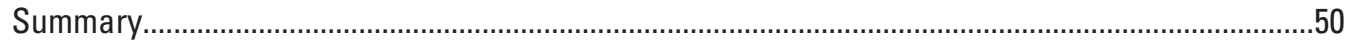

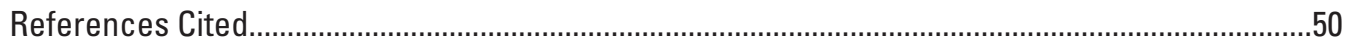

Appendix $1 \quad$ R-OWTREND Software Package ………...........................................................52

\section{Figures}

1. Flowchart showing R-OWTREND functions, inputs, and outputs..................................13

2. Screen capture showing script file for running R-QWTREND practice problems .........14

3. Screen capture showing initial workspace for running R-OWTREND practice problems.

4. Screen capture showing beginning and ending rows of the water-quality dataframe, RRFargo_Prac_0Wdata, and the daily discharge dataframe, RRFargo_Prac_DDdata, for input to the prepQWdata() function .

5. Screen capture showing rows of practice dataset produced by prepQWdata, RRFargoQWP, corresponding to June-August 1971

6. Graphs showing plots produced by prepQWdata for practice dataset, RRFargoOWP. 
7. Graphs showing page 5 of plots produced by prepOWdata for practice dataset, RRHalstadQWP, showing total phosphorus flow-adjusted and flow-adjusted and detrended concentration data versus decimal year

8. Graphs showing page 5 of plots produced by prepQWdata for practice dataset, RRHalstadQWP, with outliers removed, showing total phosphorus flow-adjusted and flow-adjusted and detrended concentration data versus decimal year.

9. Graphs showing reduced graphical output from runOWmodel for nitrate plus nitrite concentration for RRFargoOWP dataset for the null model

10. Graphs showing reduced graphical output from runQWmodel for nitrate plus nitrite concentration for RRFargoQWP dataset for the model with a single monotonic trend.

11. Graphs showing reduced output from runQWmodel for nitrate plus nitrite concentration for RRFargoQWP dataset for the model with two piecewise monotonic trends

12. Graphs showing full graphical output from runQWmodel for nitrate plus nitrite concentration for RRFargo QWP dataset for the model with two piecewise monotonic trends

13. Parameter estimation results from runQWmodel for total phosphorus concentration for RRFargoQWP dataset for the null model and two alternative trend models.

14. Graph showing flow-adjusted total phosphorus concentration for RRFargoOWP dataset for model with piecewise monotonic trend

15. Graphs showing flow-adjusted total phosphorus concentration for RRFargoOWP dataset for model with piecewise monotonic trend and step trend for remark code MPCA.

16. Graph showing flow-averaged exceedance probabilities and expected annual exceedance frequencies for total phosphorus concentration for RRFargoOWP dataset for model M2

17. Parameter estimation results for total phosphorus concentration for RRHalstadQWP dataset for piecewise monotonic trend model with no step trends and with step trend for remark code MPCA.

18. Graphs showing flow-adjusted total phosphorus concentration for RRHalstadQWP dataset for piecewise monotonic trend model with no step trends and with step trend for remark code MPCA.

19. Graphs showing standardized periodic autoregressive moving average model residuals for total phosphorus concentration for RRHalstadQWP dataset for piecewise monotonic trend model with no step trends and with step trend for remark code MPCA

20. Screen captures showing generic numerical model output for total phosphorus concentration for RRHalstadQWP dataset for model M2.

21. Graph showing graphical output for total phosphorus concentration for RRHalstadOWP dataset for model with user-specified trend.

22. Screen capture showing runtime error window produced by runOWmodel when an error is detected during the maximum likelihood estimation. 


\section{Tables}

1. Periodic autoregressive moving average model choices for R-OWTREND .....................4

2. R-QWTREND software files contained in windows folder QWTREND2018V4 ................14

\section{Conversion Factors}

U.S. customary units to International System of Units

\begin{tabular}{lcl}
\hline \multicolumn{1}{c}{ Multiply } & By & \multicolumn{1}{c}{ To obtain } \\
\hline cubic foot per second $(\mathrm{ft} 3 / \mathrm{s})$ & Flow rate & \\
\hline & 0.02832 & cubic meter per second $\left(\mathrm{m}^{3} / \mathrm{s}\right)$ \\
\hline pound, avoirdupois $(\mathrm{lb})$ & Mass & \\
ton, short $(2,000 \mathrm{lb})$ & 0.4536 & kilogram $(\mathrm{kg})$ \\
ton, long $(2,240 \mathrm{lb})$ & 0.9072 & metric ton $(\mathrm{t})$ \\
\hline
\end{tabular}

\section{Supplemental Information}

Concentrations of chemical constituents in water are given in either milligrams per liter (mg/L) or micrograms per liter $(\mu \mathrm{g} / \mathrm{L})$. 


\section{Abbreviations}

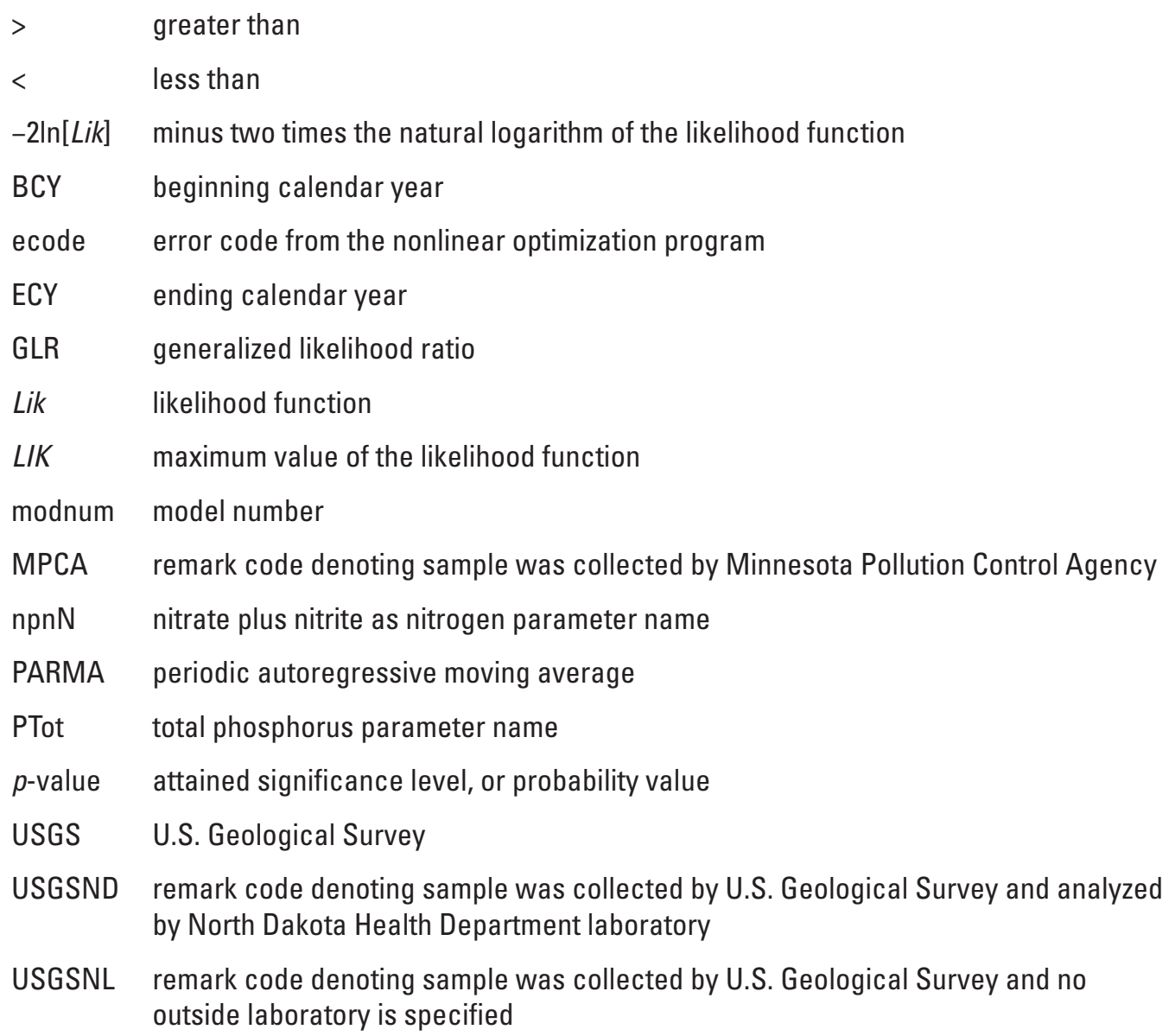

USGSNL remark code denoting sample was collected by U.S. Geological Survey and no outside laboratory is specified 


\title{
Time-Series Model, Statistical Methods, and Software Documentation for R-QWTREND-An R Package for Analyzing Trends in Stream-Water Quality
}

\author{
By Aldo V. Vecchia and Rochelle A. Nustad
}

\section{Abstract}

As part of a U.S. Geological Survey water-quality study started in 2018, in cooperation with the International Joint Commission, North Dakota Department of Environmental Quality, and Minnesota Pollution Control Agency, a publicly available software package called R-QWTREND was developed for analyzing trends in stream-water quality. The R-QWTREND package is a collection of functions written in $\mathrm{R}$, an open source language and a general environment for statistical computing and graphics. The package uses a parametric time-series model to express logarithmically transformed concentration in terms of flow-related variability, trend, and serially correlated model errors. Flow-related variability captures natural variability in concentration on the basis of concurrent and antecedent streamflow. The trend identifies systematic changes in concentration in terms of potential step trends, piecewise monotonic trends, or user-specified trends. Maximum likelihood estimation is used to estimate model parameters and determine the best-fit trend model. This report describes the time-series model and statistical methodology behind R-QWTREND and provides formal documentation for installing and using the package.

\section{Introduction}

A statistical time-series modeling methodology for analyzing trends in stream-water quality, originally developed by Vecchia (2000) and modified as described in Vecchia (2003, 2005), has been used in several subsequent water-quality studies by the U.S. Geological Survey (USGS; Galloway and others, 2012; Risch and others, 2014; Sando and others, 2014a, b, 2015; Giorgino and others, 2018) and other agencies (Jones and Armstrong, 2001; Johnson and others, 2009; Paquette, 2011; Metropolitan Council, 2014). The time-series methodology uses maximum likelihood estimation (Graybill, 1976) to handle complex (nonmonotonic) trends, complex flow-related variability, and seasonal serial correlation structure. The software used in these previous studies for fitting the time-series model to water-quality monitoring data and using the model for parametric statistical inference (hypothesis tests, probability $[p]$-values, confidence intervals) was not publicly available, and the methodology was referred to informally as "QWTREND."

As part of a USGS water-quality study started in 2018, in cooperation with the International Joint Commission, North Dakota Department of Environmental Quality, and Minnesota Pollution Control Agency, a publicly available software package called R-QWTREND was developed for applying the time-series methodology. The R-QWTREND package is a collection of functions written in R (R Development Core Team, 2019), an open source language and a general environment for statistical computing and graphics. Several enhancements to the original methodology are included in the new package, including the ability to model step trends based on remark codes, improved handling of censored data, expanded graphical output for verifying and interpreting the model results, and the capability to estimate constituent flux (load).

\section{Purpose and Scope}

This report describes the time-series model and statistical methodology behind R-QWTREND and provides formal documentation for installing and using the package. This report, along with the accompanying software package, practice datasets, and examples, provides all of the necessary materials and documentation for using R-QWTREND to analyze and interpret trends in stream-water quality based on long-term (10 or more years) datasets on constituent concentration from discrete stream-water samples collected multiple times per year (quarterly or more frequent sampling) and for which the stream-water sampling location is colocated with a streamflow-gaging station from which a complete record of daily mean streamflow is available. 


\section{Time-Series Model}

The statistical time-series model used for R-QWTREND is a modified version of the model described in Vecchia (2005). Each month is divided into six approximately $(\sim)$ 5 -day time intervals corresponding to days $1-5,6-10, \ldots$, $21-25$, and $26-N$, where $N$ is the number of days in the given month. Thus, each year consists of $72(6 \times 12)$ time intervals. Let $t$ denote the decimal year of the midpoint of each time interval, let $C(t)$ be the observed concentration from, at most, a single water-quality sample collected sometime during the interval, and let $Q(t)$ be the average of the daily mean streamflow values for the interval. A complete record of daily mean streamflow is assumed to be available from a streamflow-gaging station at the water-quality sampling site, and $Q(t)$ is the average of the daily mean streamflow values for the individual days within each time interval. Hereafter, $Q(t)$ is referred to simply as "streamflow." Each time interval is assumed to have, at most, a single observed concentration from a discrete stream-water sample collected sometime during the $\sim 5$-day interval. If there are intervals with more than one sample, the sample nearest to the beginning of the interval is selected. For typical monitoring programs, consisting of weekly or less frequent sampling, $C(t)$ may be missing for most of the time intervals, but there can be no missing values for $Q(t)$.

The logarithmically transformed concentration for each time interval is expressed in terms of a constant mean, flowrelated variability, trend, and the model error, as follows:

$$
\log [C(t)]=M L C+F R V A R(t)+\operatorname{TREND}(t)+E(t)
$$

where

$$
\begin{aligned}
& \log \quad \text { is the base-10 logarithm; } \\
& C \text { is constituent concentration, in milligrams or } \\
& \text { micrograms per liter; } \\
& t \quad \text { is the discrete time interval (72, } \sim 5 \text {-day time } \\
& \text { intervals per year), in decimal years; } \\
& M L C \quad \text { is the mean of the logarithmically transformed } \\
& \text { concentration; }
\end{aligned}
$$

Note that in previous reports based on the model described in Vecchia (2005), an 10-day time interval (3 intervals per month, or 36 per year) was used. For R-QWTREND, the time interval was cut in half. The various model components of equation 1 are defined in more detail in the following paragraphs.

FRVAR is designed to capture as much natural, flowrelated variability in logarithmically transformed concentration as possible and is a function of specially crafted variables, called flow anomalies, that depend on concurrent and antecedent streamflow:

$$
\log [Q(t)]=M L Q+L T F A(t)+M T F A(t)+S T F A(t)
$$

where

$$
\begin{aligned}
& Q \quad \text { is (daily mean) streamflow, in cubic feet } \\
& \text { per second; } \\
& t \quad \text { is the discrete time interval (72, } \sim 5 \text {-day time } \\
& \text { intervals per year), in decimal years; } \\
& M L Q \quad \text { is the mean of logarithmically transformed } \\
& \text { streamflow; } \\
& \text { LTFA is the long-term flow anomaly } \\
& \text { (dimensionless); } \\
& \text { MTFA is the midterm flow anomaly } \\
& \text { (dimensionless); and } \\
& \text { STFA is the short-term flow anomaly } \\
& \text { (dimensionless). }
\end{aligned}
$$

LTFA represents long-term (interannual) streamflow variability and is given by a 1-year trailing moving average of the deviation of logarithmically transformed streamflow from its mean,

$$
\operatorname{LTFA}(t)=\frac{1}{72} \sum_{j=0}^{71}\{\log [Q(t-j / 72)]-M L Q\}
$$

where

$j \quad$ is the index of summation.

MTFA represents midterm (seasonal) streamflow variability and is given by

$$
\begin{gathered}
\operatorname{MTFA}(t)=\frac{1}{9} \sum_{j=0}^{8}\{\log [Q(t-j / 72)]-M L Q \\
-L T F A(t-j / 72)\} .
\end{gathered}
$$

STFA represents short-term (day-to-day) streamflow variability and is given by

$$
\operatorname{STFA}(t)=\log [Q(t)]-M L Q-\operatorname{LTFA}(t)-\operatorname{MTFA}(t) .
$$

LTFA represents variability in geometric mean streamflow for the previous year (72 time intervals) with respect to the long-term geometric mean, MTFA represents variability in geometric mean streamflow for the previous 45 days ( 9 time intervals) with respect to geometric mean streamflow for the previous year, and STFA represents variability in logarithmically transformed streamflow for the current time interval with respect to geometric mean streamflow for the previous 45 days. Using the flow anomalies as potential explanatory variables to model flow-related variability often explains much more variability in concentration than using only concurrent flow, $\log [Q(t)]$. Because a trailing (rather than centered) moving average is used to compute the anomalies, the shorter term (higher frequency) anomalies lead the longer term (lower frequency) anomalies. 
The flow anomalies (eqs. 2-5) are used as regression variables in an equation for computing flow-related variability as follows:

$$
\operatorname{FRVAR}(t)=\left\{\begin{array}{l}
\beta_{1} \operatorname{LTFA}(t)+\beta_{2} \operatorname{MTFA}(t)+\beta_{3} \operatorname{MTFA}(t)^{2}+\beta_{4} \operatorname{STFA}(t)+\beta_{5} \operatorname{MTFA}(t) \times \operatorname{STFA}(t) \\
+\beta_{6} \cos (2 \pi t)+\beta_{7} \sin (2 \pi t)+\beta_{8} \cos (4 \pi t)+\beta_{9} \cos (4 \pi t)
\end{array}\right\}
$$

where

$\beta_{1}, \beta_{2}, \ldots, \beta_{9} \quad$ are model coefficients.

The periodic functions (cosine and sine functions) with periods of 1 year and one-half year are included to model seasonal variation in concentration that is not captured by the flow anomaly terms. Other publications may distinguish between flowrelated variability and seasonality but for R-QWTREND, "flow-related variability" includes the flow variables and the seasonal terms.

The flow-adjusted concentration is useful for interpreting the model output and is obtained by subtracting FRVAR from the observed concentration as follows:

$$
F A C(t)=\log [C(t)]-F R V A R(t)=M L C+T R E N D(t)+E(t)
$$

where

$F A C \quad$ is flow-adjusted concentration.

The TREND term in equation 7 is used to model potential temporal trends in the mean of $F A C$ and is assumed to consist of a linear combination of various trend functions as follows:

$$
\operatorname{TREND}(t)=\sum_{j=1}^{J} c_{j} F_{j}(t)
$$

where

$J \quad$ is the total number of trend terms,

$c_{j} \quad$ is the $j$ th trend coefficient, and

$F_{j}(t) \quad$ is the $j$ th trend function.

The trend functions are assumed to consist of four specified types as follows:

1. Piecewise monotonic trends

$$
F_{j}(t)=\left\{\begin{array}{l}
-1 / 2, \text { if } t<B_{j} \\
-1 / 2+(3 / 2)\left[\frac{t-B_{j}}{E_{j}-B_{j}}\right]-(1 / 2)\left[\frac{t-B_{j}}{E_{j}-B_{j}}\right]^{3}, \text { if } B_{j} \leq t \leq E_{j} \\
+1 / 2, \text { if } t>E_{j}
\end{array}\right\}
$$

where

$B_{j} \quad$ is the beginning time (decimal year) for the monotonic trend and

$E_{j} \quad$ is the ending time (decimal year) for the monotonic trend.

2. Step trends based on a specified time interval

$$
F_{j}(t)=\left\{\begin{array}{l}
+1 / 2, \text { if } B_{j} \leq \mathrm{t} \leq E_{j} \\
-1 / 2, \text { otherwise }
\end{array}\right\}
$$


where

$$
\begin{aligned}
& B_{j} \quad \text { is the beginning time (decimal year) for the } \\
& \text { step trend and } \\
& E_{j} \quad \text { is the ending time (decimal year) for the } \\
& \text { step trend. }
\end{aligned}
$$

3. Step trends based on specified sample attribute

$$
F_{j}(t)=\left\{\begin{array}{l}
+1 / 2, \text { if } t \in S_{j} \\
-1 / 2, \text { otherwise }
\end{array}\right\}
$$

where

$$
\begin{aligned}
& \begin{array}{l}
S_{j} \quad \text { is a subset of times corresponding to a } \\
\text { specified sample attribute and }
\end{array} \\
& t \in S_{j} \quad \text { indicates that } t \text { is in the subset } S_{j} \text {. } \\
& \text { 4. Ancillary (user-specified) trends }
\end{aligned}
$$

$$
F_{j}(t)=A(t)
$$

where

$$
A(t) \quad \text { is a user-specified function of } t \text {. }
$$

Piecewise monotonic trends model gradual, multiyear changes in flow-adjusted concentration because of potential anthropogenic causes such as changes in land use/land cover (urbanization, crop acreage or type, and so on). These trends might occur at different times and in different directions (up or down). Interval-based step trends model abrupt changes in flow-adjusted concentration because of anthropogenic causes occurring at known times (for example, a sewage treatment upgrade or dam removal). Step trends based on sample attributes model the potential bias (systematic tendency for sample concentrations to over or underestimate actual concentrations) associated with a particular collection or preservation method, laboratory analytical method, or another sample attribute. Ancillary trend variables can be any known, user-specified time series computed for the upstream drainage basin, such as total fertilizer use, percentage of the basin in a given land use/land cover category (urban, cropland, forested), or any other variable that might explain water-quality changes in the upstream drainage basin.

Next, consider the model error ( $E$ in eq. 1$)$. For a standard parametric regression analysis, the errors are often assumed to be normally distributed with a mean of zero, constant variance, and no serial correlation. However, in practice, water-quality datasets rarely satisfy all these assumptions because the error variance often differs depending on the time of year and the errors often are serially correlated, especially as the sampling frequency increases and the spacing between adjacent samples decreases. Therefore, a special type of time-series model, called a periodic autoregressive moving average (PARMA) model is assumed for the model errors (Salas and others, 1985; Vecchia, 1985). In R-QWTREND, there are three options for specifying the PARMA model number (table 1). For model 1, the error is expressed as the product of a periodic autoregressive coefficient $\left(\phi_{1}[t]\right)$ times the error for the previous time

\begin{tabular}{|c|c|c|c|}
\hline $\begin{array}{l}\text { Model } \\
\text { number }\end{array}$ & Model equation & Model coefficients & $\begin{array}{c}\text { Number of } \\
\text { model } \\
\text { parameters }\end{array}$ \\
\hline 1 & $E(t)=\phi_{1}(t) E(t-1 / 72)+\theta_{0}(t) Z(t)$ & $\begin{array}{l}\phi_{1}(t)=\phi_{10}+\phi_{11} \cos (2 \pi t)+\phi_{12} \sin (2 \pi t) \\
\theta_{0}(t)=\sigma\left[1+\theta_{01} \cos (2 \pi t)+\theta_{02} \sin (2 \pi t)\right]\end{array}$ & 6 \\
\hline 2 & $E(t)=\left\{\begin{array}{l}\phi_{1}(t) E(t-1 / 72)+\phi_{2}(t) E(t-6 / 72) \\
+\theta_{0}(t) Z(t)\end{array}\right\}$ & $\begin{array}{l}\phi_{1}(t)=\phi_{10}+\phi_{11} \cos (2 \pi t)+\phi_{12} \sin (2 \pi t) \\
\phi_{2}(t)=\phi_{20}+\phi_{21} \cos (2 \pi t)+\phi_{22} \sin (2 \pi t) \\
\theta_{0}(t)=\sigma\left[1+\theta_{01} \cos (2 \pi t)+\theta_{02} \sin (2 \pi t)\right]\end{array}$ & 9 \\
\hline 3 & $E(t)=\left\{\begin{array}{l}\phi_{1}(t) E(t-1 / 72)+\phi_{2}(t) E(t-6 / 72) \\
+\theta_{0}(t) Z(t)\end{array}\right\}$ & $\begin{array}{l}\phi_{1}(t)=\left\{\begin{array}{l}\phi_{10}+\phi_{11} \cos (2 \pi t)+\phi_{12} \sin (2 \pi t) \\
+\phi_{13} \cos (4 \pi t)+\phi_{14} \sin (4 \pi t)\end{array}\right\} \\
\phi_{2}(t)=\left\{\begin{array}{l}\phi_{20}+\phi_{21} \cos (2 \pi t)+\phi_{22} \sin (2 \pi t) \\
+\phi_{23} \cos (4 \pi t)+\phi_{24} \sin (4 \pi t)\end{array}\right\} \\
\theta_{0}(t)=\sigma\left\{\begin{array}{l}1+\theta_{01} \cos (2 \pi t)+\theta_{02} \sin (2 \pi t) \\
+\theta_{03} \cos (4 \pi t)+\theta_{04} \sin (4 \pi t)\end{array}\right\}\end{array}$ & 15 \\
\hline
\end{tabular}
point plus a periodic moving average coefficient $\left(\theta_{0}[t]\right)$ times a Gaussian white noise process, $Z(t)$. $Z(t)$ is assumed to consist of a time series of independent and identically distributed standard normal random variables. For model 1, the autoregressive and moving average coefficients are expressed in terms of a single pair of cosine and sine functions with a period of 1 year,

Table 1. Periodic autoregressive moving average model choices for R-QWTREND.

$\left[E\right.$, model error; $t$, discrete time interval (72, approximately 5-day intervals per year, expressed as decimal year); $\phi_{1}$ and $\phi_{2}$, periodic autoregressive coefficients; $\phi_{1 j}$ and $\phi_{2 j}(j=0,1, \ldots, 4)$, periodic autoregressive parameters; $\theta_{0}$, periodic moving average coefficient; $\sigma$ and $\theta_{0 j}(j=0,1, \ldots, 4)$, periodic moving average parameters; $Z$, time series of uncorrelated standard normal random variables] 
and there are six model parameters that need to be estimated (three parameters for the autoregressive coefficient and three for the moving average coefficient). For model 2, there is an additional autoregressive coefficient relating $E(t)$ to itself at a lag of 6 time intervals ( 1 month) and a total of 9 parameters. Model 3 is the same as model 2 except the autoregressive and moving average coefficients are expressed in terms of sine and cosine functions with periods of 1 year and one-half year, for a total of 15 model parameters. The methods for estimating the model parameters and guidelines for selecting the model number are given later in the "Statistical Methods" section of this report.

\section{Statistical Methods}

This section describes the statistical methods used in the R-QWTREND software package to estimate the timeseries model parameters and complete statistical inference (hypothesis tests, $p$-values, and so on) useful for water quality trend analysis. The methods for computing model output, such as estimated annual geometric mean concentration, flowweighted average concentration, flux, and exceedance frequencies, are also described. Finally, the methods used to handle censored concentration data and occasional short gaps in the streamflow record are described and guidelines are given regarding the minimum data requirements recommended for application of the time-series model.

\section{Maximum Likelihood Estimation}

Fitting the trend model requires estimation of the intercept (MLC, eq. 1), nine coefficients for FRVAR (eq. 6), the trend coefficients (eq. 8), and the PARMA model parameters (table 1). These coefficients/parameters are estimated jointly using Gaussian maximum likelihood estimation, as described in Vecchia (2000). The estimation method is complicated because of the PARMA model for the errors (table 1) and the presence of missing values for $\log [C(t)]$. A periodic Kalman filter (Jimenez and others, 1989) with missing data is used to recursively filter the data to remove serial correlation. The periodic Kalman filter is a linear filter, which, when applied to the data, filters out serial correlation:

$$
P M F\left\{Y_{i}-M L C-F R V A R_{i}-\text { TREND }_{i}\right\}=R_{i}
$$

where

$P M F\{$.$\} \quad is the PARMA model filter,$

$Y_{i}=\log \left[C\left(t_{i}\right)\right] \quad$ is the $i$ th (nonmissing) observation,

$t_{i}$ is the observation time of the $i$ th observation,

$F_{R V A R}$ is FRVAR (eq. 6) for the $i$ th observation,

$T_{R E N D_{i}}$ is the trend (eq. 8) for the $i$ th observation, and

$R_{i} \quad$ is the PARMA model residual for the $i$ th observation.
If the PARMA model assumptions are satisfied (see table 1), the PARMA model residuals should be uncorrelated and have an approximate normal distribution with a mean of zero and a variance that depends on $i$,

$$
R_{i}=\sigma s_{i} Z_{i}
$$

where

$$
\begin{array}{cl}
\sigma s_{i} & \text { is the standard deviation of } R_{i} \text { and } \\
Z_{i} & \text { is the standardized PARMA model residual } \\
& \text { for the } i \text { th observation. }
\end{array}
$$

The Gaussian likelihood function is given by

$$
-2 \ln [\operatorname{Lik}]=\sum_{i=1}^{N} \ln \left[\sigma s_{i}\right]+\sum_{i=1}^{N}\left[R_{i} /\left(\sigma s_{i}\right)\right]^{2}
$$

where

$$
\begin{aligned}
\text { ln } & \text { is the natural (base-e) logarithm, } \\
\text { Lik } & \text { is the Gaussian likelihood function, and } \\
N & \text { is the total number of nonmissing } \\
& \text { concentration values. }
\end{aligned}
$$

The Gaussian maximum likelihood parameter estimates are obtained by minimizing equation 15 with respect to the intercept (MLC), the coefficients for FRVAR (the $\beta_{j}$ values in eq. 6), the trend coefficients (the $c_{j}$ values in eq. 8 ), and the PARMA model parameters (table 1). An executable FORTRAN program for computing the maximum likelihood parameter estimates is provided as part of the R-QWTREND software package. A numerical method (modified GaussNewton method; Dennis and Schnabel, 1996) is used to minimize equation 15 . In general terms, if $-2 \ln [\mathrm{Lik}]$ has a unique, well-defined minimum with respect to the model parameters (as indicated by a positive definite Hessian matrix; Dennis and Schnabel, 1996), the data are sufficient for fitting the trend model. If the numerical method is unable to converge to a unique, well-defined minimum, the data are not sufficient to determine all the model parameters. Minimizing $-2 \ln [L i k]$ is equivalent to maximizing $L i k$. To distinguish between the likelihood function ( $L i k$ in eq. 15 ) and its maximum value obtained by minimizing equation $15, L I K$ will be used hereafter to denote the maximized value of the likelihood function.

\section{Trend Coefficients and Probability Values}

Trend analysis involves specification of one or more potential trend models (combination of one or more piecewise monotonic trends, step trends, or user-defined ancillary trends; eq. 8), estimation of the trend coefficients, and evaluation of the attained significance levels, or probability values ( $p$-values) of the specified trend models. The overall $p$-value of a specified trend model is used to test the null hypothesis that all the trend coefficients equal zero versus the alternative that at least one is nonzero. The overall $p$-value can be determined using the generalized likelihood ratio (GLR) test (Graybill, 1976). The GLR test statistic is 


$$
G=-2 \ln \left\{L I K_{0} / L I K_{J}\right\}=\left(-2 \ln \left[L I K_{0}\right]\right)-\left(-2 \ln \left[L I K_{J}\right]\right)
$$

where

$$
\begin{gathered}
G \quad \text { is the GLR test statistic, } \\
L I K_{0} \\
\begin{array}{c}
\text { is the maximum of the likelihood function for } \\
\text { the NULL (no-trend) model, and }
\end{array} \\
L I K_{J} \quad \text { is the maximum of the likelihood function for } \\
\text { the model with } J \text { trend coefficients. }
\end{gathered}
$$

The approximate overall $p$-value for testing the null hypothesis $H_{0}:\left\{c_{j}=0\right.$ for all $\left.j=1, \ldots, J\right\}$ versus the alternative hypothesis $H_{A}:\left\{c_{j} \neq 0\right.$ for at least one $\left.j\right\}$ is

$$
P=\operatorname{Prob}\left[X_{J}>G\right]
$$

where

$$
\begin{aligned}
& X_{J} \quad \text { is a chi-square random variable with } J \text { degrees } \\
& \text { of freedom. }
\end{aligned}
$$

The approximate $p$-values of the individual trend coefficients can be determined in a similar manner by comparing the likelihood function for the trend model with all the coefficients and the likelihood function for the trend model excluding each individual coefficient,

$$
P_{j}=\operatorname{Prob}\left[X_{I}>\left(-2 \ln \left[L I K_{\mathrm{J}}\right]\right)-\left(-2 \ln \left[L I K_{J-1 \mid-j}\right]\right)\right]
$$

where

$$
\begin{aligned}
P_{j} & \begin{array}{c}
\text { is the approximate } p \text {-value for the } j \text { th trend } \\
\text { coefficient; }
\end{array} \\
L I K_{J-1 \mid-j} & \begin{array}{c}
\text { is the maximum value of the likelihood } \\
\text { function for the model with } J-1 \text { trend } \\
\text { coefficients, excluding } c_{j} ; \text { and }
\end{array} \\
& \begin{array}{r}
\text { is a chi-square random variable with } 1 \text { degree } \\
\text { of freedom. }
\end{array}
\end{aligned}
$$

Evaluating equation 18 for all the trend coefficients requires fitting $J+1$ trend models (the full model plus a reduced model for each of the $J$ coefficients). An alternative approach for computing approximate individual $p$-values is based on an asymptotic (large sample size), normal approximation for the probability distribution of the maximum likelihood parameter estimates:

$$
c_{j}^{*} \sim c_{j}+s_{j}^{*} Z
$$

where

$$
\begin{gathered}
c_{j}^{*} \quad \text { is the maximum likelihood estimator of the } j \text { th } \\
\text { trend coefficient, } \\
s_{j}^{*} \quad \text { is the approximate standard error of the } \\
\text { estimated coefficient, and } \\
Z \quad \text { is a standard normal random variable. }
\end{gathered}
$$

The approximate standard errors can be computed as part of the numerical minimization of the full likelihood function with all the trend coefficients; thus (unlike equation 18), there is no need to fit additional models for each $j$. Based on equation 19 , the approximate $p$-value for testing $H_{0}: c_{j}=0$ versus $H_{A}: c_{j} \neq 0$ is given by

$$
P_{j}=2 \operatorname{Prob}\left\{Z>\left|c_{j}^{*} / s_{j}^{*}\right|\right\}
$$

where

$$
\text { |.| denotes absolute value. }
$$

Although the approximate individual $p$-values using equations 18 and 20 generally should be similar, equation 18 is more robust with respect to potential serial correlation of the model errors (as captured using the PARMA model).

When interpreting the trend coefficients, it is useful to express them in terms of raw (untransformed) concentration rather than logarithmically transformed concentration. The piecewise monotonic trends (eq. 9) are defined in such a way that the percentage change in flow-adjusted concentration during the specified trend interval is given by

$$
\Delta_{j}=100\left(10^{\wedge} c_{j}-1\right)
$$

where

$$
\begin{aligned}
& \Delta_{j} \quad \text { is the percentage change in the geometric } \\
& \text { mean of } F A C, \text { in milligrams or micrograms } \\
& \text { per liter, from the beginning }\left(t=B_{j}\right) \text { to the } \\
& \text { end }\left(t=E_{j}\right) \text { of the trend, } \\
& c_{j} \quad \text { is the trend coefficient for the } j \text { th piecewise } \\
& \text { monotonic trend, and } \\
& \wedge \quad \text { denotes exponentiation. }
\end{aligned}
$$

\section{Selecting the Best Trend Model from Several Alternatives}

The generalized likelihood ratio tests previously described (eqs. 16-18) are examples of nested alternatives in which the simpler model (corresponding to $L I K_{0}$ or $L I K_{J-1 \mid-j}$ ) is obtained from the more complex model (corresponding to $L I K_{J}$ ) by setting one or more of the trend coefficients equal to zero. There often are applications in which several alternative, nonnested, trend models may be postulated for a given dataset, all of which seem to be reasonable alternatives, and the investigator wishes to determine the most appropriate, or "best," model from the alternatives. The GLR test statistic $(G)$ can be framed in a more general context as follows. Let

$$
\begin{gathered}
G_{1 \sim 2}=\left(-2 \ln \left[L I K 1_{J-K}\right]\right)-\left(-2 \ln \left[L I K 2_{J}\right]\right) \\
P_{1 \sim 2}=\operatorname{Prob}\left[X_{K}>G_{1 \sim 2}\right]
\end{gathered}
$$

where

$$
\begin{aligned}
& G_{1 \sim 2} \quad \text { is the GLR statistic for testing if models } 1 \text { and } \\
& 2 \text { are equivalent, } \\
& L I K 1_{J-K} \quad \text { is the maximum of the likelihood function for } \\
& \text { a model } 1 \text {, } \\
& J-K \quad \text { is the number of trend coefficients } \\
& \text { for model } 1 \text {, } \\
& L I K 2_{J} \quad \text { is the maximum of the likelihood function for } \\
& \text { a model 2, } \\
& J \quad \text { is the number of trend coefficients } \\
& \text { for model } 2 \text {, }
\end{aligned}
$$


$P_{1 \sim 2} \quad$ is the $p$-value, and

$X_{K} \quad$ is a chi-square random variable with $K$ degrees of freedom.

The smaller the $p$-value, the stronger the indication that the more complex model (model 2) is a better trend model than the less complex model (model 1). To avoid overly complex models, especially when making multiple comparisons among several models, it is recommended that a high significance level (low $p$-value), such as a $p$-value less than $(<) 0.01$, be used. When both models have the same number of parameters $(K=0)$, the $p$-value is undefined. In that case, a good rule of thumb is to consider models 1 and 2 equivalent unless $G_{I \sim 2}$ is greater than (>) 1 ; in which case, model 2 is preferred over model 1.

\section{Annual Geometric Mean Concentration}

The annual geometric mean concentration is a useful statistic for evaluating overall water-quality conditions at a specified sampling location in relation to applicable aquatic benchmarks or in relation to overall water quality at other sampling locations. The annual geometric mean concentration for a given year can be expressed as follows:

$$
\begin{aligned}
& \begin{aligned}
\log \left[G M C_{y}\right]= & \frac{1}{72} \sum_{t \in y} E V\{\log [C(t)]\} \\
E V\{\log [C(t)]\} & =M L C+\operatorname{SFRVAR}(t)+\operatorname{TREND}(t) \\
& +F R V A R(t)-\operatorname{SFRVAR}(t)
\end{aligned} \\
& \operatorname{SFRVAR}(t=y+i / 72)=\frac{1}{N} \sum_{j=B C Y}^{E C Y} \operatorname{FRVAR}(j+i / 72)
\end{aligned}
$$

where

$G M C_{y} \quad$ is the annual geometric mean concentration for year $y$, in milligrams or micrograms per liter.

$y \quad$ is a specified calendar year;

$E V\{$.$\} denotes the expected value (mean) of the$ quantity in braces;

tey indicates that the summation is for all time point in year $y$;

SFRVAR is seasonal flow-related variability;

$i \quad$ is the seasonal time index $(i=1, \ldots, 72)$;

$j \quad$ is an index of summation;

$B C Y$ and $E C Y$ are the beginning and ending calendar years of the period of record; and

$N=E C Y-B C Y+1$ is the number of calendar years in the period of record.

SFRVAR is interpreted as the flow-related variability that would occur under the hypothetical assumption that streamflow conditions were the same year after year. Equation 23 can be expressed as

$$
\begin{aligned}
& G M C_{y}=T_{R G M C_{y} \times F R V G M C_{y}} \\
& T_{R} G M C_{y}=10^{M L C+F A B C F+T R E N D_{y}} \\
& F R V G M C_{y}=10^{\frac{1}{72} \sum_{t \in y}[F R V A R(t)-\operatorname{SFRVAR}(t)]} \\
& F A B C F=\frac{1}{72} \sum_{t \in y} \operatorname{SFRVAR}(t) \\
& \operatorname{TREND}_{y}=\frac{1}{72} \sum_{t \in y} \operatorname{TREND}(t)
\end{aligned}
$$

where

$T R G M C_{y} \quad$ is the trend in annual $G M C$ for year $y$;

$F R V G M C_{y}$ is the flow-related variability in annual GMC for year $y$;

$F A B C F$ is a flow-averaged bias correction factor; and $T R E N D_{y} \quad$ is the annual average of $\operatorname{TREND}(t)$ for year $y$.

The estimated value of $G M C_{y}$ is obtained by substituting the maximum likelihood estimators of the model parameters in place of the true parameters in equation 24. The trend in annual geometric mean concentration defined in equation 24 is often called a "flow-averaged" or "flow-normalized" trend because it is an unbiased estimate of the annual geometric mean concentration that would be observed under the hypothetical assumption that streamflow, and hence flow-related variability, was the same year after year $(F R V A R=S F R V A R)$.

\section{Annual Flow-Weighted Mean Concentration}

When using the trend model (eq. 1) for estimating quantities such as annual flow-weighted mean concentration or annual mean flux, it is important to ensure that the estimates are approximately unbiased when expressed in terms of raw (untransformed) concentration or flux. Annual flow-weighted mean concentration is defined as

$$
F W M C_{y}=\frac{\sum_{t \in y} E V\{C(t)\} Q_{V}(t)}{\sum_{t \in y} Q_{V}(t)}
$$

where

$F W M C_{y} \quad$ is the annual flow-weighted mean concentration for calendar year $y$, in milligrams or micrograms per liter, and

$Q_{V}(t) \quad$ is the total flow volume, in cubic meters, for time interval $t$.

Given the trend model (eq. 1) and the PARMA model for the errors (table 1), concentration has a lognormal distribution with expected value

$$
\begin{aligned}
E V\{C(t)\} & =10^{\wedge}\{M L C+F R \operatorname{VAR}(t)+\operatorname{TREND}(t) \\
& +(1 / 2) \ln [10] \times \operatorname{Var}[E(t)]\}
\end{aligned}
$$


where

$\operatorname{Var}[E(t)] \quad$ is the error variance.

In equation 26 , the error variance depends on the time of year and can be computed directly from the PARMA model (table 1) given the PARMA model parameters. The annual $F W M C$ can be expressed in a similar manner to equation 24 is as follows:

$$
\begin{aligned}
& F W M C_{y}=T R F W M C_{y} \times F R V F W M C_{y} \\
& T R F W M C_{y}=10^{\wedge}\left\{M L C+F A B C F^{*}+T_{R E N D_{y}}\right\}
\end{aligned}
$$

where

$T R F W M C_{y} \quad$ is the trend in in annual $F W M C$ for year $y$, $F R V F W M C_{y} \quad$ is the flow-related variability in annual

$F W M C$ for year $y$, and

$F A B C F^{*} \quad$ is a flow-averaged bias correction factor.

The trend $\left(T R F W M C_{y}\right)$ defined in equation 27, which can also be referred to as "flow-averaged" trend, is the trend that would have occurred under the hypothetical assumption that flow conditions for the analysis period were the same every year. Because $F W M C$ (eq. 25) is expressed in terms of a flow-weighted average of raw (untransformed) concentration, $F A B C F^{*}$ and $F R V F W M C_{y}$ (eq. 27) are much more complicated compared to $F A B C F$ and $F R V G M C_{y}$ (eq. 24), where the latter formulas were easily derived because $G M C$ (eq. 23) is a simple average of logarithmically transformed concentration. In R-QWTREND, $F A B C F^{*}$ and $F R V F W M C_{y}$ are computed internally using a numerical algorithm and explicit formulas are not provided.

The estimated value of $F W M C_{y}$ is obtained by substituting the maximum likelihood estimators of the model parameters in place of the true parameters in equation 25. By the asymptotic (large sample) properties of maximum likelihood estimation (Graybill, 1976), as the sample size becomes large, the resulting estimated value is approximately unbiased and optimal (minimum variance). However, for small sample sizes, the estimator may have substantial bias (Cohn and others, 1989). As a general rule of thumb, the estimated value of $F W M C$ should be approximately unbiased for sample sizes of at least 60 observations and record lengths of at least 10 years, provided the samples are reasonably spread out among seasons (time of year), flow conditions (as represented by the flow anomaly terms), and calendar years. The minimum data requirements recommended for the application of $\mathrm{R}-$ QWTREND are described later in this section.

\section{Annual Mean Flux}

Annual mean flux (often referred to as "load") is an important statistic for determining which subbasins of a large watershed contribute the most constituent mass (load). Annual mean flux is defined as

$$
F L U X_{y}=\frac{10^{6}}{365} F W M C_{y} \times A F V_{y}
$$

where

FLUX $X_{y}$ is annual mean flux for calendar year $y$, in metric tons $(1,000$ kilograms $[\mathrm{kg}])$ per day (if concentration is in milligrams per liter) or kilograms per day (if concentration is in micrograms per liter);

$F W M C_{y} \quad$ is annual flow-weighted mean concentration (eq. 25), in milligrams or micrograms per liter; and

$A F V_{y}$ is annual flow volume, in cubic meters.

In a similar manner to equation 27 , the annual mean flux can be expressed as

$$
\begin{aligned}
& F^{\prime} U X_{y}=\operatorname{TRFLUX}_{y} \times F R V F L U X_{y} \\
& \operatorname{TRFLUX}_{y}=10^{\wedge}\left\{M L C+F A B C F^{* *}+\operatorname{TREND}_{y}\right\}
\end{aligned}
$$

where

TRFLUX $X_{y}$ is the trend in in annual flux for year $y$, FRVFLUX $X_{y}$ is the flow-related variability in annual flux for year $y$, and

$F A B C F^{* *}$ is a flow-averaged bias correction factor.

As described previously for $F W M C$, the estimated

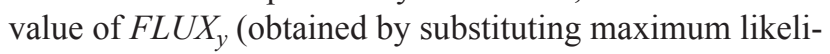
hood parameter estimates in place of true parameter values in eq. 28) should be approximately unbiased for a large sample size (at least 60 observations) but may have substantial bias for a smaller sample size.

\section{Flow-Averaged Exceedance Probability}

Flow-averaged exceedance probabilities are useful for determining how the likelihood of exceeding a specified concentration threshold during a fixed time of year changes through time in response to potential concentration trends. Given the time-series model (eq. 1) for logarithmically transformed concentration, the probability of exceeding a specified concentration is given by

$$
\begin{aligned}
& P_{e}(t)=\operatorname{Prob}\left\{C(t)>C_{e}\right\}= \\
& \operatorname{Prob}\left\{Z>\frac{\log C_{e}-M L C-F R V A R(t)-\operatorname{TREND}(t)}{S D\{E(t)\}}\right\}
\end{aligned}
$$

where

$$
\begin{array}{cl}
P_{e} & \text { is the exceedance probability, } \\
C_{e} & \text { is a specified exceedance level, } \\
S D\{E(t)\} & \text { is the standard deviation of the error, } E(t), \text { and } \\
Z & \text { is a standard normal random variable. } \\
\text { Year-to-year differences in FRVAR generally cause } \\
\text { substantial interannual variability in the exceedance probabil- } \\
\text { ity. Therefore, alternative probabilities, called flow-averaged }
\end{array}
$$


exceedance probabilities, are computed under the hypothetical assumption that flow-related variability during each year is equal to the seasonal average flow-related variability:

$$
\operatorname{FRVAR}(t)=\operatorname{SFRVAR}(t)
$$

where

SFRVAR is seasonal flow-related variability (eq. 23). Combining equations 30 and 31 yields

$$
\begin{aligned}
& F A P_{e}(t)= \\
& \operatorname{Prob}\left\{Z>\frac{\log C_{e}-M L C-\operatorname{SFRVAR}(t)-\operatorname{TREND}(t)}{S D\{E(t)\}}\right\}
\end{aligned}
$$

where

$F A P_{e} \quad$ is the flow-averaged exceedance probability.

For any given decimal time, $t=y+i / 72, F A P_{e}(t)$ is interpreted as the probability that $C(t)$ will be greater than the specified exceedance level given "typical" (annually averaged) flow conditions for that time of year.

\section{Annual Flow-Averaged Exceedance Frequency}

The flow-averaged exceedance probability (eq. 32) indicates the relative chance of exceeding a specified level of concern during any fixed 5-day time interval. For example, if $F A P_{e}(t)=0.9$, there is a 90 -percent chance that concentration at time $t$ exceeds the level of concern, whereas $\operatorname{FAP}_{e}(t)=0.1$ indicates only a 10-percent chance of exceeding the level of concern. Another important consideration for some applications is to determine the amount of time during a given year that concentration is expected to exceed the specified level of concern. Given the flow-averaged exceedance probabilities (eq. 32), annual flow-averaged exceedance frequency is defined as follows:

$$
F_{A} F_{e}(y)=\frac{1}{72} \sum_{i=1}^{72} F A P_{e}(y+i / 72)
$$

where

$$
\begin{gathered}
F A F_{e}(y) \quad \text { is the annual flow-averaged exceedance } \\
\text { frequency for year } y .
\end{gathered}
$$

The annual flow-averaged exceedance frequency is interpreted at the expected fraction of time during year $y$ that concentration exceeds the specified level of concern, assuming "typical" (flow-averaged) conditions. For example, if $F A F_{e}(y)=0.25$, we would expect to see about 3 decimal months (18, 5-day time intervals) during year $y$ with concentrations greater than the specified exceedance level. If $F A F_{e}(y)=0.001$, which is small in relation to the model time step $(1 / 72=0.015)$, we would expect virtually none of the 5-day intervals to exceed the specified level.

\section{Censored Concentration Data}

The maximum likelihood parameter estimation methods previously described in this report assume that the concentration data used to fit the model are known (uncensored) values. Exact maximum likelihood parameter estimation with censored data and PARMA errors (table 1) is not tractable; however, an alternative, approximate maximum likelihood estimation methodology can be used when there is a moderate amount (less than about 25 percent) of censored data. The $i$ th observed concentration is censored if it is known to be less than a specified detection limit,

$$
C\left(t_{i}\right)<D L\left(t_{i}\right)
$$

where

$t_{i}$ is the time index of a censored observation,

$C\left(t_{i}\right) \quad$ is the true (but unknown) concentration for the censored observation, and

$D L\left(t_{i}\right) \quad$ is a specified detection limit.

Concentration values for censored observations are imputed using a preliminary trend model with uncorrelated errors:

$$
\log [C(t)]=M L C+F R V A R(t)+\operatorname{TREND} *(t)+\sigma Z^{*}(t)
$$

where

TREND* is a preliminary trend model defined below and

$Z^{*}(t) \quad$ is a time series of uncorrelated standard normal random variables.

The preliminary trend model consists of a quadratic spline with number and placement of interior knots that depend on the record length,

$$
\operatorname{TREND*}(t)=\sum_{j=1}^{D+1} c_{j}^{*} F_{j}^{*}(t)
$$

where

$D=\operatorname{int}[R L / 10] \quad$ is the number of full decades in the period of record;

$R L \quad$ is the record length, in calendar years; int[.] is the greatest integer less than or equal to the quantity in brackets; and

$F_{j}^{*}(t) \quad$ is the $j$ th basis function $(j=1,2, \ldots, D+1)$ for a quadratic spline with $D$ interior knots where the knots are spaced 10 years apart and are symmetrically distributed around the midpoint of the record.

For example, if the beginning and ending calendar years of the record are $B C Y=1990$ and $E C Y=2004$, then $R L=15$, $D=1$, and there is a single interior knot at decimal year 1997.5. If $B C Y=1990$ and $E C Y=2010$, then $R L=21, D=2$, and there are two interior knots at decimal years 1995.5 and 2005.5. 
Given the preliminary trend model (eq. 35), the expected value for a censored observation (eq. 34) is computed using the following formula:

$$
\begin{aligned}
\log \left[C^{*}\left(t_{i}\right)\right]=M L C & +F R V A R\left(t_{i}\right)+\operatorname{TREND}^{*}\left(t_{i}\right) \\
& +\sigma E\left[Z \mid Z<Z_{i}^{*}\right]
\end{aligned}
$$

where

$C^{*}\left(t_{i}\right) \quad$ is the expected value for the censored concentration (eq. 34);

$Z_{i}^{*}=\frac{\log \left[D L\left(t_{i}\right)\right]-M L C-F R V A R\left(t_{i}\right)-\operatorname{TREND}^{*}\left(t_{i}\right)}{\sigma} \quad$ is the model error assuming $C\left(t_{i}\right)=D L\left(t_{i}\right)$; and

$E\left[Z \mid Z<Z_{i}^{*}\right] \quad$ is the conditional expected value of a standard normal random variable $(Z)$ given $Z$ is less than $Z_{i}^{*}$.

A two-step procedure is used to estimate values for censored observations:

1. The survreg function in the Survival Analysis package (Therneau, 2019) is used to obtain maximum likelihood estimates of the model parameters for the preliminary trend model with censored observations (eq. 35).

2. For censored observations, the parameter estimates from step 1 are used in equation 37 to compute the estimated concentration $C^{*}\left(t_{i}\right)$. For subsequent trend analysis, the resulting estimated value(s) are treated the same as if they were known (uncensored) observations.

This approach is preferred to the naive method of substituting arbitrary values (such as one-half of the detection limit) for censored observations, while still being computationally straightforward. Because the assumed preliminary trend model does not depend on the actual (and a priori unknown) trend, nor on the actual (and a priori unknown) serial correlation structure, the estimated values remain the same no matter what the fitted trend model might look like. Allowing the estimated values to depend on the actual (rather than preliminary) trend model is too computationally intensive to be feasible. However, extra care should be taken when verifying and interpreting the fitted trend models using this approach, particularly with respect to $p$-values, especially for moderate to high (greater than 25 percent) censoring rates.

\section{Flagging Potential Outliers}

The R-QWTREND methodology is based on a parametric time-series model (eq. 1), in which log-transformed concentration is modeled using a multiple linear regression model with Gaussian (normally distributed), serially correlated errors. As is the case with any parametric model, outliers must be carefully examined and dealt with to ensure that the fitted model is not unduly influenced by a very small fraction (or perhaps even one) of the observations. For a general discussion of outliers in a multiple linear regression setting, see Helsel and Hirsch (1992).
Outliers can generally be grouped into two cases: outliers for which the reported concentration value is erroneous (for example, data transcription error, improper sample collection or preservation methods, laboratory equipment malfunction) or outliers for which the reported concentration is accurate but for which the environmental conditions at the time of the sample were extreme compared to the vast majority of samples (for example, dam failure, record flood or drought). In either case, outliers should be either corrected (if feasible) or removed before analyzing trends. For purposes of trend analysis, provided a small fraction (say, less than about 2 percent) of the observations are removed, there should be little in the way of adverse consequences of removing outliers. Conversely, if the outliers are not removed, there can be serious adverse consequences such as misidentification of trends or highly biased model output, depending on how influential the outliers are in determining the maximum likelihood parameter estimates. In any case, the investigator needs to carefully examine potential outliers and, if not removed, at least verify that they are not adversely affecting the model results.

Much time and effort can be saved by identifying and removing potential outliers before performing a rigorous trend analysis. The preliminary trend model for filling in censored concentrations (eq. 35) provides a good tool for identifying potential outliers before performing a rigorous analysis. For R-QWTREND, an observation is flagged as a potential outlier if the absolute value of the standardized residual from the preliminary trend model (eq. 35), $Z^{*}(t)=\{\log [C(t)]-M L C-$ $\left.\operatorname{FRVAR}(t)-\operatorname{TREND}^{*}(t)\right\} / \sigma$, is larger than 3.5 in absolute value. The chance that the absolute value of a standard normal random variable exceeds 3.5 is very small (less than 1 in 2,000), therefore, this criterion is conservative in that it is likely to flag only true outliers. In general, if more than a small fraction (2 percent or less) of observations are flagged as potential outliers using this criterion, the data may not be appropriate for analysis using R-QWTREND.

\section{Missing Streamflow Data}

The computations previously described require that there be no missing values for the streamflow variable, $Q(t)$. A small amount of missing streamflow data can be filled in using the streamflow interpolation method described in this section. This interpolation method should be used only if there are occasional short gaps (less than 6 months in duration) in the record. In particular, the following minimum streamflow data requirements are recommended:

- At least 80 percent (four out of five) of the calendar years in the period of analysis have a compete streamflow record, including the first and last year of the period of analysis.

- There are no streamflow gaps longer than 6 months in duration. 
If these recommendations hold, the following steps may be used to fill in missing streamflow record. Let the missing streamflow values for a generic gap in the record be given by

$$
Q M I S=\left\{Q(t), t_{b}<t<t_{e}\right\}
$$

where

QMIS is the set of the missing streamflow values for a generic gap in the record,

$t_{b}, t_{e} \quad$ are the beginning and ending times of the gap, and

$Q\left(t_{b}\right), Q\left(t_{e}\right) \quad$ are known (nonmissing) streamflow values bracketing the gap.

The first step for filling in the streamflow gap is to compute a time series of seasonal average streamflow:

$$
\begin{aligned}
& S A Q(t=k+j / 72)=A v e\left\{Q \in N M_{j}\right\} \\
& j=1,2, \ldots, 72 ; k=B C Y, \ldots, E C Y
\end{aligned}
$$

where

$\begin{aligned} S A Q & \text { is seasonal average streamflow, } \\ t=k+j / 72 & \text { is the decimal year, } \\ k & \text { is the integer year, } \\ j & \text { is the integer season, } \\ N M_{j} & \text { is the set of all nonmissing streamflow values } \\ & \text { for season } j, \text { and } \\ \text { Ave }\{.\} & \begin{array}{c}\text { denotes the average of the values in } \\ \text { the braces. }\end{array}\end{aligned}$

Next, to remove seasonality in the streamflow time series, streamflow is divided by $S A Q$ to obtain flow ratios,

$$
F R(t)=Q(t) / S A Q(t)
$$

where

$F R \quad$ is the flow ratio.

Note that the missing values for $F R$ correspond to the missing values for $Q$. Interpolated streamflow values for the generic gap (eq. 38) are computed by linearly interpolating the streamflow ratios across the gap and multiplying the interpolated ratios by the seasonal average streamflow as follows:

$$
\begin{gathered}
Q^{\sim}(t)=S A Q(t)\left\{F R\left(t_{b}\right)+\frac{t-t_{b}}{t_{e}-t_{b}}\left[F R\left(t_{e}\right)-F R\left(t_{b}\right)\right]\right\} \\
t_{b}<t<t_{e}
\end{gathered}
$$

where

$Q^{\sim} \quad$ is interpolated streamflow for the generic gap QMIS (eq. 38).

This streamflow interpolation method relies on the assumption that seasonal streamflow conditions (as indicated by the flow ratios) across an occasional short (less than 6 month) gap are similar to conditions immediately before and after the gap. The method may not be appropriate when flow conditions during the gap are thought to be considerably more extreme (higher or lower) compared to conditions before or after the gap, or for flashy streams where flow conditions can vary rapidly during the gap. In such cases, more rigorous streamflow interpolation methods such as rainfall-runoff modeling or routing/reverse routing of known streamflows from nearby upstream/downstream locations should be considered.

\section{Recommended Minimum Data Requirements}

The statistical methods previously described are based upon two general assumptions: (1) that the data can be modeled using the general framework described in the "TimeSeries Model" section of this report and (2) that the data available to fit the model are sufficient to allow the asymptotic (large-sample) properties of Gaussian maximum likelihood estimation to be applied. Whether or not a particular dataset is sufficient to obtain reliable estimates of trend coefficients and $p$-values, annual flow-weighted average concentration, annual flux, and other quantities using R-QWTREND depend on a host of factors, including the number of observations, record length, sampling design (distribution of samples among different years, seasons, and flow conditions), and the complexity of the trend model. Although there are no minimum data requirements that are guaranteed to provide reliable results for every possible water-quality constituent and sampling location, a few general recommendations are provided to lead to reliable results for most applications:

1. At least 10 separate calendar years with 1 or more observations (water-quality samples) in each of the following 3-month windows: January-March, February-April, March-May, April-June, May-July, June-August, JulySeptember, August-October, September-November, and October-December.

2. A total of at least 60 observations.

3. At most 25-percent censored data.

4. Minus 2 times the logarithm of the likelihood function $(-2 \ln [L i k]$; eq. 15$)$ has a well-defined minimum (positive definite Hessian matrix) with respect to the model parameters.

5. The model assumptions are reasonable, judging by examination of diagnostic model output (see example applications later in this report for suggested diagnostic output and model verification).

These requirements ensure that observations are reasonably spread out among multiple $(10+)$ years and among sliding 3-month seasons within each year, starting with January-March and ending with October-December. For example, 10 years of bimonthly sampling (sampling every 2 months, 6 samples per year, 60 observations) would satisfy the minimum requirements, as would 15 years of quarterly sampling (sampling every 3 months, 4 samples per year, 
60 observations). However, 10 years of monthly sampling during April-September (60 observations) would not satisfy the requirements, nor would monthly sampling for 5 years (60 observations).

\section{R-OWTREND Software Documentation}

The R-QWTREND package is a collection of functions written in R (R Development Core Team, 2019), an open source language and a general environment for statistical computing and graphics. Although R can be run on a variety of operating systems, including Linux, Mac OS, UNIX, and Windows, R-QWTREND can only be run using the following requirements:

- Windows 10 operating system

- $\mathrm{R}$ (version 3.4 or later; 64 bit recommended)

- RStudio (version 1.1.456 or later).

A flowchart of the R-QWTREND functions, inputs, and outputs is shown in figure 1. In this section, instructions for installing the software are provided, and the components of figure 1 are described in detail. Examples are provided to illustrate the R-QWTREND commands and provide handson practice using the software to analyze trends for practice datasets provided with the package.

\section{Initializing R-OWTREND}

The R-QWTREND software package is provided as an appendix to this report. The package consists of a folder called QWTREND2018V4, which contains the files described in table 2. This folder can be downloaded as described in the appendix. For the practice problems in this section, the files in this folder are assumed to be at the following pathname:

QWModPath = "C: \RQWTRENDI|QWTREND2018V4|॥"

To get started, use RStudio to open the

QWTrendV4 practice.RData workspace and the script file StartQWTrendV4.R (fig. 2). To initialize R-QWTREND, run the commands in lines $1-17$ of the script file. These commands load the required R packages (truncnorm, survival, and splines); specify the path of the QWTREND2018V4 folder (QWModPath); and create the R-QWTREND functions plotQWtrend, prepQWdata, and runQWmodel (R Development Core Team, 2019; Therneau, 2019; fig. 3). If the pathname of the QWTREND2018V4 folder differs from the one shown above, the pathname needs to be changed to the correct pathname before running line 11. Four dataframes provided in the practice workspace are used for all practice problems in this section.

\section{Input Dataframes}

Two dataframes are required as inputs for $\mathrm{R}-$ QWTREND: a water-quality dataframe (generic name QWdata) and a daily discharge (streamflow) dataframe (generic name DDdata). These dataframes must be in the format described later in this section. Users are required to import water-quality and streamflow data into $\mathrm{R}$ and may need to transform the data into the proper format before running R-QWTREND. The simplest file format for importing data into $\mathrm{R}$ is a comma delimited Excel (".csv”) file, which can be imported using the read.csv() function. Users with limited R programming skills may wish to transform their data into the proper format using Excel before importing the data into R. Alternatively, the data can be imported first and then transformed into the proper format using $\mathrm{R}$ commands. The examples provided in this section use four dataframes that have already been imported into $\mathrm{R}$ and transformed into the proper format: RRFargo_Prac_DDdata, RRFargo_Prac_QWdata, RRHalstad_Prac_DDdata, and RRHalstad_Prac_QWdata. These dataframes contain nutrient concentration data and daily streamflow data for the Red River of the North at Fargo, North Dakota (USGS streamflow-gaging station 05054000), and the Red River at Halstad, Minnesota (USGS streamflow-gaging station 05064500), for 1970-2017. The streamflow data used in the examples were downloaded from the USGS National Water Information System database (U.S. Geological Survey, 2019) and the nutrient concentration data were downloaded from the National Water Quality Monitoring Council database (National Water Quality Monitoring Council, 2019). The dataframes must be configured as follows:

- Water-quality input data (for example, RRFargo_Prac_ QWdata, see fig. 4):

- First column must have type character and name "date" and consists of the date of the water-quality sample, in "YYYY-MM-DD" format. This column should be in ascending order, but there can be dates with multiple rows (multiple samples on the same day).

- Concentration data must be in a column of type numeric with name "P_XXX," where the first two characters of the name must be "P_," "XXX" is the specified parameter name, and there are no spaces. For this example, "P_npnN" designates nitrate plus nitrite as nitrogen $(\mathrm{npnN})$ concentration (hereafter referred to as nitrate plus nitrite concentration) and "P_PTot" designates total phosphorus (PTot) concentration.

- Immediately following each parameter column ("P XXX") must be a remark column ("R_XXX"). This column must be of type character and have the format "YYY=" or "YYY<," where "YYY" is a remark code. There can be no blanks, and the last character must be either " $=$ " (if the value is not censored) or 
R-QWTREND objects

Description

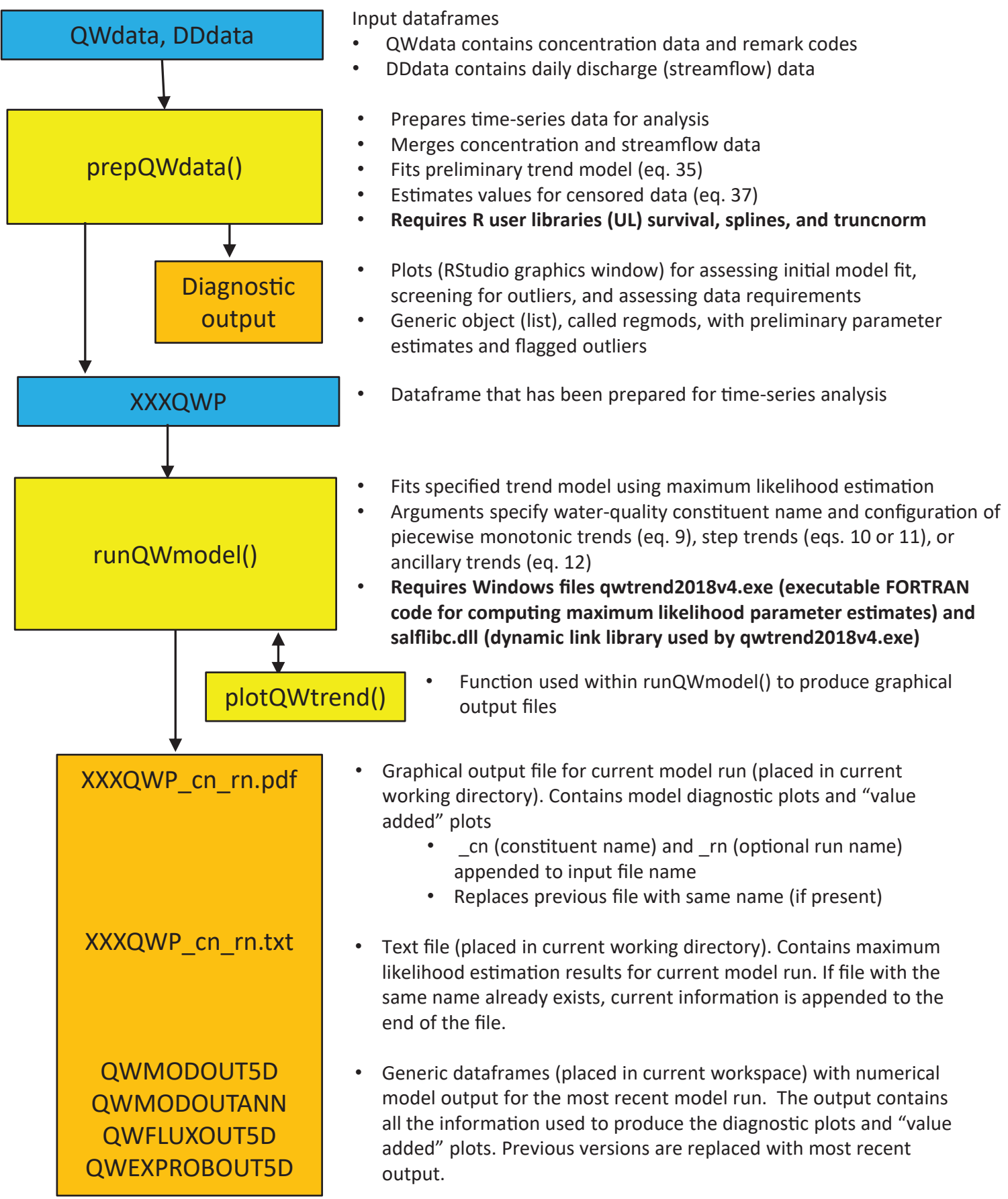

Figure 1. Flowchart of R-OWTREND functions, inputs, and outputs. 
Table 2. R-QWTREND software files contained in windows folder QWTREND2018V4.

\begin{tabular}{ll}
\hline \multicolumn{1}{c}{ File name } & \multicolumn{1}{c}{ Description } \\
\hline prepQWdataV4.txt & Text file containing R code for creating function prepQWdata(). \\
runQWmodelV4.txt & Text file containing R code for creating function runQWmodel(). \\
plotQWtrendV4.txt & Text file containing R code for creating function plotQWtrend(). \\
qwtrend2018v4.exe & Windows executable file used for computing maximum likelihood parameter estimates. \\
salflibc.dll & Dynamic link library required by qwtrend2018v4.exe. \\
QWTrendV4_practice.RData & R workspace with example datasets. \\
StartQWTrendV4.R & R script for installing and running R-QWTREND. \\
\hline
\end{tabular}

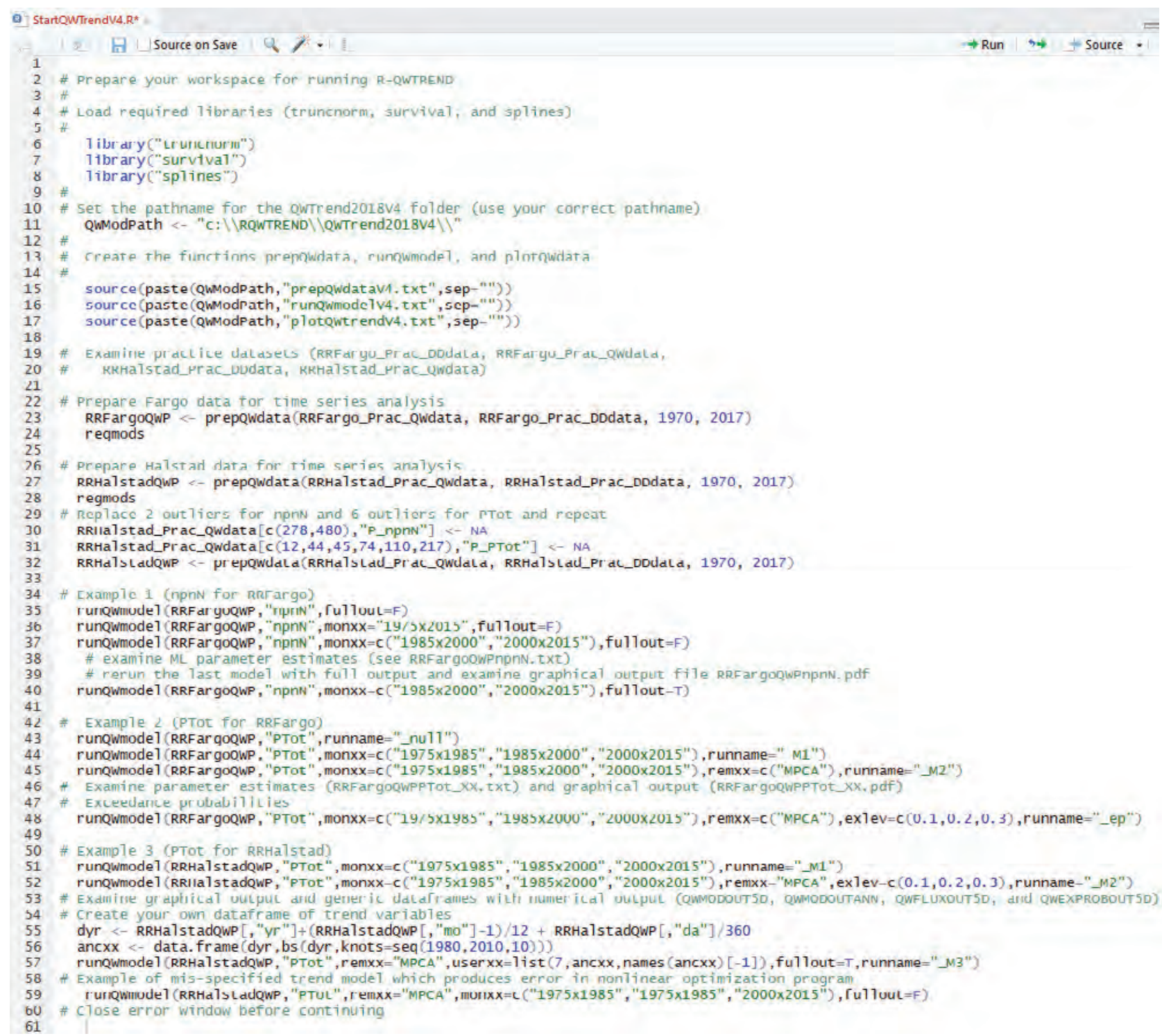

Figure 2. Script file (StartQWTrendV4.R) for running R-OWTREND practice problems. 


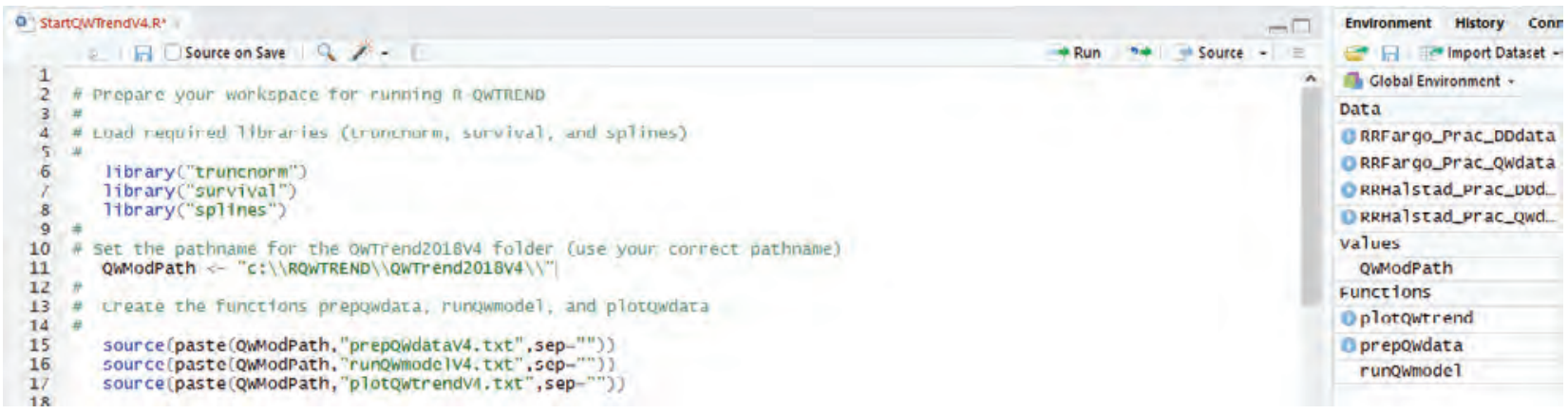

Figure 3. Initial workspace for running R-QWTREND practice problems.

\begin{tabular}{|c|c|c|c|c|c|c|c|}
\hline \multicolumn{3}{|c|}{ (8) StartQWTrendV4.R $\times$} & \multicolumn{3}{|c|}{ RRFargo_Prac_QWdata X } & \multicolumn{2}{|c|}{ RRFargo_Prac_DDdata $x$} \\
\hline \multicolumn{8}{|c|}{\begin{tabular}{l|l|l|l|l|} 
& $\nabla$ \\
\end{tabular}} \\
\hline$\Delta$ & date & P_npn & $v \geqslant$ & R_npnN & P_PTot $\hat{\forall}$ & R_PTot & snameld \\
\hline 1 & $1971-06-03$ & & 0.05 & USGSNL $<$ & NA & NA & RRFargo_4 \\
\hline 2 & 1971-07-14 & & 0.43 & USGSNL= & NA & NA & RRFargo_4 \\
\hline 3 & $1971-07-26$ & & NA & NA & 0.690 & $\mathrm{MPCA}=$ & RRFargo_4 \\
\hline 4 & $1971-08-04$ & & 0.05 & USGSNL $<$ & NA & NA & RRFargo_4 \\
\hline 5 & $1971-08-24$ & & NA & NA & 0.170 & $M P C A=$ & RRFargo_4 \\
\hline 6 & 1971-08-31 & & 0.12 & USGSNL= & NA & NA & RRFargo_4 \\
\hline
\end{tabular}

Q 2 StartQWTrendV4.R $\times$ RRFargo_Prac_QWdata $\times$ RRFargo_Prac_DDdata $\times$

\begin{tabular}{|c|c|c|c|c|c|c|}
\hline $\boldsymbol{\wedge}$ & date & P_npnN & R_npnN & P_PTot & R_PTot & snamelD \\
\hline 532 & $2017-04-24$ & 2.920 & USGSND= & 0.220 & USGSND= & RRFargo_4 \\
\hline 533 & $2017-05-22$ & 0.560 & USGSND= & 0.090 & USGSND= & RRFargo_4 \\
\hline 534 & $2017-06-26$ & 0.820 & USGSND= & 0.160 & USGSND= & RRFargo_4 \\
\hline 535 & 2017-07-05 & 0.400 & USGSND= & 0.110 & USGSND= & RRFargo_4 \\
\hline 536 & $2017-07-31$ & 0.160 & USGSND= & 0.230 & USGSND= & RRFargo_4 \\
\hline 537 & $2017-10-13$ & 1.210 & USGSND= & 0.240 & USGSND= & RRFargo_4 \\
\hline
\end{tabular}

\begin{tabular}{|c|c|c|c|c|c|}
\hline \multicolumn{3}{|c|}{ (8) StartQWTrendV4.R $\times$} & \multicolumn{3}{|c|}{ RRFargo_Prac_DDdata $\times$} \\
\hline \multicolumn{6}{|c|}{$\checkmark \quad|a| \nabla$ Filter } \\
\hline 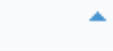 & staid $\hat{\vee}$ & flow & 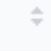 & date & qualcode \\
\hline 1 & 05054000 & & 107 & $1970-01-01$ & NA \\
\hline 2 & 05054000 & & 107 & $1970-01-02$ & NA \\
\hline 3 & 05054000 & & 114 & $1970-01-03$ & NA \\
\hline 4 & 05054000 & & 125 & $1970-01-04$ & NA \\
\hline 5 & 05054000 & & 148 & $1970-01-05$ & NA \\
\hline 6 & 05054000 & & 152 & $1970-01-06$ & NA \\
\hline
\end{tabular}

\begin{tabular}{|c|c|c|c|c|c|}
\hline \multicolumn{3}{|c|}{ (8) StartQWTrendV4.R $\times$} & & \multicolumn{2}{|c|}{ RRFargo_Prac_DDdata $\times$} \\
\hline \multicolumn{6}{|c|}{\begin{tabular}{l|l|l|l|l|} 
& $\nabla$ \\
\end{tabular}} \\
\hline 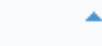 & staid $\hat{\imath}$ & flow & $\hat{F}$ & date & qualcode \\
\hline 17527 & 05054000 & & 438 & $2017-12-26$ & NA \\
\hline 17528 & 05054000 & & 438 & $2017-12-27$ & NA \\
\hline 17529 & 05054000 & & 442 & $2017-12-28$ & NA \\
\hline 17530 & 05054000 & & 452 & $2017-12-29$ & NA \\
\hline 17531 & 05054000 & & 469 & $2017-12-30$ & NA \\
\hline 17532 & 05054000 & & 479 & $2017-12-31$ & NA \\
\hline
\end{tabular}

Figure 4. Beginning and ending rows of the water-quality dataframe, RRFargo_Prac_0Wdata, and the daily discharge dataframe, RRFargo_Prac_DDdata, for input to the prepOWdata() function. 
"<" (if the value is left censored). Every nonmissing concentration must have a nonmissing remark code. If there is no remark code, a placeholder such as "_=" or "_<" can be used.

- Daily discharge input data (for example, RRFargo_ Prac_DDdata, see fig. 4):

- There must be a column named "date," of type character, with the date in "YYYY-MM-DD" format.

- There must be a column named "flow," of type numeric, with daily mean streamflow, in cubic feet per second.

- Unlike the concentration data, the daily streamflow data must consist of complete calendar years, and there should be only a limited number of days with missing streamflow values (see the earlier "Missing Streamflow Data" section of this report for guidelines regarding missing streamflow). In this case, the flow data consist of a complete record for calendar years 1970-2017.

\section{Preparing Data for Time-Series Analysis Using Prep0Wdata}

The function prepQWdata prepares the water-quality and daily streamflow data for time-series analysis. This function requires as inputs the water-quality and daily discharge dataframes described previously. The command for running the function has the following form:

$$
\begin{gathered}
\text { XXXQWP }<- \text { prepQWdata(QWdata, DDdata, } \\
\text { yrbeg, yrend })
\end{gathered}
$$

where

QWdata is a water-quality input dataframe,

DDdata is a daily discharge (streamflow) input dataframe,

yrbeg is the beginning calendar year (integer),

yrend is the ending calendar year (integer), and

XXXQWP is an output dataframe (or dataset) that has

been prepared for analysis.

The user can assign any name for the output, but it is recommended to use "QWP" as the last three characters to indicate that the data have been prepared for time-series analysis; for example, executing line 23 of the practice script (fig. 2) produces a dataset called RRFargoQWP. Note that a shorter period of record can be used, if desired, by specifying either a beginning year later than 1970 or ending year earlier than 2017, or both. The format of RRFargoQWP is shown in figure 5, which shows the rows corresponding to JuneAugust 1971. Each month consists of six $\sim 5$-day time intervals. The first nonmissing concentration value for this example was for parameter npnN from a sample collected on June 3,
1971 (during the first interval of the month, days 1-5). A day of 3 (the midpoint of the interval) is assigned to this observation. The original concentration was left censored $(<0.05)$, and the concentration value for that observation $(0.023)$ is the estimated value from the preliminary trend model (eq. 37). The streamflow, or discharge, value (column name "dis") for the same time interval (324.8) is daily mean streamflow, in cubic feet per second, for June 1-5, 1971. There are no missing values for streamflow. The next nonmissing concentration value for this example was for the third time interval (days 11-15) of July 1971 and consists of an npnN concentration of 0.430 . Although the original concentration was from July 14, 1971, day 13 (the midpoint of the interval) is used for the day. Columns with the remark codes are at the end of this dataframe (remark codes are defined below).

Several pages of rough plots are produced by prepQWdata (fig. 6). These plots are shown in the default RStudio Plots window. Page 1 of the plots shows the flow anomalies (eqs. 3-5, fig. 6A). The horizonal black line in all three plots equals $M L Q$. The top plot shows $\log [Q]$ (black line) along with $M L Q+L T F A$ (coral line). For this site there were 12 days with zero flow (all during 1976). To allow logarithmic transformation, flow values less than 0.1 cubic foot per second are replaced by 0.1 when running prepQWdata. The middle plot shows $\log [Q]-L T F A$ (black line) along with $M L Q+M T F A$ (coral line). MTFA captures seasonal flow variability remaining after removing LTFA. The bottom plot shows MLQ+STFA (coral line), which captures short-term (day-to-day) flow variability after removing LTFA and MTFA.

Two additional pages of plots are produced for each water-quality parameter (fig. $6 B-C$ ). Page 2 of the plots shows logarithmically transformed npnN concentration versus decimal year and decimal season or decimal month (fig. 6B). Colors indicate distinct remark codes detected in the input data. In this case, there were three distinct remark codes: MPCA, sample collected and analyzed by Minnesota Pollution Control Agency; USGSND, sample collected by USGS and analyzed by the North Dakota Health Department laboratory; and USGSNL, sample collected by USGS and no outside laboratory specified (generally indicating the sample was analyzed by the USGS National Water-Quality Laboratory). Open circles indicate that the original concentration value was left censored and was replaced by the estimated value using equation 37.

Page 3 of the plots (fig. $6 \mathrm{C}$ ) is the second page of plots for npnN and can be used to detect and correct potential outliers and spot potential concerns related to different remark codes, gaps in the water-quality record, or other irregularities that may affect the ability to analyze trends. These plots are based on the preliminary trend model (eq. 35). The top plot shows flow-adjusted concentration $(\log [C]-F R V A R)$ along with the preliminary trend $\left(M L C+T R E N D^{*}\right.$, eq. 35). In this case the water-quality record spans four complete decades, so the preliminary trend consists of a quadratic spline with five basis functions (eq. 36). The second plot shows flow-adjusted 


\begin{tabular}{|c|c|c|c|c|c|c|c|c|c|c|}
\hline \multicolumn{3}{|c|}{ (8) StartQWTrendV4.R $\times$} & \multicolumn{3}{|c|}{ RRFargoQWP $\times$} & \multirow{2}{*}{\multicolumn{2}{|c|}{ ERFargo_Prac_DDdata $\times$}} & \multicolumn{3}{|c|}{ RRHalstad_Prac_QW } \\
\hline \multicolumn{9}{|c|}{\begin{tabular}{l|l|l|} 
& $\nabla$ Filter
\end{tabular}} & & \\
\hline$\wedge$ & yr $\quad \hat{~}$ & mo & 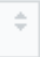 & da & dis $\hat{\vee}$ & P_npnN $\rightleftharpoons$ & P_PTot $\hat{~}$ & R_npnN & R_PTot & 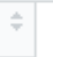 \\
\hline 103 & 1971 & & 6 & 3 & 324.8 & 0.023 & NA & USGSNL< & NA & \\
\hline 104 & 1971 & & 6 & 8 & 345.4 & NA & NA & NA & NA & \\
\hline 105 & 1971 & & 6 & 13 & 297.2 & NA & NA & NA & NA & \\
\hline 106 & 1971 & & 6 & 18 & 446.4 & NA & NA & NA & NA & \\
\hline 107 & 1971 & & 6 & 23 & 383.2 & NA & NA & NA & NA & \\
\hline 108 & 1971 & & 6 & 28 & 415.4 & NA & NA & NA & NA & \\
\hline 109 & 1971 & & 7 & 3 & 651.0 & NA & NA & NA & NA & \\
\hline 110 & 1971 & & 7 & 8 & 1443.4 & NA & NA & NA & NA & \\
\hline 111 & 1971 & & 7 & 13 & 800.2 & 0.430 & NA & USGSNL= & NA & \\
\hline 112 & 1971 & & 7 & 18 & 683.2 & NA & NA & NA & NA & \\
\hline 113 & 1971 & & 7 & 23 & 389.6 & NA & NA & NA & NA & \\
\hline 114 & 1971 & & 7 & 28 & 343.5 & NA & 0.69 & NA & $M P C A=$ & \\
\hline 115 & 1971 & & 8 & 3 & 211.4 & NA & NA & NA & NA & \\
\hline 116 & 1971 & & 8 & 8 & 185.4 & NA & NA & NA & NA & \\
\hline 117 & 1971 & & 8 & 13 & 178.8 & NA & NA & NA & NA & \\
\hline 118 & 1971 & & 8 & 18 & 110.8 & NA & NA & NA & NA & \\
\hline 119 & 1971 & & 8 & 23 & 96.6 & NA & 0.17 & NA & $M P C A=$ & \\
\hline 120 & 1971 & & 8 & 28 & 76.0 & 0.120 & NA & USGSNL= & NA & \\
\hline
\end{tabular}

Figure 5. Rows of practice dataset produced by prepQWdata, RRFargoOWP, corresponding to June-August 1971.

and detrended concentration $\left(\log [C]-F R V A R-T R E N D^{*}\right.$, eq. 35). The solid horizontal line corresponds to $M L C$. In this case, there were no apparent outliers or other abnormalities.

Page 5 of the output from prepQWdata (fig. $6 D$ ) is the second page of plots for total phosphorus (PTot). The dashed lines in the bottom plot correspond to plus and minus 3.5 times the estimated error standard deviation (these lines were outside of the plot limits for npnN, fig. 6C). Points outside of these bounds may indicate potential outliers. In this case, like npnN, there were no apparent outliers. However, after about 2003, there seems to be a higher frequency of negative errors for the USGSND and USGSNL remark codes and positive errors for the MPCA remark code (differences related to remark codes are explored in more detail later in this section).

Next, run line 27 of the script file (fig. 2) to create the practice dataset RRHalstadQWP and examine page 5 of the plot output (fig. 7). In this case, there were five observations for PTot for this site for which the flow-adjusted and detrended concentrations were well outside of the dashed lines, indicating potential outliers. A generic list, called regmods, is produced in the current workspace when running prepQWdata. This list contains information regarding the preliminary regression models, including flagged outliers. The element of this list corresponding to the outliers for PTot is shown below the plots. These observations correspond to rows 12, $44,45,74$, and 110 of the original water-quality dataframe (RRHalstad_Prac_QWdata). Another observation during 1985 (row 217) also was determined to be an outlier. Outliers should be carefully examined and either removed or corrected in the original water-quality dataframe before completing a formal trend analysis. For the practice problems in this section, run lines 30-32 of the script file (fig. 2) to replace 6 outliers for PTot and 2 outliers for npnN with missing values and rerun prepQWdata to prepare RRHalstadQWP with outliers removed. After removing outliers, the results for PTot for this site (fig. 8) were similar to the previous results for RRFargoQWP (fig. 6D). Although there were no remaining outliers, there tended to be a higher frequency of negative flowadjusted and detrended concentrations for the USGSND and USGSNL remark codes compared to the MPCA remark code.

\section{Analyzing Trends Using RunOWmodel}

After preparing the data using prepQWdata, the next step is to use maximum likelihood estimation to fit alternative trend models, select the best model from among the alternatives, and verify the model assumptions for the selected trend model. 
$\boldsymbol{A}$

Files

Plots Packages Help Viewer

(4) Zoom Export - 0

F. Publish

Flow anomalies for RRFargo_Prac_QWdata
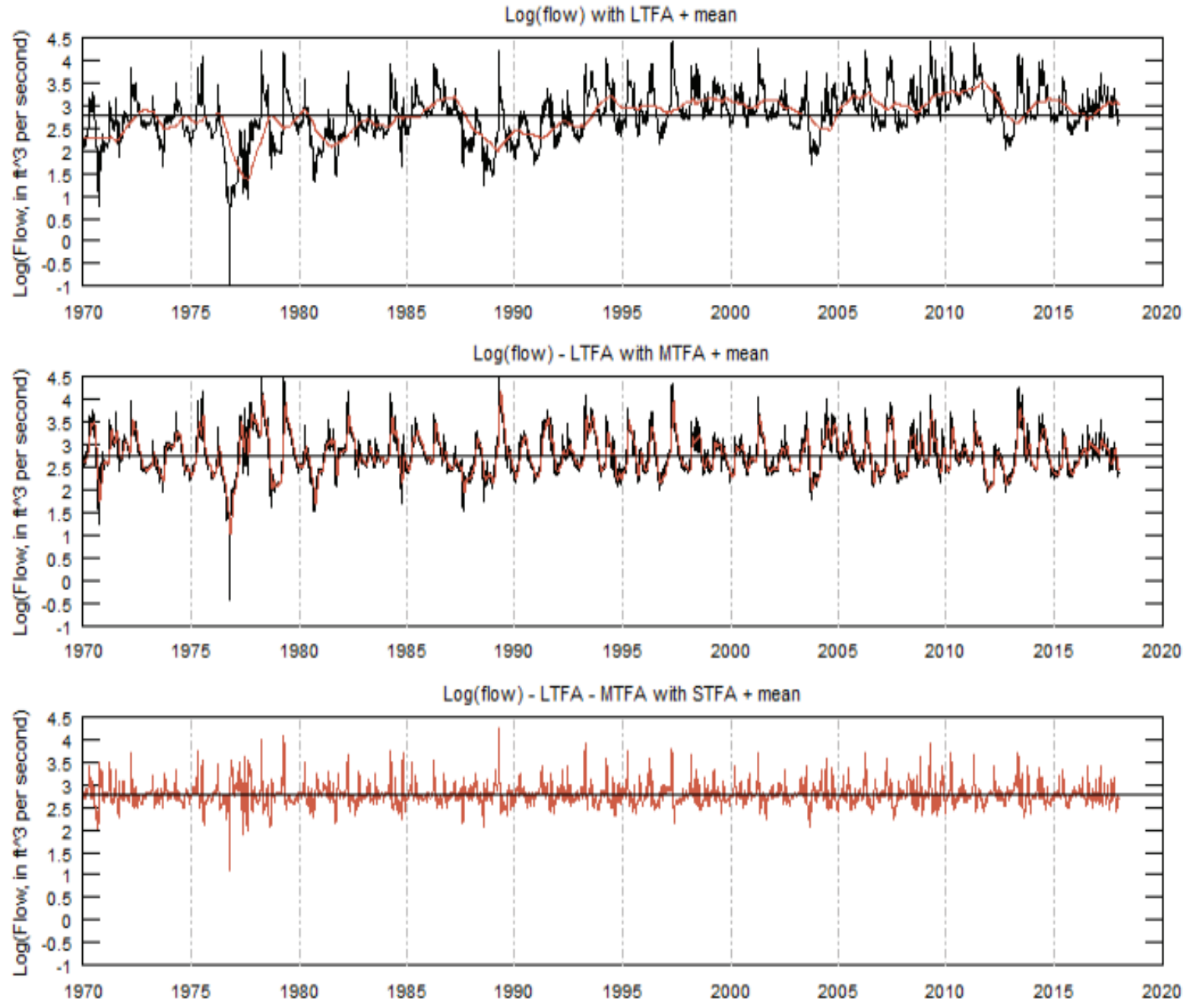

EXPLANATION

Log-Base-10 logarithm

LTFA - Long-term flow anomaly

MTFA-Midterm flow anomaly

STFA-Short-term flow anomaly

Figure 6. Plots produced by prepQWdata for practice dataset, RRFargoOWP. $A$, page 1, flow anomalies; $B$, page 2, nitrate plus

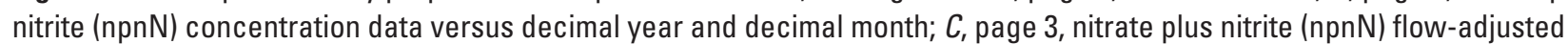
and flow-adjusted and detrended concentration data versus decimal year; $D$, page 5 , total phosphorus (PTot) flow-adjusted and flow-adjusted and detrended concentration data versus decimal year. 
B

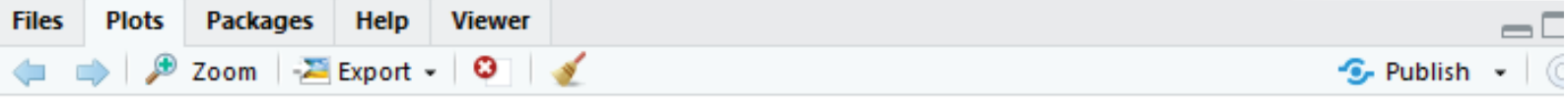

\section{P_npnN for RRFargo_Prac_QWdata}
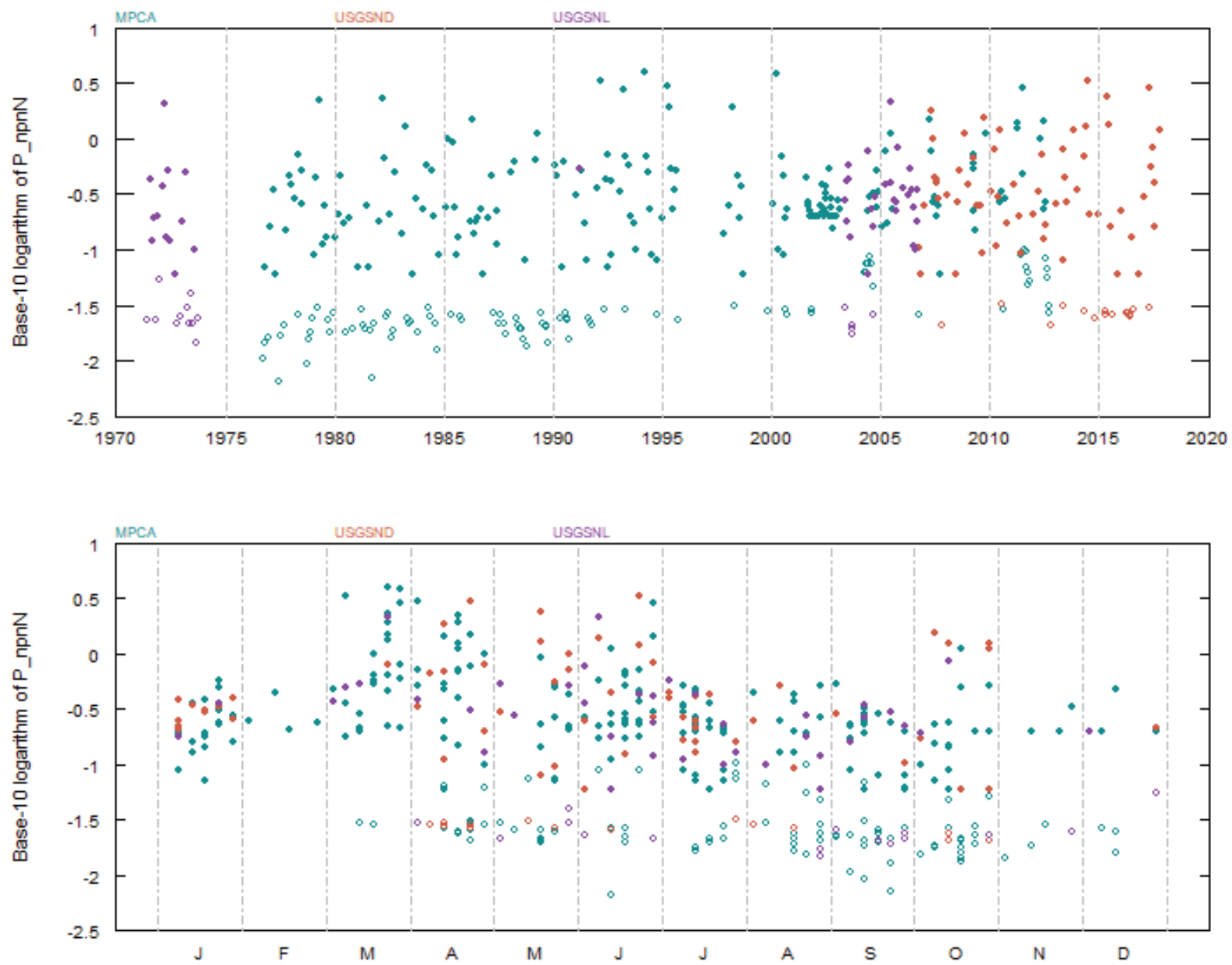

EXPLANATION

Nitrate plus nitrite concentration data

- MPCA - Sample collected and analyzed by Minnesota Pollution Control Agency

- USGSND - Sample collected by U.S. Geological Survey and analyzed by North Dakota Health Department

- USGSNL-Sample collected by U.S. Geological Survey and no outside laboratory specified
Estimated values for censored concentrations

MPCA - Sample collected and analyzed by Minnesota Pollution Control Agency

- USGSND-Sample collected by U.S. Geological Survey and analyzed by North Dakota Health Department

- USGSNL-Sample collected by U.S. Geological Survey and no outside laboratory specified

Figure 6. Plots produced by prepQWdata for practice dataset, RRFargoQWP. $A$, page 1, flow anomalies; $B$, page 2, nitrate plus nitrite (npnN) concentration data versus decimal year and decimal month; $C$, page 3 , nitrate plus nitrite (npnN) flow-adjusted and flow-adjusted and detrended concentration data versus decimal year; $D$, page 5 , total phosphorus (PTot) flow-adjusted and flow-adjusted and detrended concentration data versus decimal year.-Continued 


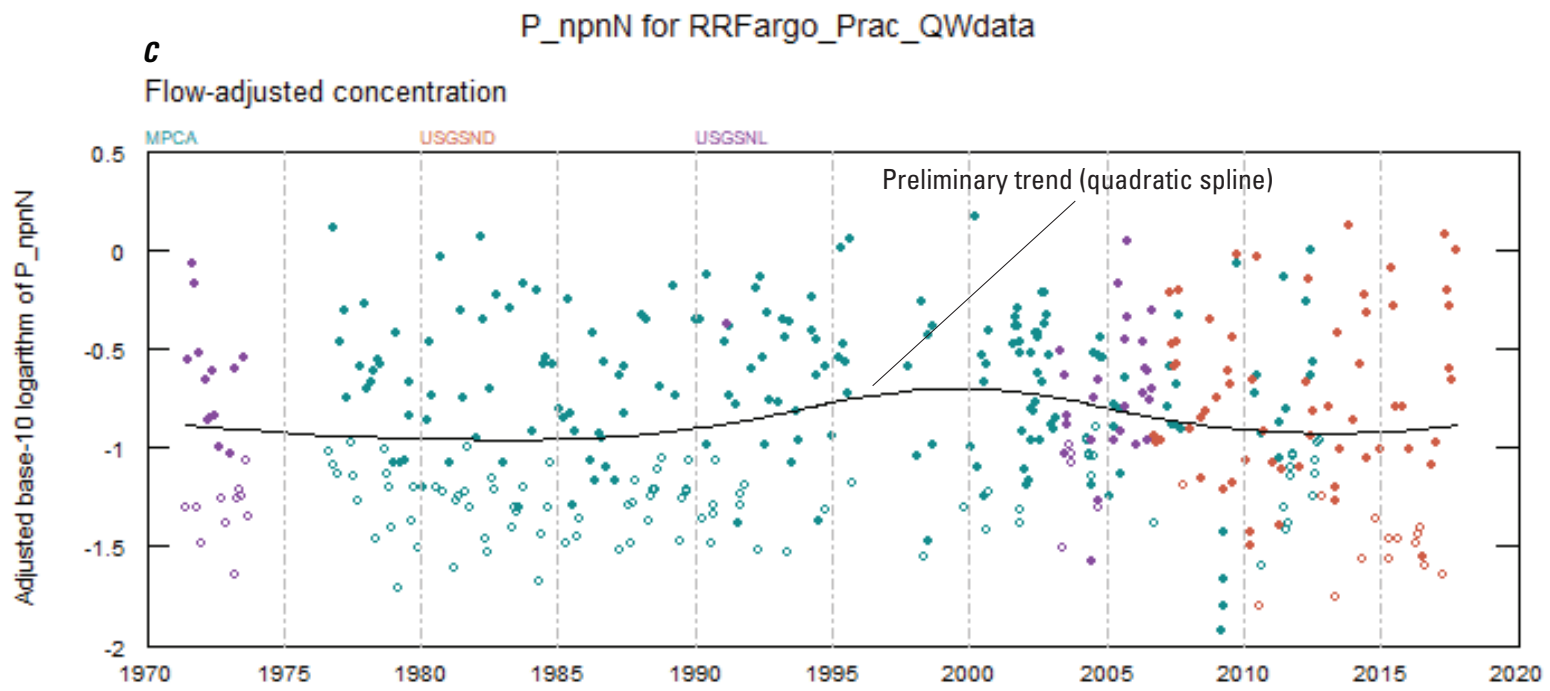

Flow-adjusted and detrended concentration

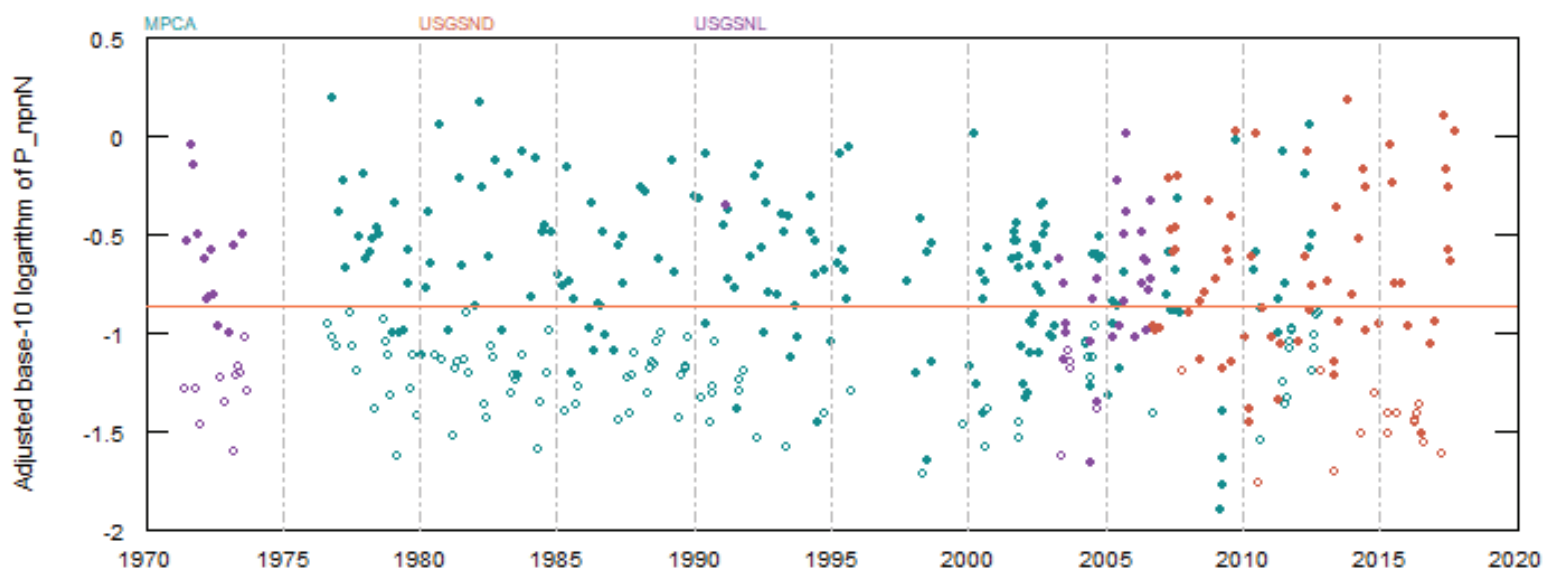

EXPLANATION

\begin{tabular}{|c|c|c|}
\hline \multirow{4}{*}{$\begin{array}{l}\text { Mean of logarithmically transformed } \\
\text { concentration }\end{array}$} & Nitrate plus nitrite concentration data & Estimated values for censored concentrations \\
\hline & $\begin{array}{l}\text { MPCA-Sample collected and analyzed by } \\
\text { Minnesota Pollution Control Agency }\end{array}$ & $\begin{array}{l}\text { - MPCA_Sample collected and analyzed by } \\
\text { Minnesota Pollution Control Agency }\end{array}$ \\
\hline & $\begin{array}{l}\text { - USGSND_Sample collected by U.S. Geological Survey } \\
\text { and analyzed by North Dakota Health Department }\end{array}$ & $\begin{array}{l}\text { - USGSND_Sample collected by U.S. Geological Survey } \\
\text { and analyzed by North Dakota Health Department }\end{array}$ \\
\hline & $\begin{array}{l}\text { - USGSNL_-Sample collected by U.S. Geological Survey } \\
\text { and no outside laboratory specified }\end{array}$ & $\begin{array}{l}\text { - USGSNL-Sample collected by U.S. Geological Survey } \\
\text { and no outside laboratory specified }\end{array}$ \\
\hline
\end{tabular}

Figure 6. Plots produced by prepQWdata for practice dataset, RRFargoOWP. $A$, page 1, flow anomalies; $B$, page 2, nitrate plus nitrite (npnN) concentration data versus decimal year and decimal month; $C$, page 3 , nitrate plus nitrite (npnN) flow-adjusted and flow-adjusted and detrended concentration data versus decimal year; $D$, page 5 , total phosphorus (PTot) flow-adjusted and flow-adjusted and detrended concentration data versus decimal year.-Continued 


\section{D}

Flow-adjusted concentration

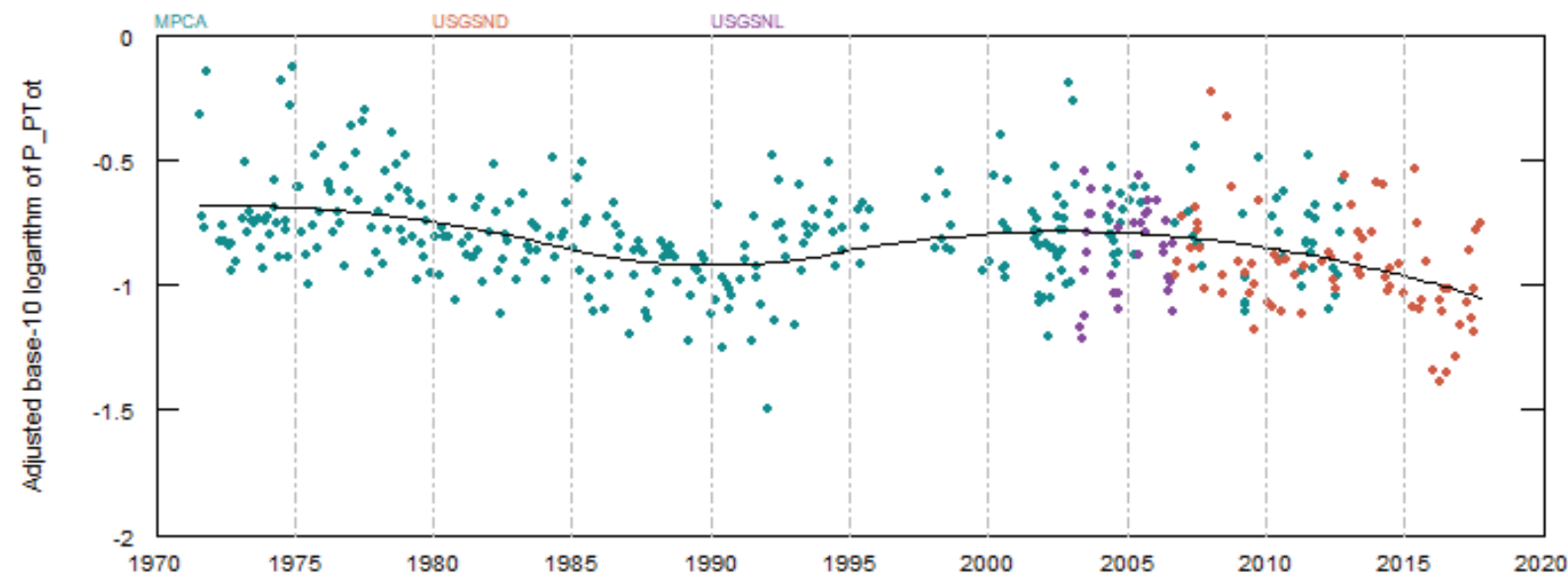

Flow-adjusted and detrended concentration

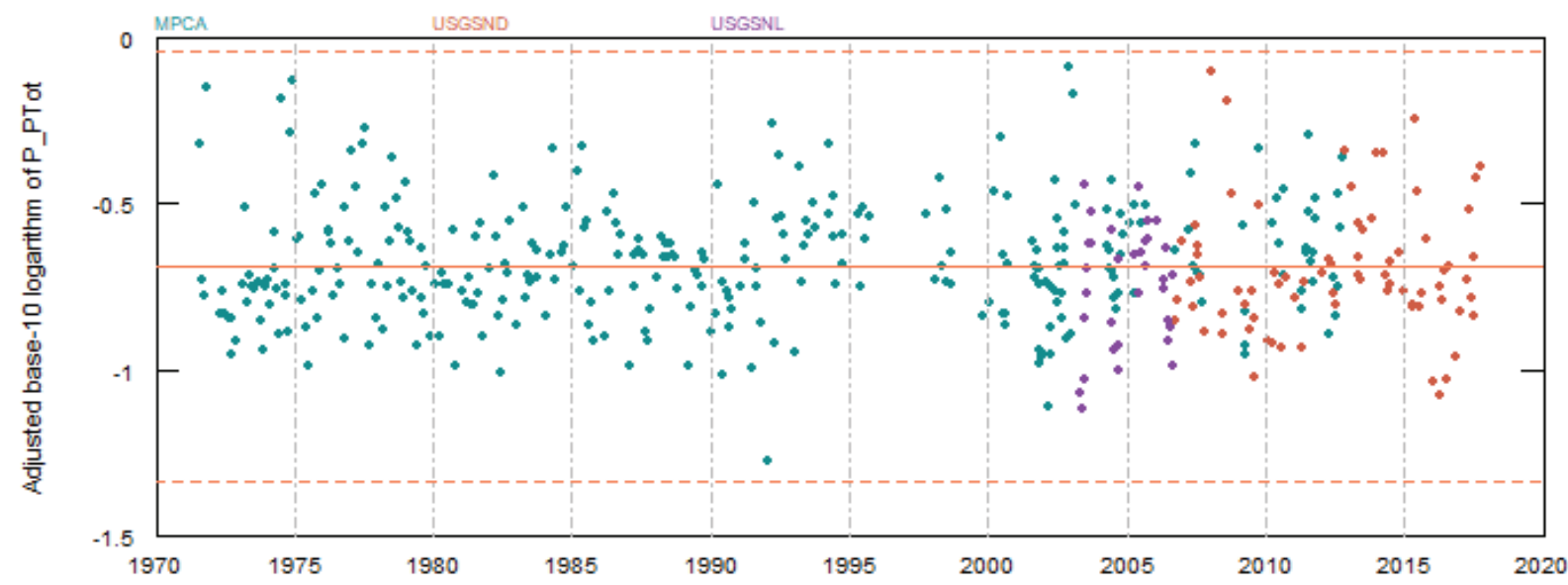

\section{EXPLANATION}

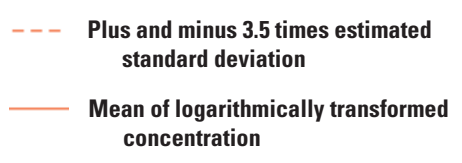

Total phosphorus concentration data

- MPCA-Sample collected and analyzed by Minnesota Pollution Control Agency

- USGSND-Sample collected by U.S. Geological Survey and analyzed by North Dakota Health Department

- USGSNL-Sample collected by U.S. Geological Survey and no outside laboratory specified

Figure 6. Plots produced by prepQWdata for practice dataset, RRFargoQWP. $A$, page 1, flow anomalies; $B$, page 2, nitrate plus nitrite (npnN) concentration data versus decimal year and decimal month; $C$, page 3 , nitrate plus nitrite (npnN) flow-adjusted and flow-adjusted and detrended concentration data versus decimal year; $D$, page 5 , total phosphorus (PTot) flow-adjusted and flow-adjusted and detrended concentration data versus decimal year.-Continued 


\section{P_PTot for RRHalstad_Prac_QWdata}

\section{Flow-adjusted concentration}

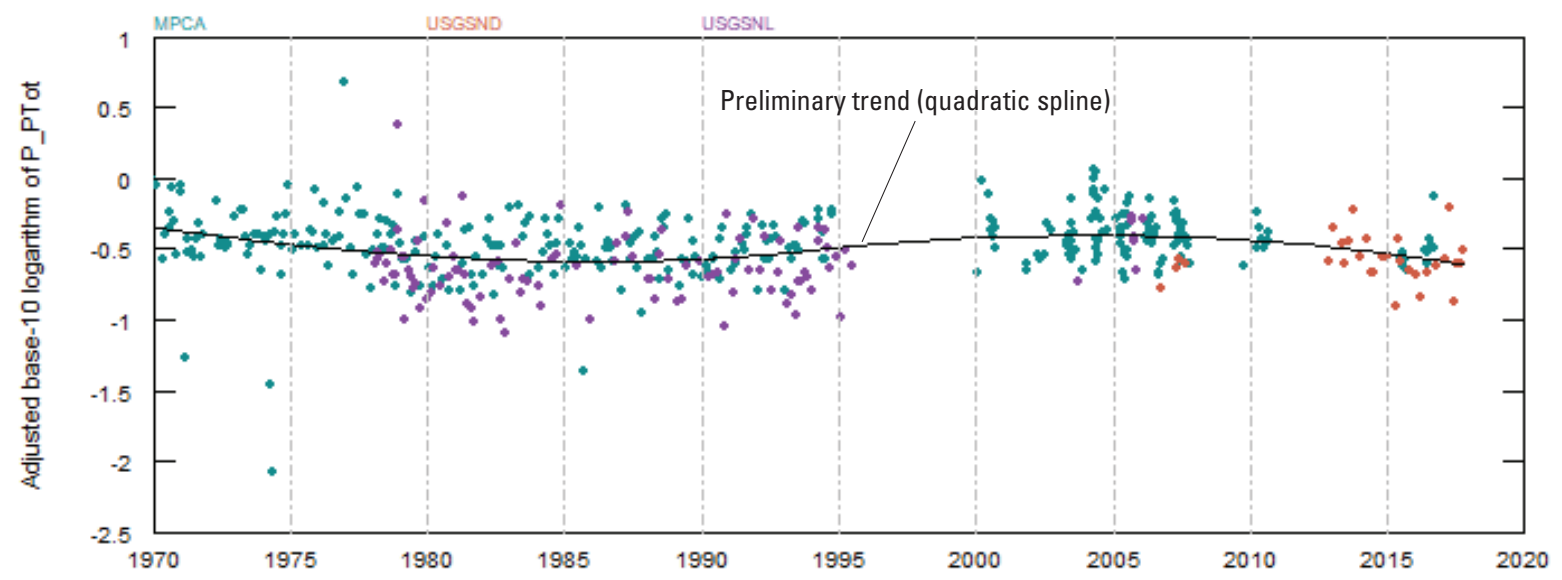

Flow-adjusted and detrended concentration

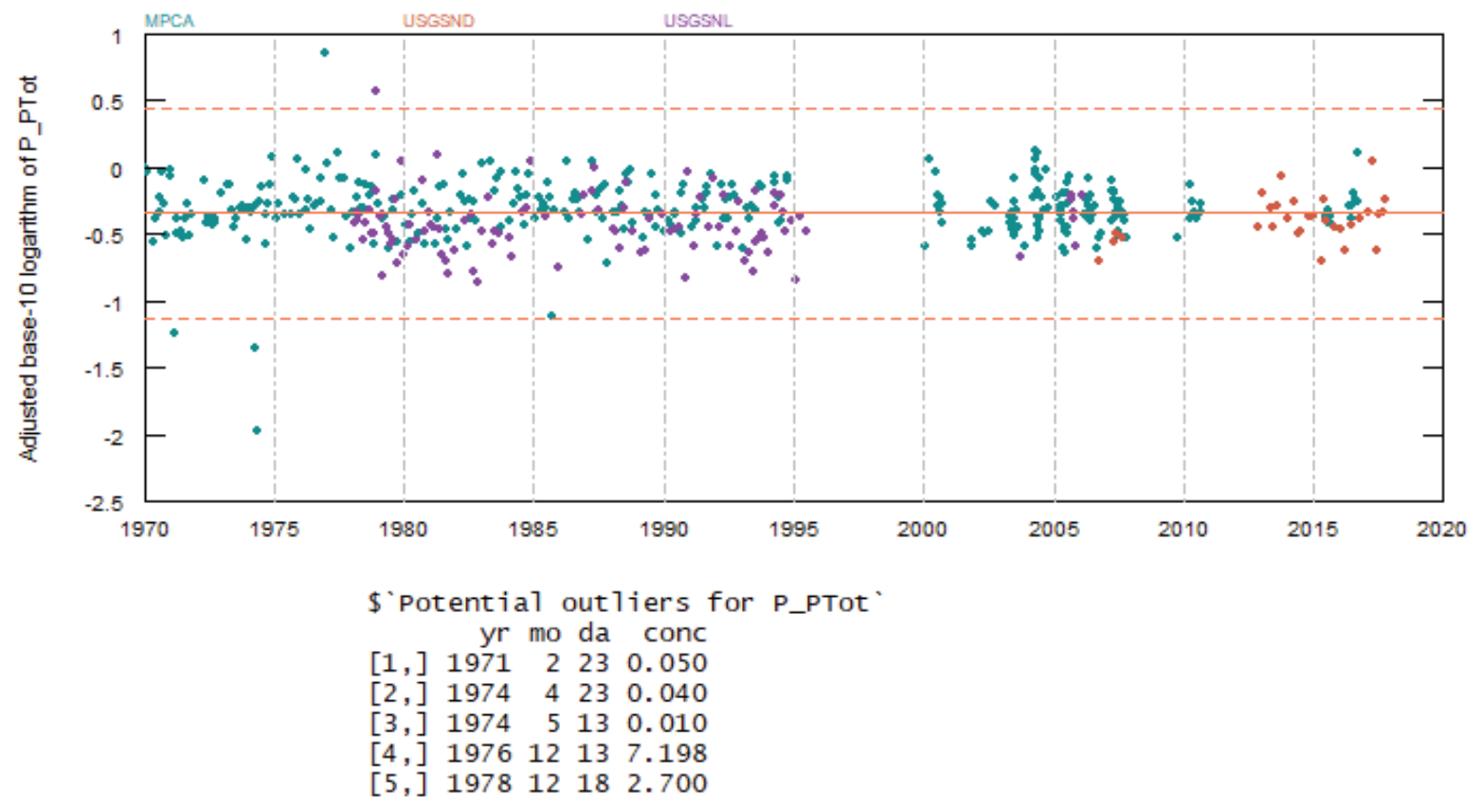

\section{EXPLANATION}

[Table at bottom, element from generic list (regmods) showing flagged outliers]

yr-Year
mo-Month
da-Day

conc-Concentration

\section{Plus and minus 3.5 times estimated standard deviation}

Mean of logarithmically transformed concentration
Total phosphorus concentration data

- MPCA-Sample collected and analyzed by Minnesota Pollution Control Agency

- USGSND-Sample collected by U.S. Geological Survey and analyzed by North Dakota Health Department

- USGSNL-Sample collected by U.S. Geological Survey and no outside laboratory specified

Figure 7. Page 5 of plots produced by prepQWdata for practice dataset, RRHalstadQWP, showing total phosphorus (PTot) flow-adjusted and flow-adjusted and detrended concentration data versus decimal year. 
P_PTot for RRHalstad_Prac_QWdata

Flow-adjusted concentration

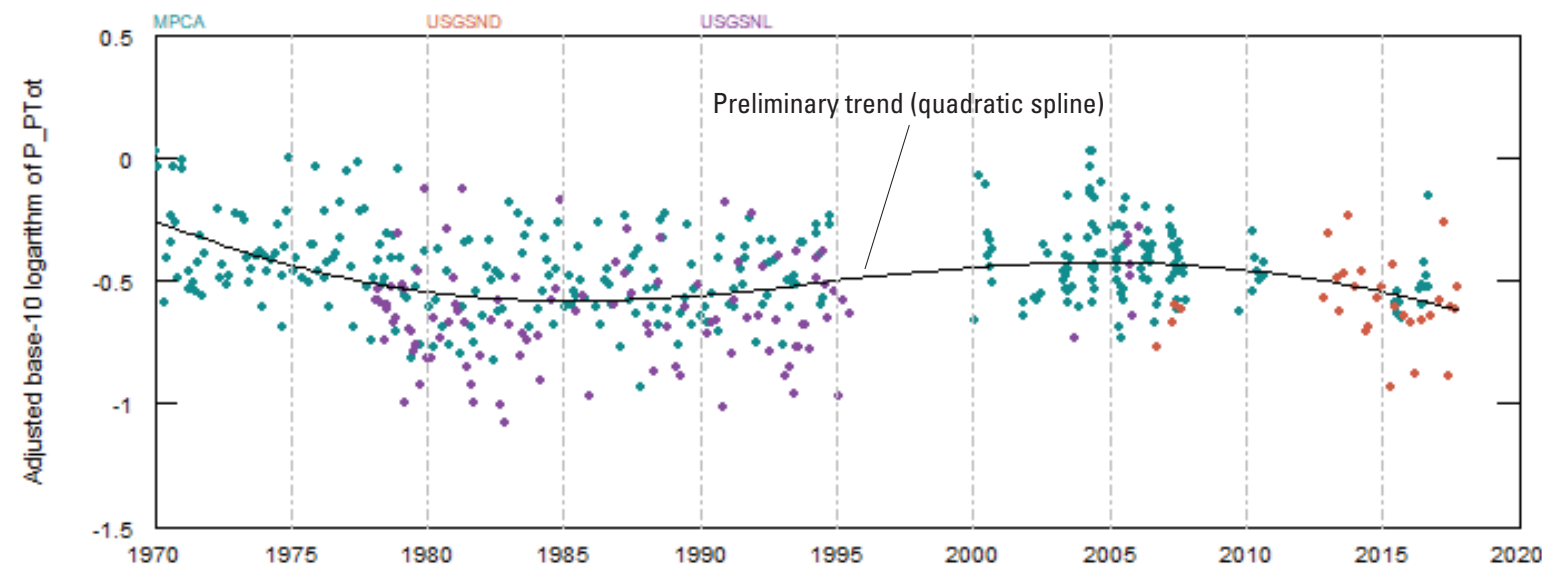

Flow-adjusted and detrended concentration

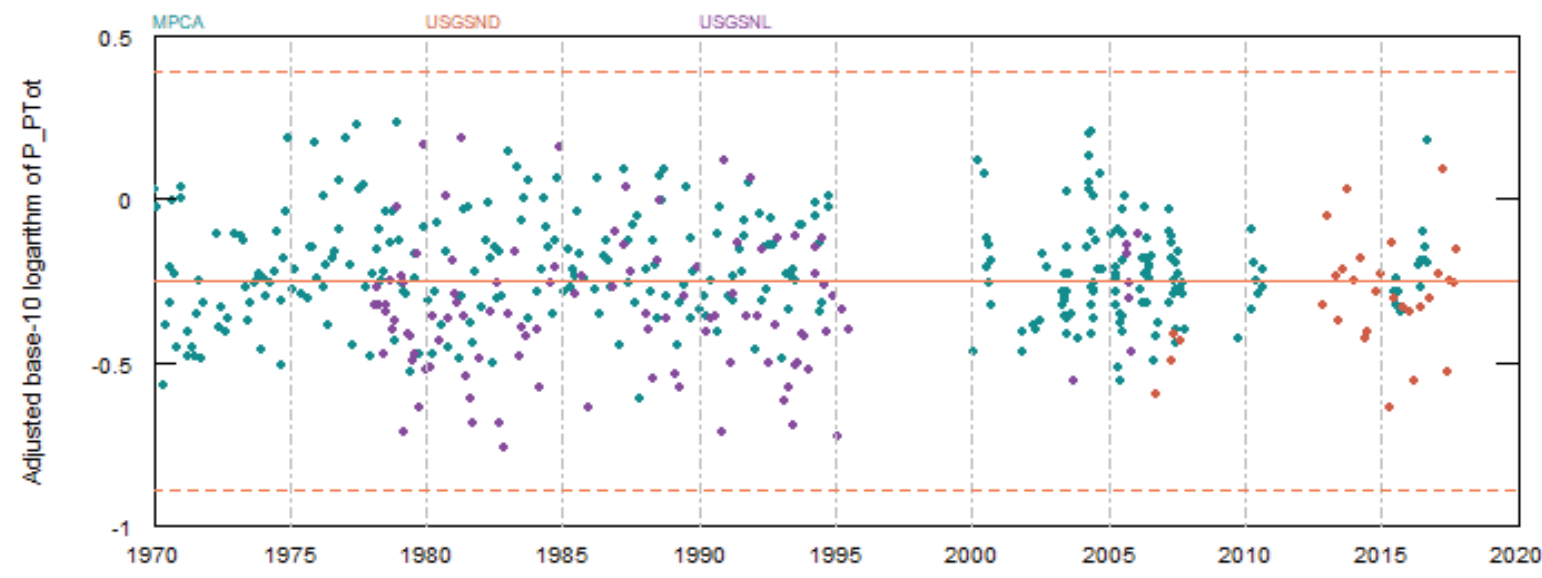

EXPLANATION

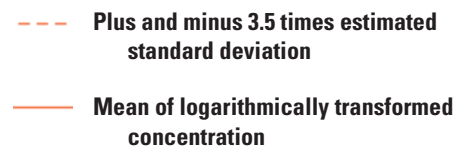

Total phosphorus concentration data

- MPCA-Sample collected and analyzed by Minnesota Pollution Control Agency

- USGSND—Sample collected by U.S. Geological Survey and analyzed by North Dakota Health Department

- USGSNL-Sample collected by U.S. Geological Survey and no outside laboratory specified

Figure 8. Page 5 of plots produced by prepQWdata for practice dataset, RRHalstadQWP, with outliers removed, showing total phosphorus (PTot) flow-adjusted and flow-adjusted and detrended concentration data versus decimal year. 
The function runQWmodel is used to compute maximum likelihood parameter estimates and specify alternative trend models. The function is executed using the following command:

runQWmodel $(X X X Q W P$, pname, $\operatorname{monxx}=\mathrm{NULL}$, step $x \mathrm{x}=\mathrm{NULL}$, rem $x \mathrm{x}=\mathrm{NULL}$, userxx $=\mathrm{NULL}$, fullout $=\mathrm{T}$, units $=1$, runname $=",$, modnum $=3$, exlev $=$ NULL)

where

\begin{tabular}{|c|c|}
\hline XXXQWP & $\begin{array}{l}\text { is a time-series dataframe (dataset) produced } \\
\text { by prepQWdata; }\end{array}$ \\
\hline pname & $\begin{array}{l}\text { is a character variable specifying the } \\
\text { parameter name for analysis; }\end{array}$ \\
\hline $\begin{array}{r}\operatorname{monxx} \\
\text { stepxx }\end{array}$ & $\begin{array}{l}\text { specifies piecewise monotonic trends (eq. 9); } \\
\text { specifies step trends based on time interval } \\
\quad \text { (eq. } 10) \text {; }\end{array}$ \\
\hline remxx & $\begin{array}{l}\text { specifies step trends based on sample } \\
\text { attributes, or remark codes (eq. 11); }\end{array}$ \\
\hline userxx & $\begin{array}{l}\text { specifies trends based on ancillary, or } \\
\text { user-specified, variables (eq. 12); }\end{array}$ \\
\hline fullout & $\begin{array}{l}\text { specifies whether to provide full output } \\
\quad(\text { fullout }=\mathrm{T}) \text { or reduced output (fullout=F); }\end{array}$ \\
\hline units & $\begin{array}{l}\text { specifies whether concentration is in } \\
\text { milligrams per liter (units }=1 \text { ) or } \\
\text { micrograms per liter (units }=2 \text { ) }\end{array}$ \\
\hline runname & $\begin{array}{l}\text { is an optional character string to append to } \\
\text { output files; }\end{array}$ \\
\hline modnum & $\begin{array}{l}\text { specifies the PARMA model number } \\
\text { (table 1); and }\end{array}$ \\
\hline exlev & $\begin{array}{l}\text { is a vector of exceedance levels for computing } \\
\text { exceedance probabilities. }\end{array}$ \\
\hline
\end{tabular}

The first two arguments (XXXQWP and pname) are mandatory, and the remaining arguments are optional. Default values of NULL for the specified trend components indicate there are no trend variables of that type in the model. The methods for specifying trends is described later in this section.

\section{Example 1-Parameter NpnN for RRFargoOWP}

The command on line 35 of the script file (fig. 2) fits the NULL (no trend) model for parameter npnN for the RRFargoQWP dataset created previously, with reduced output (fullout=F). When running this command, a message ("fitting the trend model ...") should appear in the commands window indicating that the maximum likelihood estimates are being computed. Depending on the speed of your computer, it typically takes a few seconds to no more than 1 minute to complete the estimation; at which time the message "Program terminated normally" will appear in the command window. For reduced output, a single page of plots will be produced in the RStudio Plots window (fig. 9). The plots are similar to the output from prepQWdata (see fig. 6C). The top plot in figure 9 shows the flow-adjusted data along with the fitted trend (in this case, a flat line for the null model). The second plot shows the flow-adjusted, detrended, and PARMA filtered data (after removing serial correlation) along with a quadratic spline to help spot possible lack of fit of the specified trend model. The second plot in figure 9 is similar to figure $6 C$, except that the effects of serial correlation have been removed in figure 9, whereas for the preliminary model (fig. 6C), there was assumed to be no serial correlation.

In general, the no-trend (null) model usually is fitted first and the results are examined before specifying more complicated trend models. The quadratic spline fitted to the flowadjusted, detrended, and PARMA filtered observations for the null model (fig. 9) can be used to help postulate potential piecewise monotonic trends for the data. For this example, two trend models were postulated, one with a single monotonic trend from 1975 to 2015 (see line 36 of the script, fig. 2) and the other with two piecewise monotonic trends from 1985 to 2000 and from 2000 to 2015 (see line 37 of the script, fig. 2). Monotonic trends are specified using a character vector for the monxx argument. For example, the model with two piecewise monotonic trends (line 37 ) uses monxx $=c$ (" $1985 \times 2000 "$, "2000x2015") to specify the two trends. There can be no spaces in the character names of the trends and the single character " $x$ " is used to separate the beginning and ending times of each trend. Note that the beginning and ending times are in decimal years; for example, the first trend starts at the beginning of 1985 (decimal year 1985.0) and ends at the beginning of 2000 (decimal year 2000.0). Character name "1985.5x2001", for example, would specify a trend starting in the middle of 1985 (July 1, 1985) and ending at the beginning of 2001 (January 1, 2001). Run lines 36 and 37 of the script and examine the graphical output results (figs. 10 and 11A).

Next, examine the maximum likelihood estimation results for the three fitted trend models. These results are in the text file called RRFargoQWPnpnN.txt which is in the current working directory. The elements of each table are defined as follows (see text file RRFargoQWPnpnN.txt, fig. 11B):

- $-2 \ln L i k$ is minus two times the natural logarithm of the maximized likelihood function (the minimum value of eq. 15).

- AIC is a penalized likelihood value (not used for this report).

- ecode is the error code from the nonlinear optimization program.

- Values ecode $=1$ (absolute convergence) or ecode $=2$ (iterates within tolerance) signify that the optimization was successful.

- Values ecode $=3$ (function too nonlinear to obtain convergence) or ecode $=4$ (iteration limit exceeded) indicate that the results are not reliable. If ecode $=3$ or ecode $=4$, the PARMA model number (modnum) should be reduced from the default (modnum $=3$ ) to a lower value (modnum $=2$ or modnum $=1$ ) until convergence is achieved. If convergence can- 
RRFargoQWPnpnN

Trends

Points: flow-adjusted data; Line: fitted trend

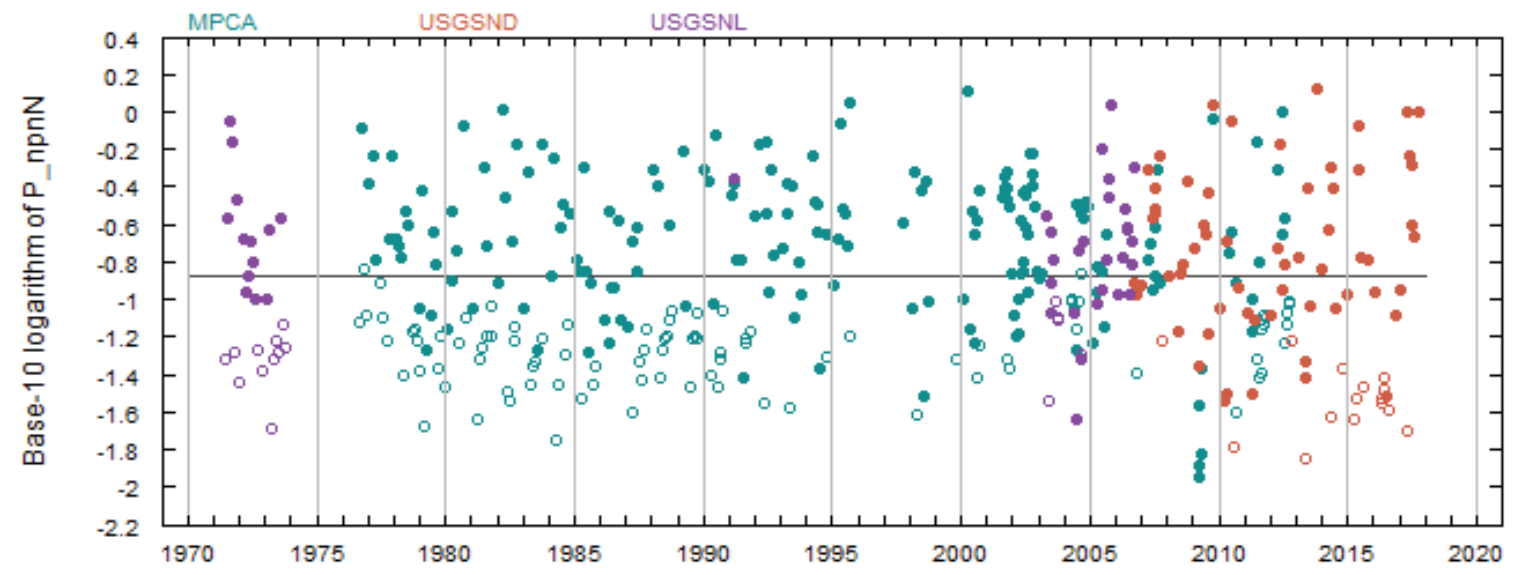

Points: flow-adjusted, detrended, and PARMA filtered data; Line: quadratic spline

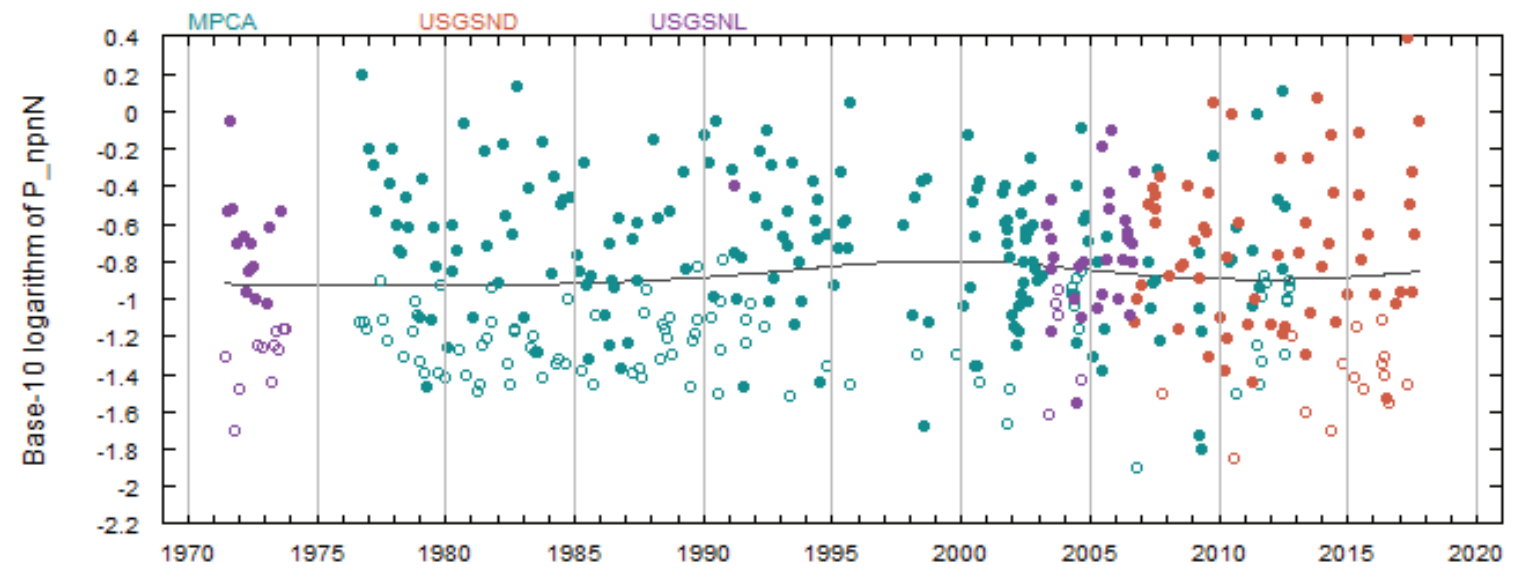

EXPLANATION

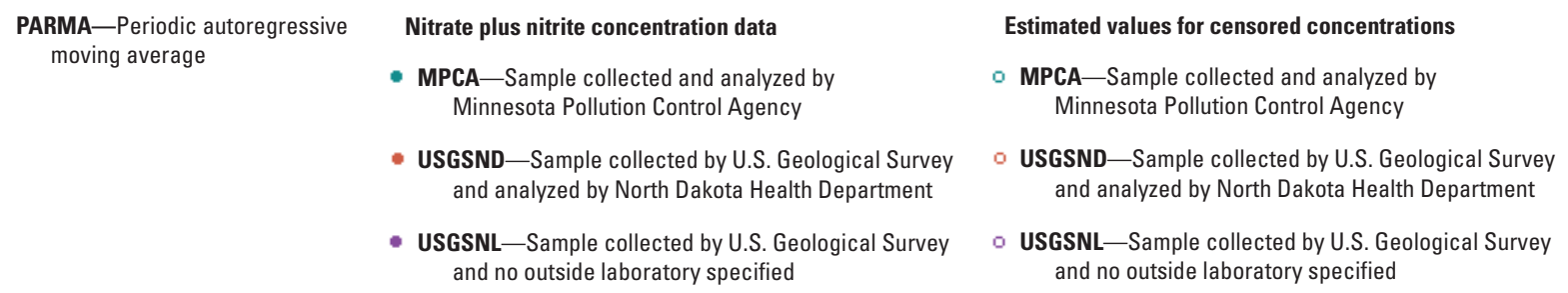

Figure 9. Reduced graphical output (fullout=F) from runQWmodel for nitrate plus nitrite (npnN) concentration for RRFargoQWP dataset for the null (no trend) model. 
RRFargoQWPnpnN

Trends -mon- 1975×2015

Points: flow-adjusted data; Line: fitted trend

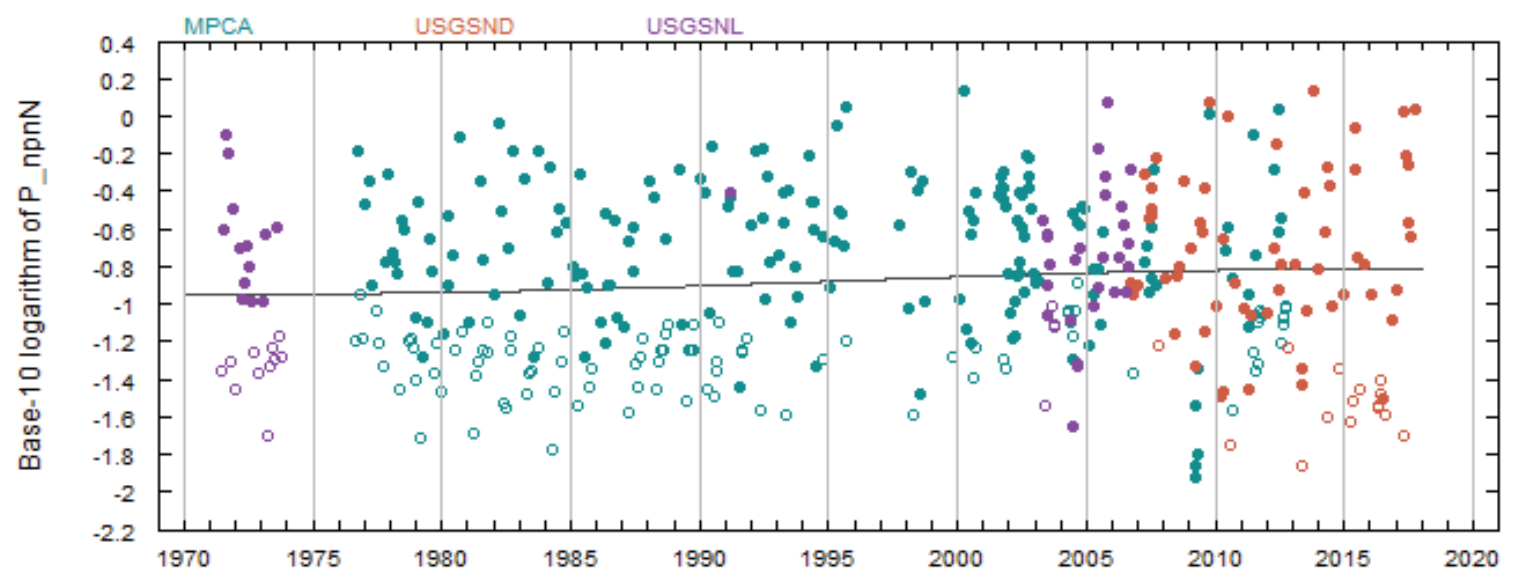

Points: flow-adjusted, detrended, and PARMA filtered data; Line: quadratic spline

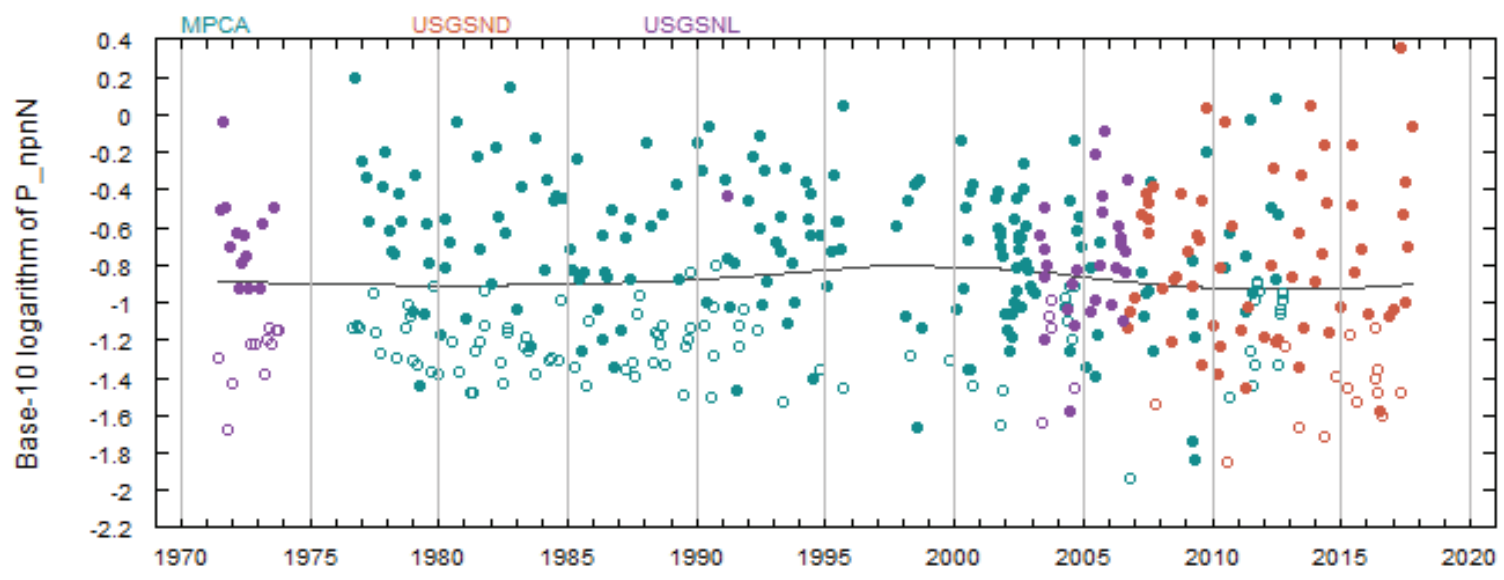

EXPLANATION
PARMA—Periodic autoregressive
Nitrate plus nitrite concentration data
moving average
- MPCA-Sample collected and analyzed by
Minnesota Pollution Control Agency
Estimated values for censored concentrations
-mon--Monotonic trend
- MPCA-Sample collected and analyzed by Minnesota Pollution Control Agency
- USGSND—Sample collected by U.S. Geological Survey
and analyzed by North Dakota Health Department
- USGSND_Sample collected by U.S. Geological Survey
and analyzed by North Dakota Health Department
- USGSNL-Sample collected by U.S. Geological Survey and no outside laboratory specified
- USGSNL-Sample collected by U.S. Geological Survey and no outside laboratory specified

Figure 10. Reduced graphical output (fullout=F) from runQWmodel for nitrate plus nitrite (npnN) concentration for RRFargoOWP dataset for the model with a single monotonic trend. 


\section{RRFargoQWPnpnN}

Trends -mon- 1985×2000 2000×2015

$\boldsymbol{A}$

Points: flow-adjusted data; Line: fitted trend

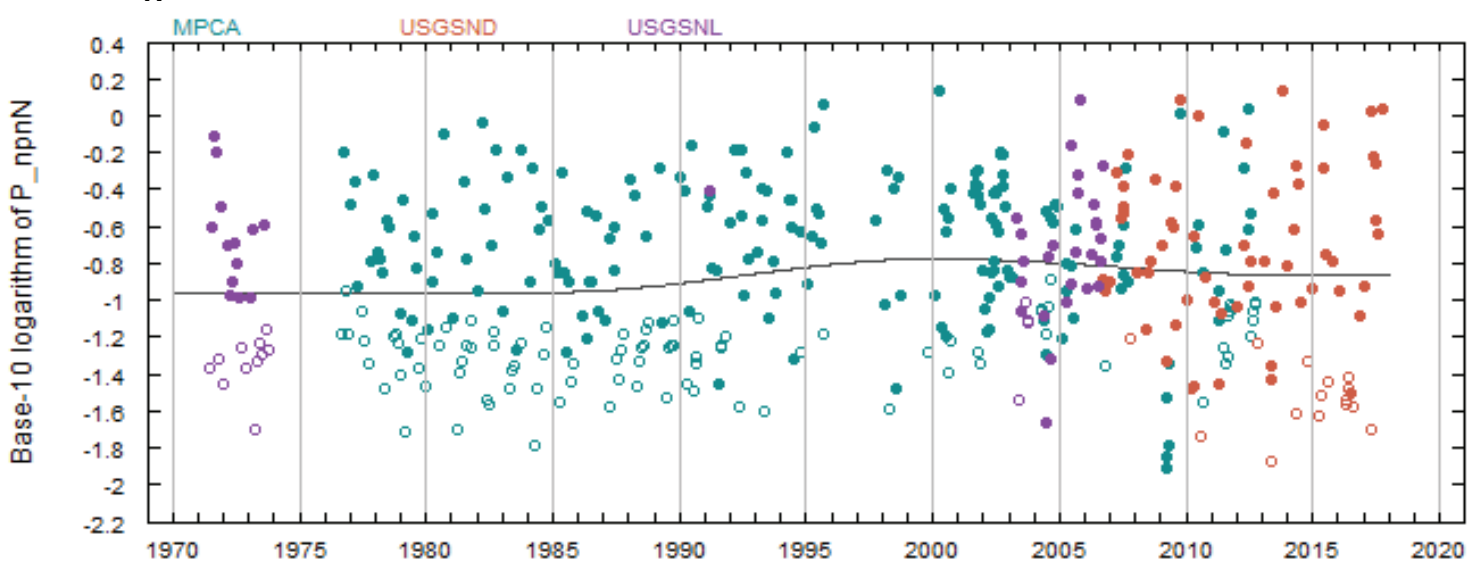

Points: flow-adjusted, detrended, and PARMA filtered data; Line: quadratic spline

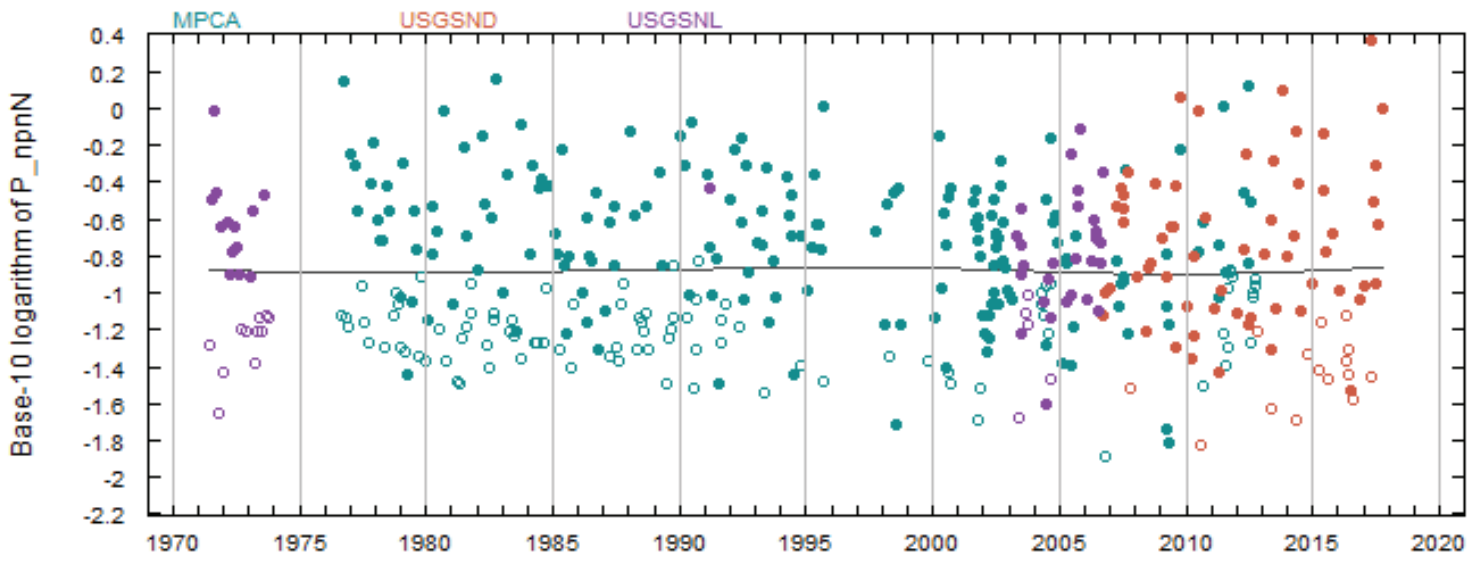

EXPLANATION

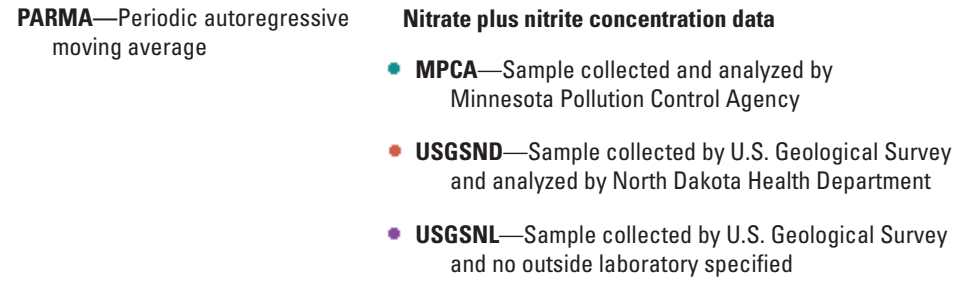

Estimated values for censored concentrations

- MPCA-Sample collected and analyzed by Minnesota Pollution Control Agency

- USGSND-Sample collected by U.S. Geological Survey and analyzed by North Dakota Health Department

- USGSNL-Sample collected by U.S. Geological Survey and no outside laboratory specified

Figure 11. Reduced output (fullout=F) from runQWmodel for nitrate plus nitrite (npnN) concentration for RRFargoQWP dataset for the model with two piecewise monotonic trends. $A$, graphical output; $B$, maximum likelihood estimation results from text file RRFargoOWPnpnN.txt. 
B

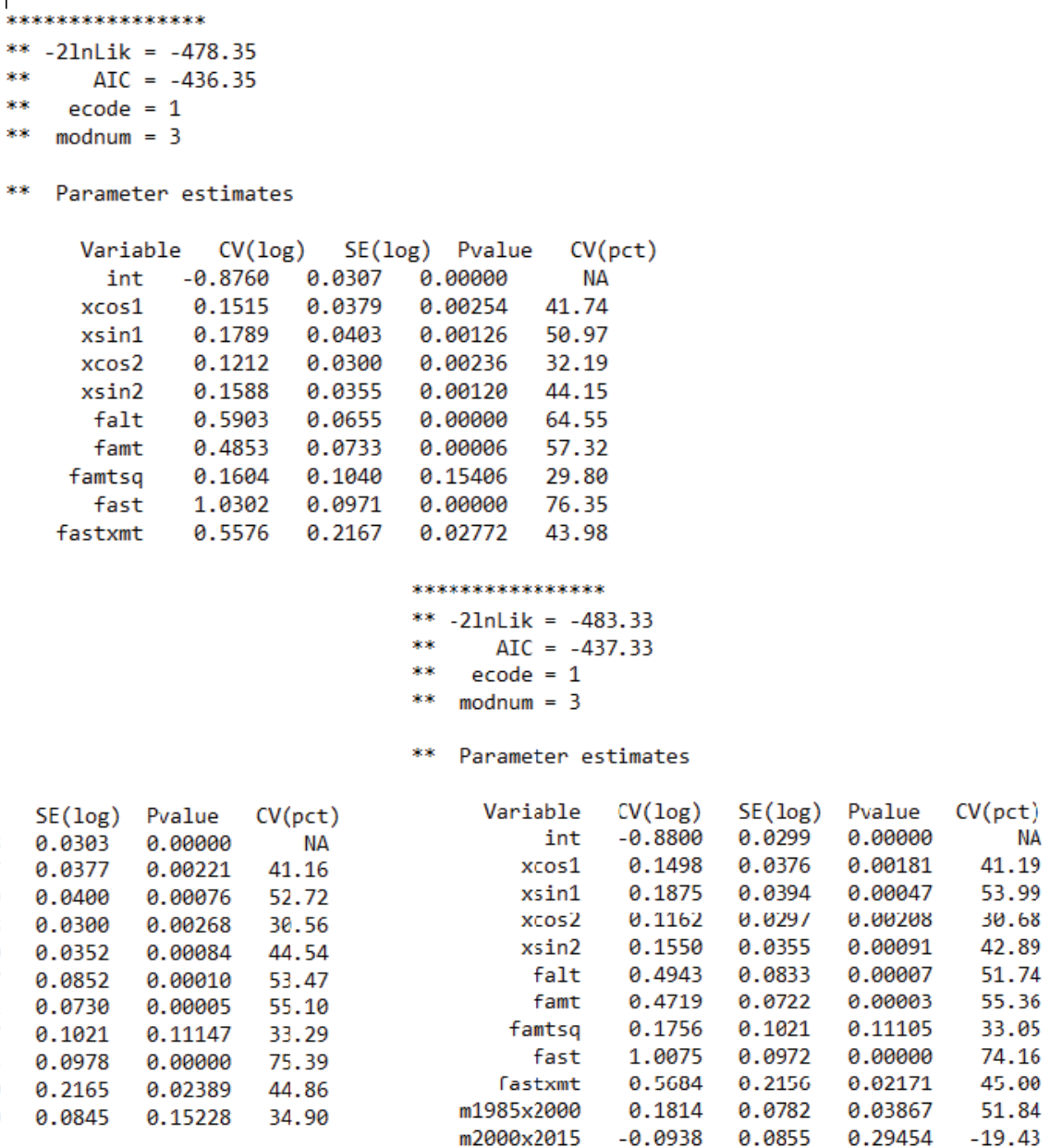

\section{EXPLANATION}

[Top, null model; bottom left, model with a single monotonic trend; bottom right, model with two piecewise monotonic trends]

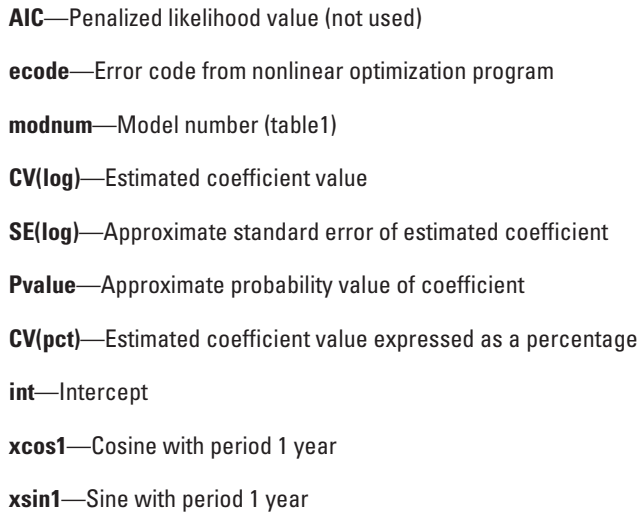

xsin1-Sine with period 1 year

Figure 11. Reduced output (fullout=F) from runQWmodel for nitrate plus nitrite (npnN) concentration for RRFargoQWP dataset for the model with two piecewise monotonic trends. $A$, graphical output; $B$, maximum likelihood estimation results from text file RRFargoQWPnpnN.txt.-Continued 
not be achieved with a lower model number, the data are not sufficient for trend analysis using R-QWTREND.

- Column labeled "variable" specifies the variable corresponding to the intercept (int or $M L C$, eq. 1), the coefficients of the model for FRVAR (eq. 6, xcos1 or $\cos (2 \pi t), \mathrm{x} \sin 1$ or $\sin (2 \pi t), \mathrm{x} \cos 2$ or $\cos (4 \pi t), \mathrm{x} \sin 2$ or $\sin (4 \pi t)$, falt or $L T F A$, famt or MTFA, famtsq or $M T F A^{2}$, fast or STFA, and fastxmt or STFA times $M T F A$ ), and coefficients for the specified trend model (for the NULL model, there are no trend coefficients).

- Column labeled "CV( $(\log )$ " is the estimated coefficient value from the maximum likelihood estimation in base-10 logarithmic (log) units.

- $\mathrm{SE}(\log )$ is the approximate standard error of the estimated coefficient (eq. 19).

- Pvalue is the approximate individual $p$-value for the coefficient (eq. 20).

- $\mathrm{CV}(\mathrm{pct})$ is the estimated coefficient value, expressed as a percentage. For the flow anomaly terms ( $\mathrm{X}=$ falt, famt, famtsq, fast, or fastxmt), CV(pct)= $100(10 S D(X) C V(\log )-1)$, where $\operatorname{SD}(X)$ is the standard deviation of $\mathrm{X}$. For the sine and cosine variables and all trend variables, $\mathrm{CV}(\mathrm{pct})=100\left(10^{C V}(\log )-1\right)$. In this case, all of the variables except famtsq were significant (Pvalue $<0.05$ ) and all of the coefficient values for the flow anomalies were positive, indicating that high flow anomalies tend to produce high $\mathrm{npnN}$ concentrations for all time scales (annual, seasonal, and daily). For example, for fast and the null model, $\mathrm{CV}(\mathrm{pct})=76.35$, which means that concentrations tend to be about 76 percent higher when fast is high (equal to plus one $\mathrm{SD}$ [fast]) compared to concentrations when fast is low (equal to negative one $\mathrm{SD}$ [fast]).

For the model with a single monotonic trend (figs. 10, $11 B$, bottom left table), there was an estimated uptrend of about 35 percent from 1975 to 2015 (m1975×2015 in variable column), with an approximate $p$-value using the normal approximation (eq. 19) of about 0.152 . The value of $-2 \ln L i k$ for this model was -480.5 with ecode $=2$ compared to -478.35 with ecode $=1$ for the null model. Note that an ecode of 3 or 4 would indicate that the model is probably too complex to be determined from the observed data and should not be considered as a good alternative. In this case, both models are acceptable alternatives. The GLR test statistic for comparing the null and single trend models (eq. 16) was (-478.35)$(-480.5)=2.15$, and the overall $p$-value using the GLR test statistic (eq. 17) was calculated to be

$$
P=1-p \operatorname{chis} q(2.15, d f=1)=0.142
$$

where

$p \operatorname{chisq}() \quad$ is the $\mathrm{R}$ function for computing probabilities for the chi-square distribution.

Note that this $p$-value is similar to the approximate $p$-value for the trend coefficient $(0.152$, fig. $11 B)$ because there is a single trend coefficient.

For the second trend model (fig. 11A-B), there was an estimated uptrend of about 52 percent from 1985 to 2000 (approximate $p$-value 0.039 ) followed by an estimated downtrend of about 19 percent from 2000 to 2015 (approximate $p$-value 0.295 ). The value of $-2 \ln L i k$ was -483.33 compared to -478.35 for the null model, for a difference of $-478.35-(-483.34)=4.98$ and the overall $p$-value of the twotrend model using the GLR test statistic was calculated to be $P=1-p \operatorname{chis} q(4.98, d f=2)=0.083$. Because the overall $p$-value of the two-trend model (0.083) was smaller compared to the one-trend model (0.142), the two-trend model appears to be a viable alternative to the one-trend model. To determine if the two-trend model is preferred, the GLR test for comparing the two models (eq. 22) can be used. The GLR test statistic is $\mathrm{G}_{1 \sim 2}=(-480.5)-(-483.33)=2.83$ and the $p$-value is $P=1-$ pchisq $(2.83, d f=1)=0.092$.

Based on the GLR statistics, the two-trend model is better $(p<0.1)$ than the one-trend model. Furthermore, the flowadjusted, detrended, and PARMA filtered observations for the two-trend model (fig. 11A, bottom plot) seem not to have any obvious trends remaining. Therefore, in this example the two-trend model seems to be a better alternative than the onetrend model.

After selecting the "best," or at least a "good," trend model, the full diagnostic output should be examined to verify the model assumptions before using the "value-added" output from the model (such as estimated annual flow-weighted average concentration or annual flux). The full diagnostic output can be obtained by using the default (fullout=T) option (see line 40 of the script). After running line 40, 10 pages of plots are produced in a graphical output file (RRFargoQWPnpnN. pdf) in the current working directory. The first six plots show detailed model diagnostic information, and the remaining plots show the "value-added" model output (see fig. 12A-I):

- Page 1: Observed data along with flow-related variability (eq. 6).

- Page 2: Flow-adjusted data (eq. 7) along with the fitted trend $(M L C+T R E N D)$.

- Page 3: Flow-adjusted and PARMA filtered data (MLC+TREND+R, where $R$ is defined in eq. 13) along with the fitted trend.

- Page 4: Flow-adjusted, detrended, and PARMA filtered data $(M L C+R)$ along with a quadratic spline to indicate potential residual trends. 


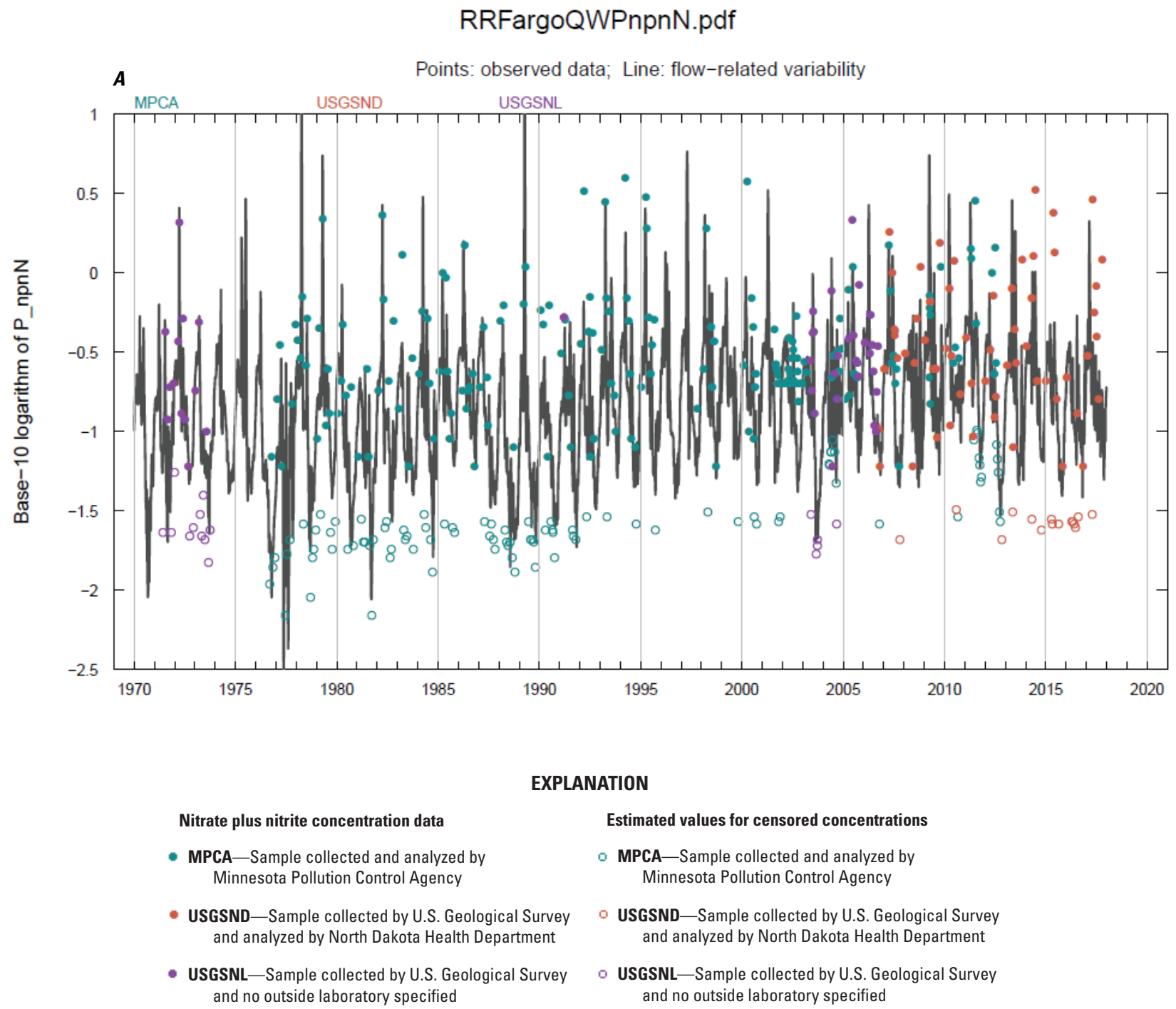

Figure 12. Full graphical output from run $Q W$ model for nitrate plus nitrite $(\mathrm{npnN})$ concentration for RRFargoOWP dataset for the model with two piecewise monotonic trends. $A$, page $1 ; B$, page $2 ; C$, page $3 ; D$, page $4 ; E$, page $5 ; F$, page $6 ; G$, page $7 ; H$, page 8 ; I, page 9 ; $J$, page 10 . 


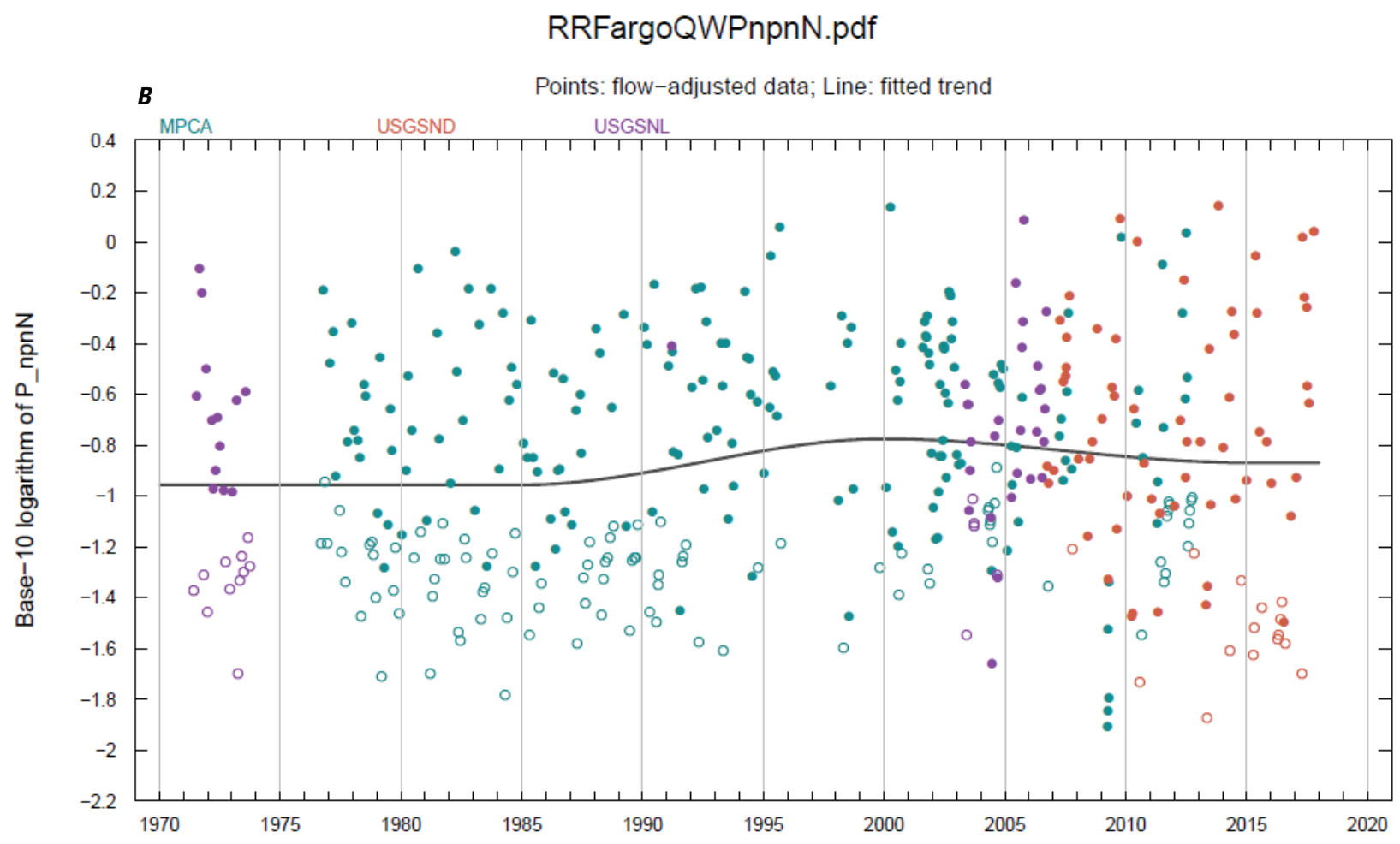

EXPLANATION

Nitrate plus nitrite concentration data

- MPCA-Sample collected and analyzed by Minnesota Pollution Control Agency

- USGSND-Sample collected by U.S. Geological Survey and analyzed by North Dakota Health Department

- USGSNL-Sample collected by U.S. Geological Survey and no outside laboratory specified
Estimated values for censored concentrations

- MPCA—Sample collected and analyzed by Minnesota Pollution Control Agency

- USGSND-Sample collected by U.S. Geological Survey and analyzed by North Dakota Health Department

- USGSNL-Sample collected by U.S. Geological Survey and no outside laboratory specified

Figure 12. Full graphical output from runQWmodel for nitrate plus nitrite $(\mathrm{npnN})$ concentration for RRFargoOWP dataset for the model with two piecewise monotonic trends. $A$, page $1 ; B$, page $2 ; C$, page $3 ; D$, page $4 ; E$, page $5 ; F$, page $6 ; G$, page $7 ; H$, page $8 ; I$, page 9 ; $J$, page 10.-Continued 


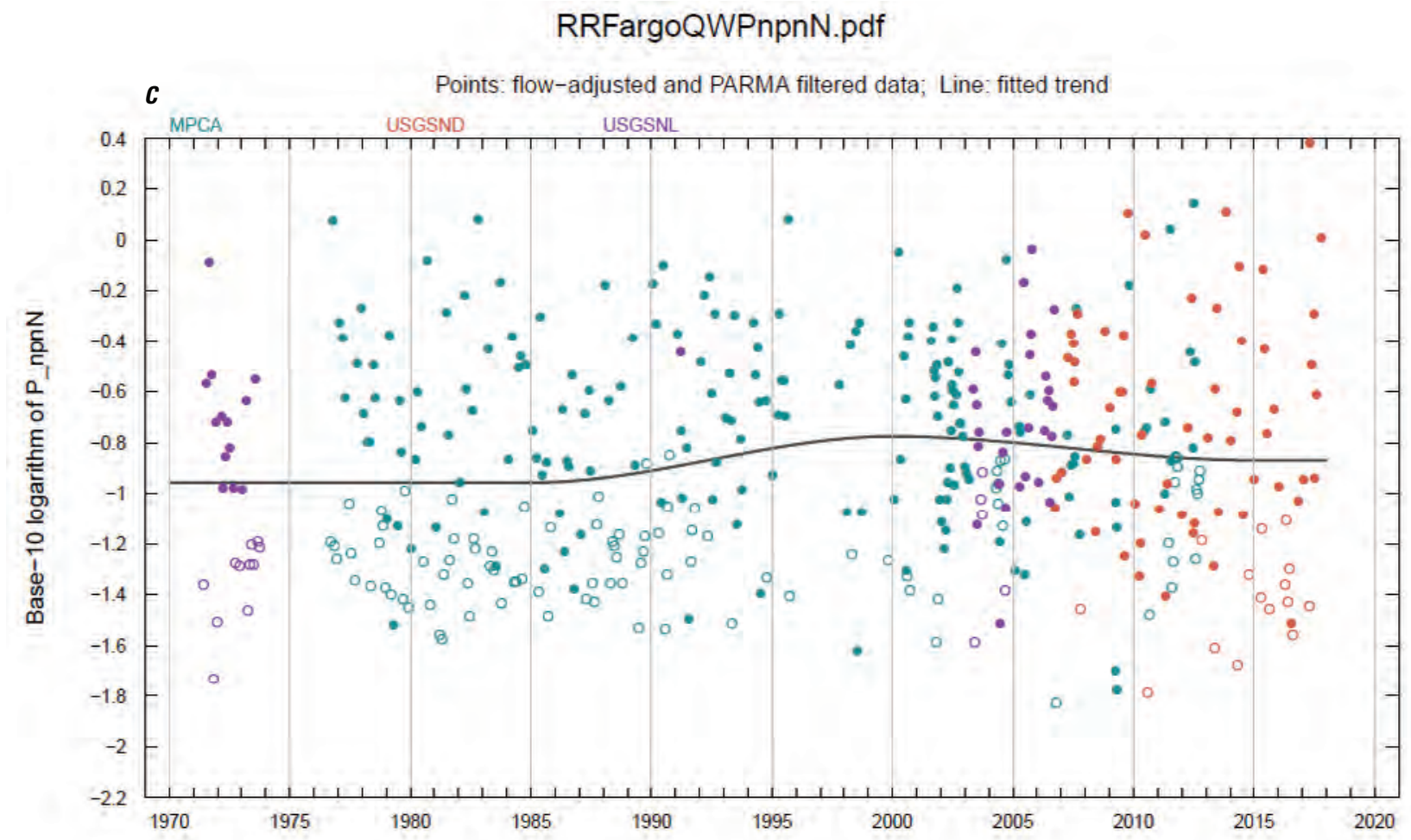

EXPLANATION

PARMA-Periodic autoregressive moving average
Nitrate plus nitrite concentration data

- MPCA-Sample collected and analyzed by Minnesota Pollution Control Agency

- USGSND—Sample collected by U.S. Geological Survey and analyzed by North Dakota Health Department

- USGSNL-Sample collected by U.S. Geological Survey and no outside laboratory specified
Estimated values for censored concentrations

- MPCA-Sample collected and analyzed by Minnesota Pollution Control Agency

- USGSND-Sample collected by U.S. Geological Survey and analyzed by North Dakota Health Department

- USGSNL-Sample collected by U.S. Geological Survey and no outside laboratory specified

Figure 12. Full graphical output from runQWmodel for nitrate plus nitrite $(\mathrm{npnN})$ concentration for RRFargoOWP dataset for the model with two piecewise monotonic trends. $A$, page $1 ; B$, page $2 ; C$, page $3 ; D$, page $4 ; E$, page $5 ; F$, page $6 ; G$, page $7 ; H$, page 8 ; $I$, page 9 ; $J$, page 10.-Continued 


\section{RRFargoQWPnpnN.pdf}

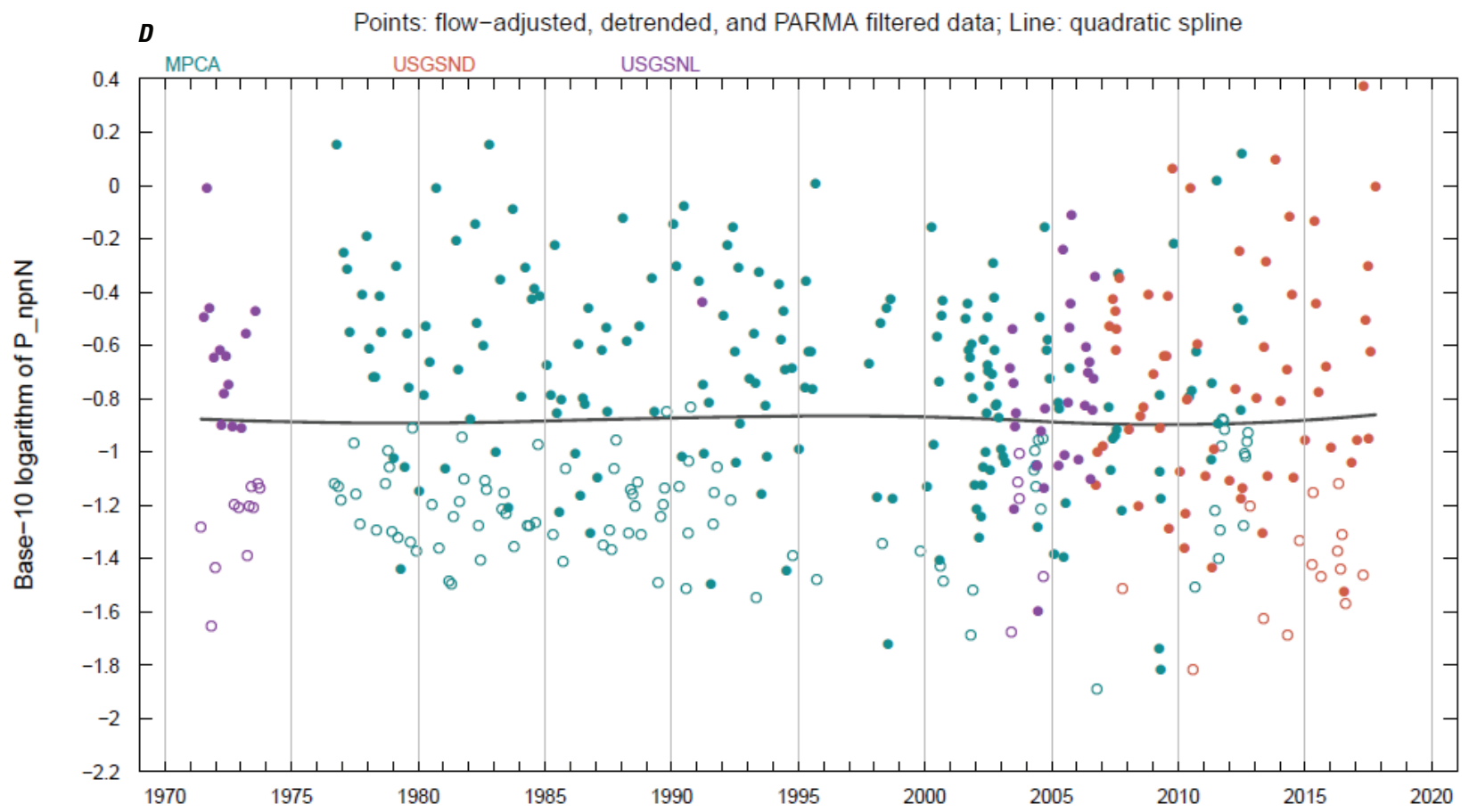

EXPLANATION

PARMA-Periodic autoregressive moving average
Nitrate plus nitrite concentration data

- MPCA-Sample collected and analyzed by Minnesota Pollution Control Agency

- USGSND - Sample collected by U.S. Geological Survey and analyzed by North Dakota Health Department

- USGSNL-Sample collected by U.S. Geological Survey and no outside laboratory specified
Estimated values for censored concentrations

- MPCA—Sample collected and analyzed by Minnesota Pollution Control Agency

- USGSND-Sample collected by U.S. Geological Survey and analyzed by North Dakota Health Department

- USGSNL-Sample collected by U.S. Geological Survey and no outside laboratory specified

Figure 12. Full graphical output from runQWmodel for nitrate plus nitrite $(\mathrm{npnN})$ concentration for RRFargoQWP dataset for the model with two piecewise monotonic trends. $A$, page $1 ; B$, page $2 ; C$, page $3 ; D$, page $4 ; E$, page $5 ; F$, page $6 ; G$, page $7 ; H$, page 8 ; I, page 9 ; $J$, page 10.-Continued 


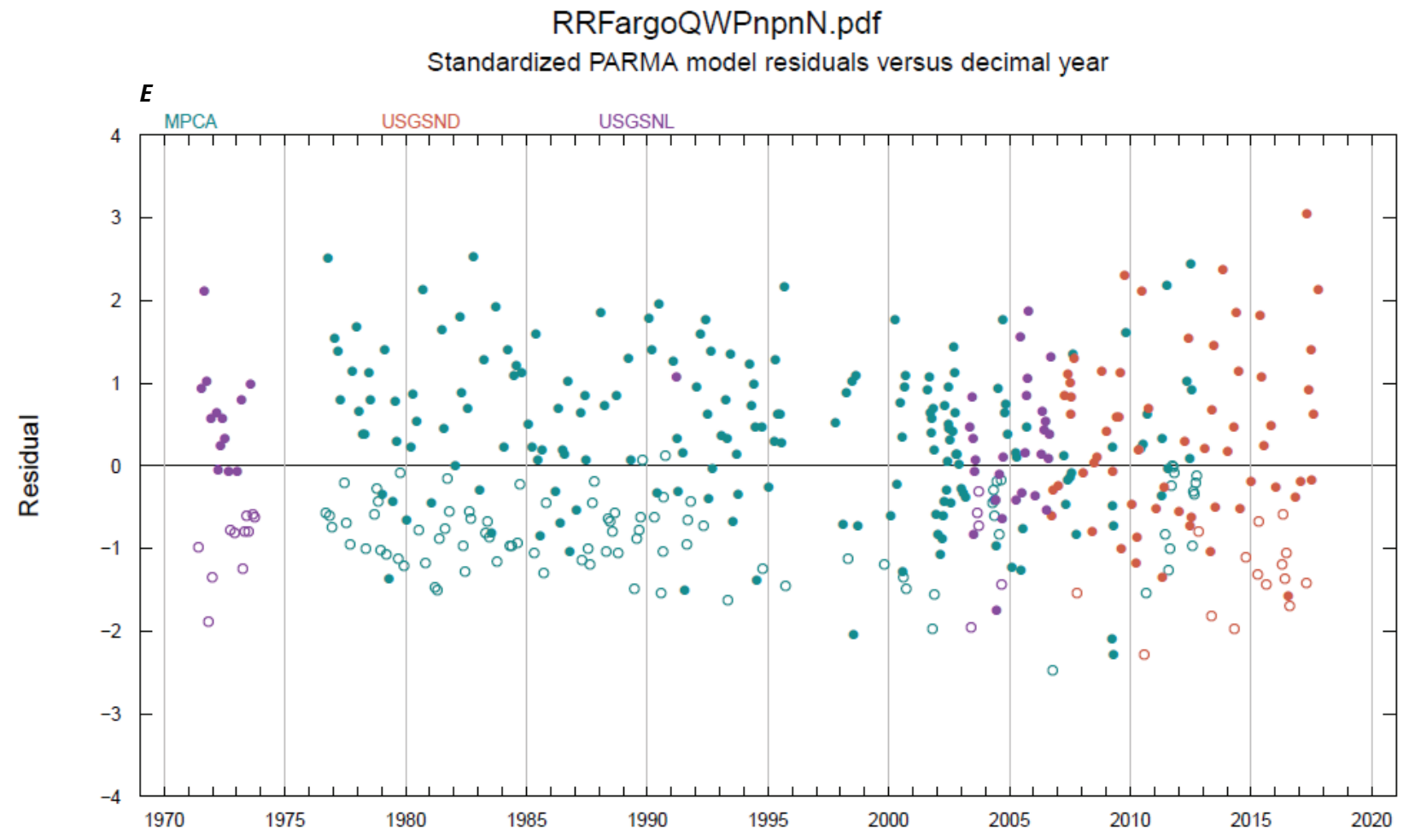

EXPLANATION

PARMA-Periodic autoregressive moving average
Nitrate plus nitrite concentration data

- MPCA-Sample collected and analyzed by Minnesota Pollution Control Agency

- USGSND-Sample collected by U.S. Geological Survey and analyzed by North Dakota Health Department

- USGSNL-Sample collected by U.S. Geological Survey and no outside laboratory specified
Estimated values for censored concentrations

- MPCA-Sample collected and analyzed by Minnesota Pollution Control Agency

- USGSND-Sample collected by U.S. Geological Survey and analyzed by North Dakota Health Department

- USGSNL-Sample collected by U.S. Geological Survey and no outside laboratory specified

Figure 12. Full graphical output from runQWmodel for nitrate plus nitrite $(\mathrm{npnN})$ concentration for RRFargoQWP dataset for the model with two piecewise monotonic trends. $A$, page $1 ; B$, page $2 ; C$, page $3 ; D$, page $4 ; E$, page $5 ; F$, page $6 ; G$, page $7 ; H$, page 8 ; $I$, page 9 ; $J$, page 10.-Continued 


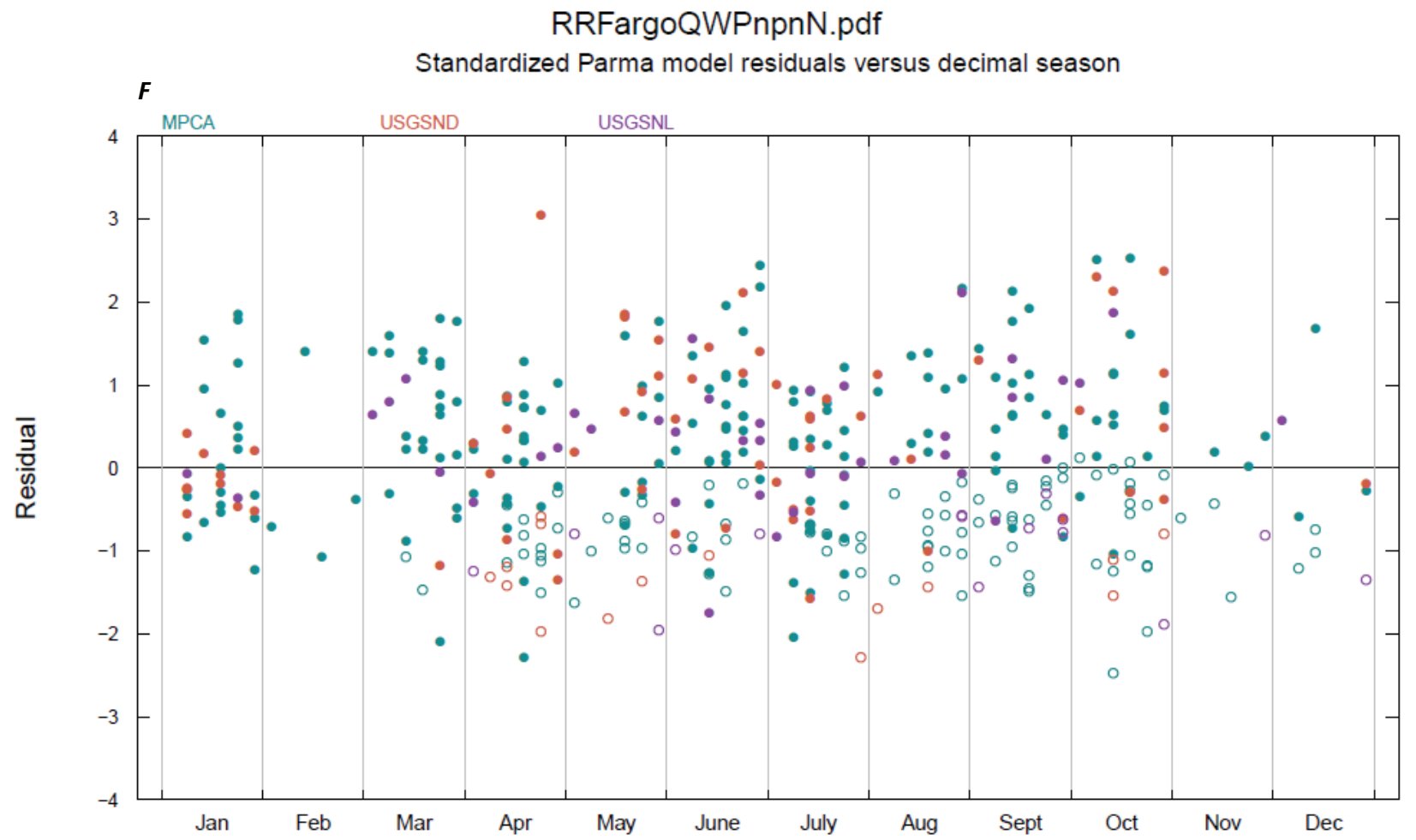

\section{EXPLANATION}

PARMA-Periodic autoregressive moving average
Nitrate plus nitrite concentration data

- MPCA-Sample collected and analyzed by Minnesota Pollution Control Agency

- USGSND-Sample collected by U.S. Geological Survey and analyzed by North Dakota Health Department

- USGSNL-Sample collected by U.S. Geological Survey and no outside laboratory specified

\section{Estimated values for censored concentrations}

- MPCA-Sample collected and analyzed by Minnesota Pollution Control Agency

- USGSND-Sample collected by U.S. Geological Survey and analyzed by North Dakota Health Department

- USGSNL-Sample collected by U.S. Geological Survey and no outside laboratory specified

Figure 12. Full graphical output from runQWmodel for nitrate plus nitrite $(\mathrm{npnN})$ concentration for RRFargoOWP dataset for the model with two piecewise monotonic trends. $A$, page $1 ; B$, page $2 ; C$, page $3 ; D$, page $4 ; E$, page $5 ; F$, page $6 ; G$, page $7 ; H$, page 8 ; $I$, page 9 ; $J$, page 10.-Continued 


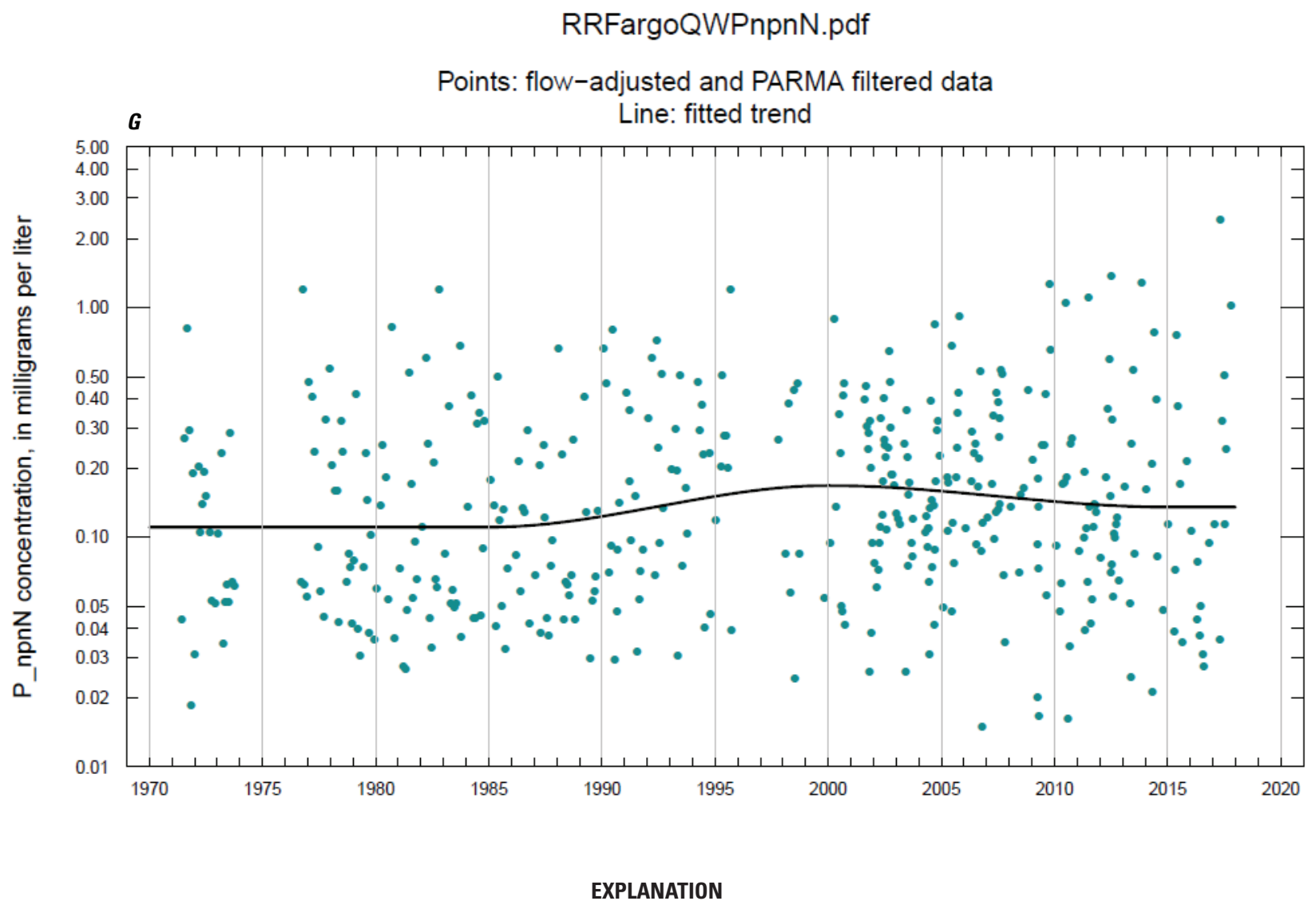

PARMA_-Periodic autoregressive moving average

Figure 12. Full graphical output from run $Q W$ model for nitrate plus nitrite $(\mathrm{npnN})$ concentration for RRFargoQWP dataset for the model with two piecewise monotonic trends. $A$, page $1 ; B$, page $2 ; C$, page $3 ; D$, page $4 ; E$, page $5 ; F$, page $6 ; G$, page $7 ; H$, page 8 ; $I$, page 9 ; $J$, page 10.-Continued 


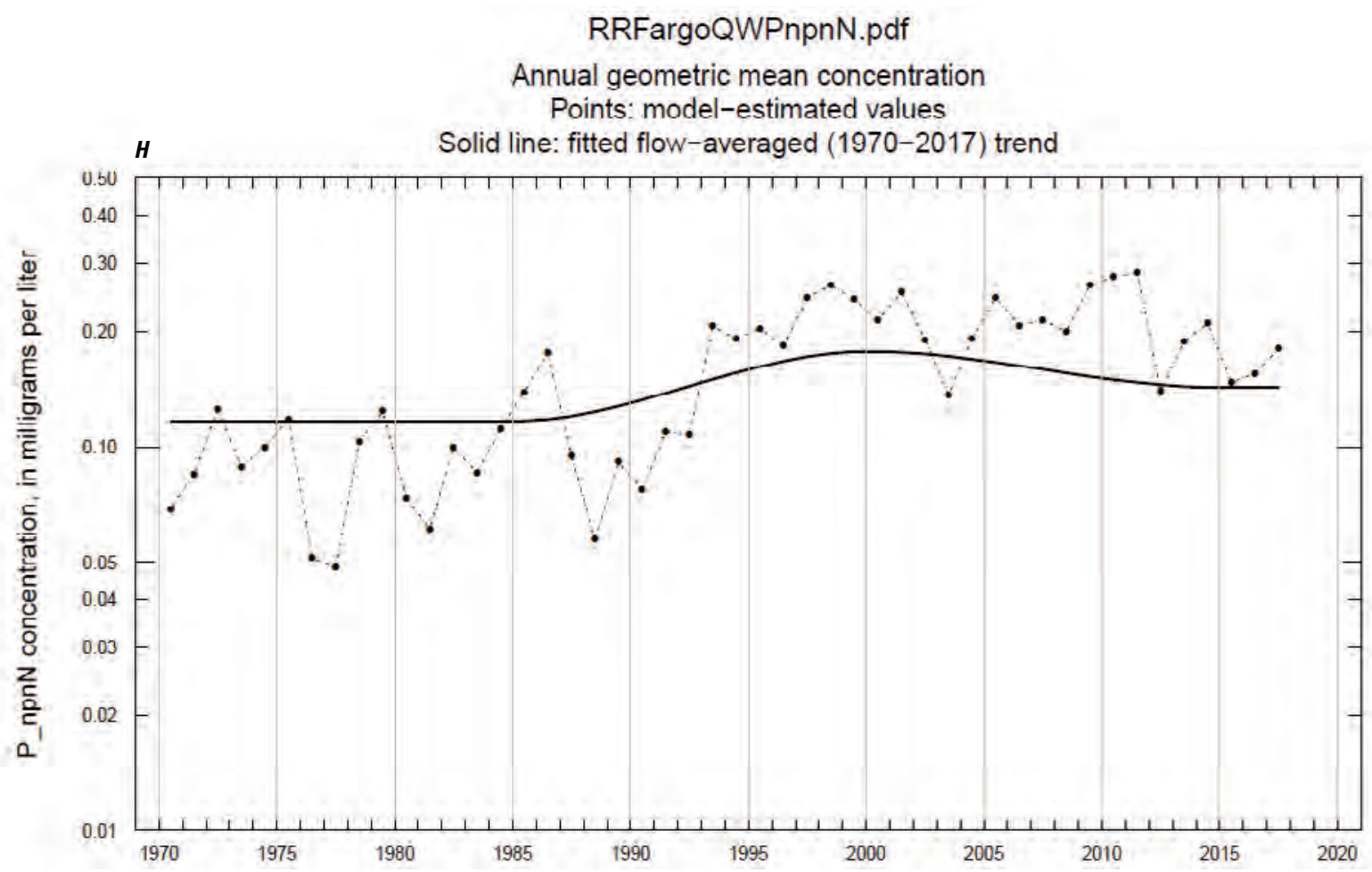

Figure 12. Full graphical output from runQWmodel for nitrate plus nitrite $(\mathrm{npnN})$ concentration for RRFargoQWP dataset for the model with two piecewise monotonic trends. $A$, page $1 ; B$, page $2 ; C$, page $3 ; D$, page $4 ; E$, page $5 ; F$, page $6 ; G$, page $7 ; H$, page 8 ; I, page 9 ; $J$, page 10.-Continued

\section{RRFargoQWPnpnN.pdf}

Annual flow-weighted average concentration

Points: model-estimated values

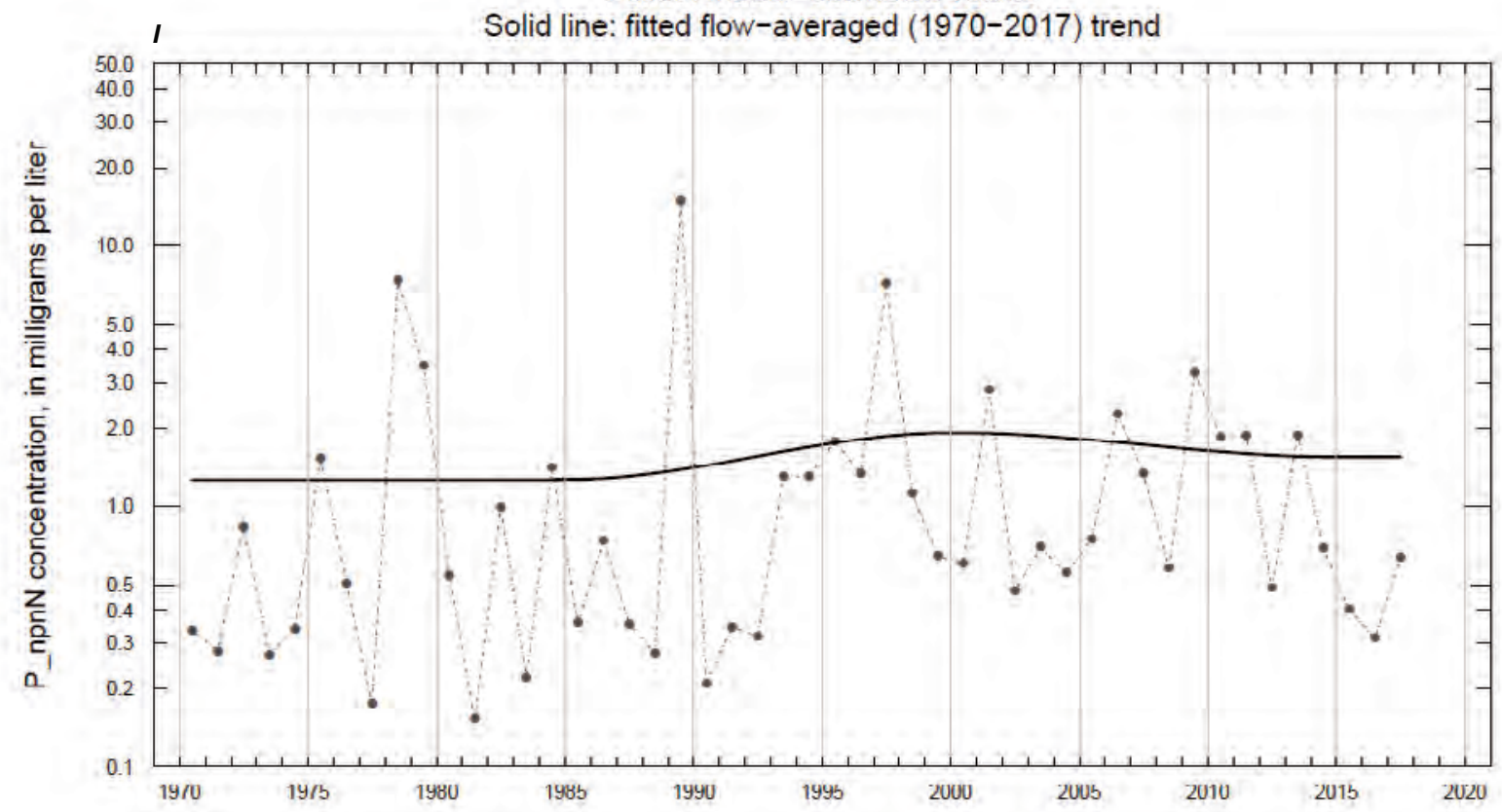

Figure 12. Full graphical output from runQWmodel for nitrate plus nitrite $(\mathrm{npnN})$ concentration for RRFargoQWP dataset for the model with two piecewise monotonic trends. $A$, page $1 ; B$, page $2 ; C$, page $3 ; D$, page $4 ; E$, page $5 ; F$, page $6 ; G$, page $7 ; H$, page $8 ; I$, page 9 ; $J$, page 10.-Continued 


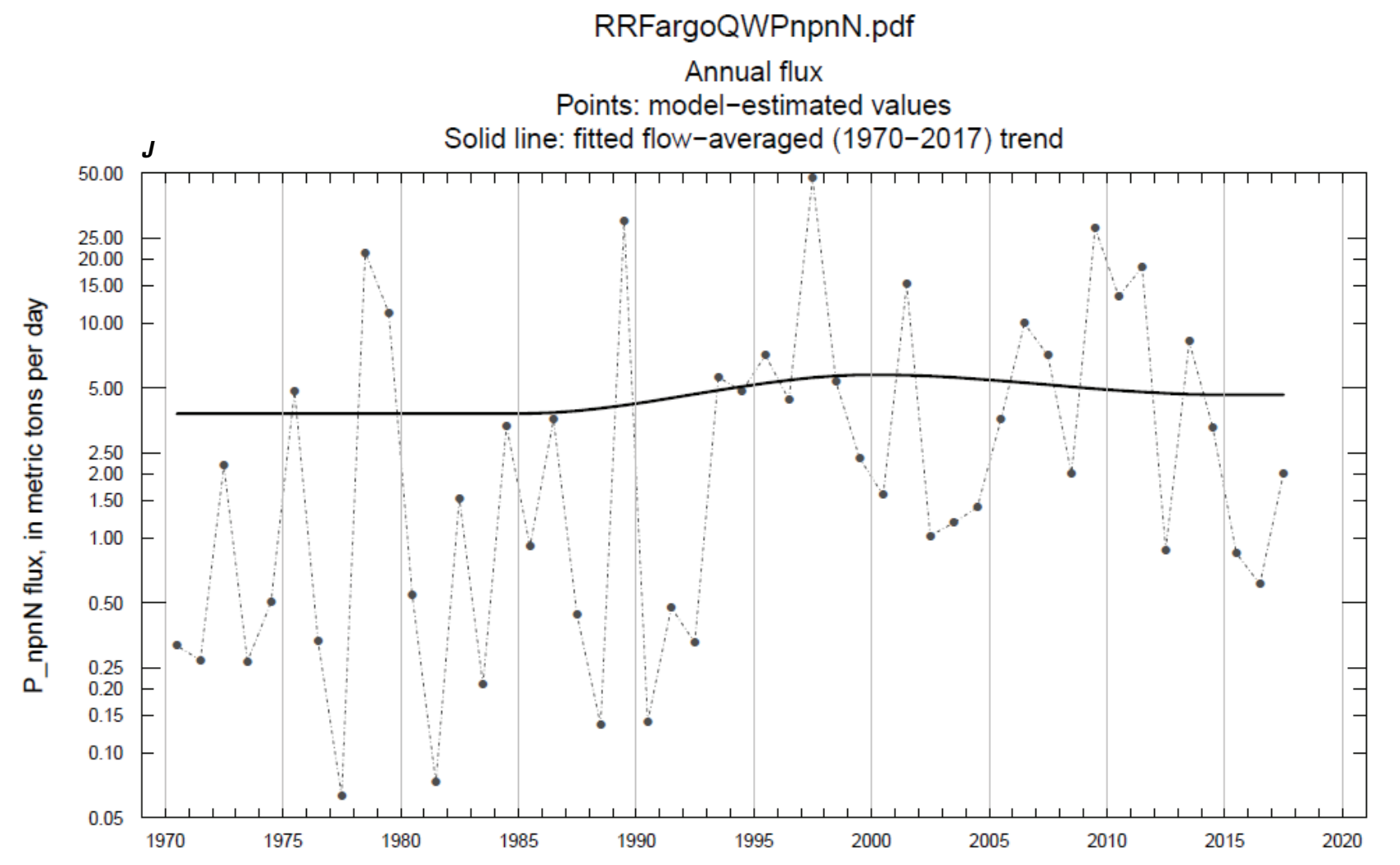

Figure 12. Full graphical output from runQWmodel for nitrate plus nitrite $(\mathrm{npnN})$ concentration for RRFargoQWP dataset for the model with two piecewise monotonic trends. $A$, page $1 ; B$, page $2 ; C$, page $3 ; D$, page $4 ; E$, page $5 ; F$, page $6 ; G$, page $7 ; H$, page 8 ; $I$, page 9 ; $J$, page 10.-Continued

- Page 5: Standardized PARMA model residuals (eq. 14) versus decimal year. The residuals should be approximately independent, standard normal random variables. Obvious nonsymmetrical (skewed) residuals, outliers (values larger than about 3.5 in absolute value), or nonrandom structure (systematic changes in central tendency or variability, excessive clumping, etc.) may indicate that the model results are unreliable.

- Page 6: Standardized PARMA model residuals (eq. 14) versus decimal season. These should be examined in a similar manner to the previous plot (page 5) to ensure that there is no obvious seasonal structure remaining in the residuals.

- Page 7: Same as page 3, but without the error codes and censoring information and with improved y-axis tick marks and labels.

- Page 8: Estimated annual geometric mean concentration along with the fitted trend (eq. 24). The trend is referred to as a "flow-averaged" trend because it is an estimate of the geometric mean concentration under the hypothetical assumption that flow-related variability was the same year after year.
- Page 9: Estimated annual flow-weighted average concentration (eq. 25) along with the fitted flow-averaged trend (eq. 27). Note that, for this example, the annual flow-weighted average concentrations are much higher than the annual geometric mean concentrations (page 8) because npnN concentrations tend to be much higher during high-flow conditions compared to lowflow conditions.

- Page 10: Estimated annual flux (eq. 28) along with the fitted flow-averaged trend (eq. 29). Note the high degree of flow-related variability in the estimated annual flux as indicated by large deviations of the annual values from the fitted trend. Flux tended to be much lower compared to the flow-averaged trend during dry years such as 1977 and 1981 and much higher during wet years such as 1997 and 2009.

\section{Example 2-Parameter PTot for RRFargoOWP}

The second example shows how to combine monotonic trends with potential step trends related to differences in sample collection or laboratory analysis methods. Run lines 43-45 of the script file (fig. 2) to obtain the full output (default argument, fullout $=\mathrm{T}$ ) for the null model and two potential trend models for PTot (total phosphorus) for the RRFargoQWP 


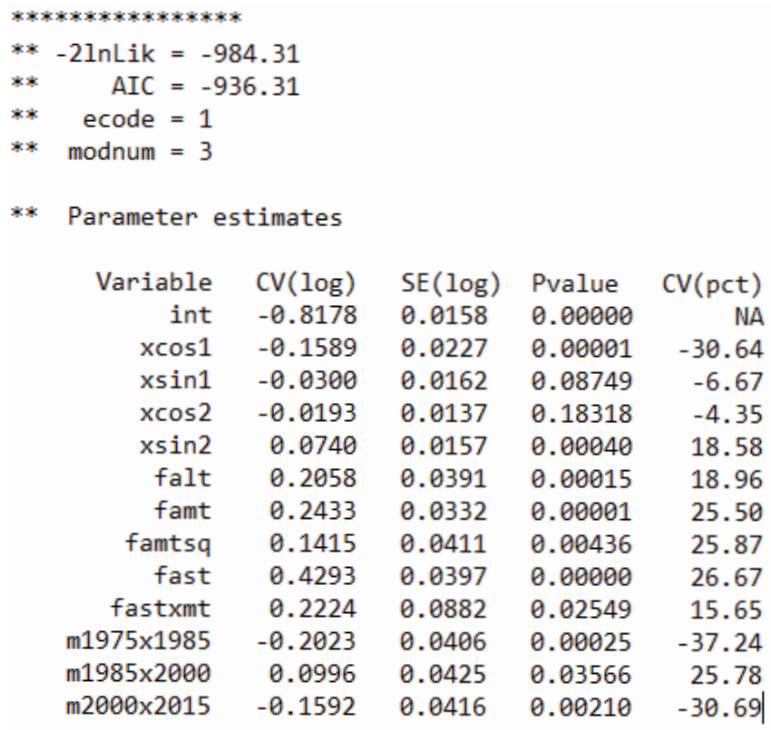

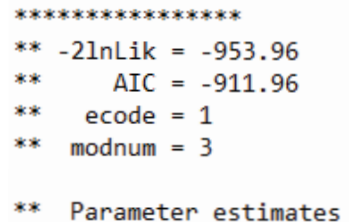

\begin{tabular}{|c|c|c|c|c|}
\hline Variable & CV(lc & SE( & Pvalue & $C V(p c t$ \\
\hline int & -0.8208 & 0.0198 & 0.00000 & NA \\
\hline$x \cos 1$ & -0.1532 & 0.0248 & 0.00011 & -29.73 \\
\hline$x \sin 1$ & -0.0270 & 0.0173 & 0.15064 & -6.03 \\
\hline$x \cos 2$ & -0.0217 & 0.0140 & 0.15358 & -4.87 \\
\hline$x \sin 2$ & 0.0763 & 0.0156 & 0.00063 & 19.21 \\
\hline falt & 0.1314 & 0.0390 & 0.00716 & 11.72 \\
\hline famt & 0.2344 & 0.0373 & 0.00009 & 24.46 \\
\hline famtsq & 0.1492 & 0.0432 & 0.00620 & 27.46 \\
\hline fast & 0.4087 & 0.0397 & 0.00000 & 25.24 \\
\hline fastxmt & 0.2504 & 0.0882 & 0.01762 & 17.78 \\
\hline
\end{tabular}

\begin{tabular}{|c|c|c|c|c|c|}
\hline$k * * * * * * * * * * * * * * *$ & \multicolumn{5}{|c|}{$-2 \operatorname{lnLik}=-995.67$} \\
\hline k* & \multirow{2}{*}{\multicolumn{5}{|c|}{$\begin{aligned} \text { AIC } & =-945.67 \\
\text { ecode } & =1\end{aligned}$}} \\
\hline k* & & & & & \\
\hline k* & \multicolumn{5}{|l|}{ modnum $=3$} \\
\hline k* & \multicolumn{5}{|c|}{ Parameter estimates } \\
\hline & Variable & CV $(\log )$ & SE (log) & Pvalue & $C V(p c t)$ \\
\hline & int & -0.8754 & 0.0234 & 0.00000 & NA \\
\hline & $x \cos 1$ & -0.1557 & 0.0231 & 0.00001 & -30.13 \\
\hline & $x \sin 1$ & -0.0301 & 0.0164 & 0.08867 & -6.70 \\
\hline & $x \cos 2$ & -0.0149 & 0.0139 & 0.30025 & -3.37 \\
\hline & $x \sin 2$ & 0.0713 & 0.0156 & 0.00044 & 17.84 \\
\hline & falt & 0.1967 & 0.0384 & 0.00016 & 18.05 \\
\hline & famt & 0.2444 & 0.0332 & 0.00000 & 25.63 \\
\hline & famtsq & 0.1403 & 0.0414 & 0.00440 & 25.63 \\
\hline & fast & 0.4330 & 0.0394 & 0.00000 & 26.93 \\
\hline & fastxmt & 0.2253 & 0.0871 & 0.02156 & 15.87 \\
\hline & rMPCA & 0.0892 & 0.0258 & 0.00380 & 22.80 \\
\hline & m1975x1985 & -0.2042 & 0.0400 & 0.00016 & -37.51 \\
\hline & m1985x2000 & 0.1209 & 0.0422 & 0.01251 & 32.10 \\
\hline & $\mathrm{m} 2000 \times 2015$ & -0.1034 & 0.0442 & 0.03460 & -21.19 \\
\hline
\end{tabular}

\section{EXPLANATION}

[Top, null model; bottom left, model M1; bottom right, model M2;

MPCA, sample collected and analyzed by Minnesota Pollution Control Agency]

-2InLik-Minus two times the natural logarithm of the maximized likelihood function

$\mathbf{x c o s} 2$ - Cosine with period 6 months

AIC-Penalized likelihood value (not used)

xsin2 - Sine with period 6 months

ecode-Error code from nonlinear optimization program

falt-Long-term flow anomaly

modnum-Model number (table1)

famt-Midterm flow anomaly

$\mathbf{C V}(\log )$-Estimated coefficient value

famtsq-Square of midterm flow anomaly

SE( $(\log )$-Approximate standard error of estimated coefficient

fast-Short-term flow anomaly

Pvalue-Approximate probability value of coefficient

fastxmt-Product of short-term and midterm flow anomalies

CV(pct)-Estimated coefficient value expressed as a percentage

rMPCA - Step trend for remark code MPCA

int-Intercept

m1975x1985-Monotonic trend from 1975 to 1985

xcos1-Cosine with period 1 year

m1985x2000-Monotonic trend from 1985 to 2000

$\mathbf{x} \sin 1-$ Sine with period 1 year

m2000x2015-Monotonic trend from 2000 to 2015

Figure 13. Parameter estimation results from runQWmodel for total phosphorus concentration for RRFargoOWP dataset for the null model and two alternative trend models. 


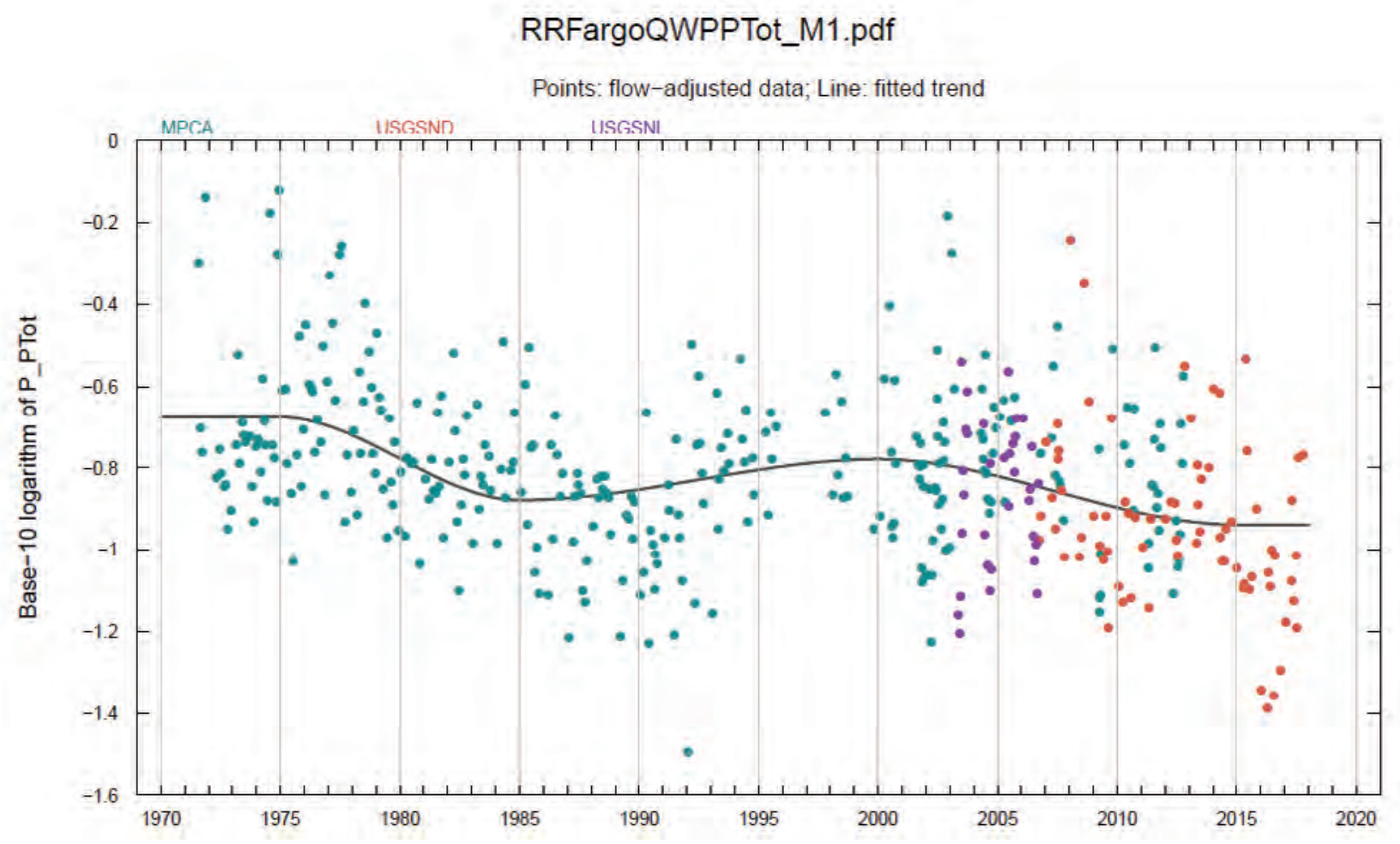

EXPLANATION

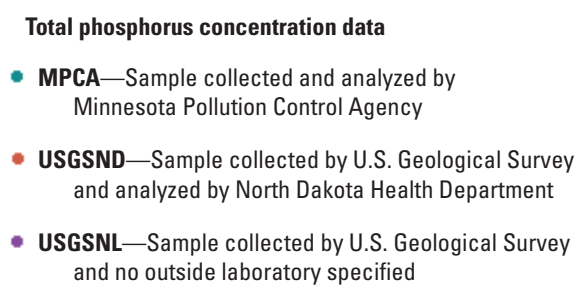

Figure 14. Flow-adjusted total phosphorus (PTot) concentration for RRFargoOWP dataset for model with piecewise monotonic trend (model M1).

dataset, and examine the parameter estimation results from the files RRFargoQWPPTot_null.txt, RRFargoQWPPTot_M1.txt, and RRFargoQWPPTot_M2.txt (see fig. 13). The optional runname argument is used in these commands to name the output files. If this command was not used, the graphical output file from each successive model run would have the same name (RRFargoQWPPTot.pdf) and would be overwritten each time the new output is produced. Model M2 $(-2 \ln L i k=-995.67)$, which includes the piecewise monotonic trends and a step trend for remark code "MPCA," is a much better alternative than model M1 ( $-2 \ln L i k=-984.31)$, which includes just the piecewise monotonic trends. The $p$-value for the GLR test for comparing model M2 versus M1 $(G=-984.31+995.67=11.36$, $P=1-p \operatorname{chis} q(11.36, d f=1)=0.00075)$ is small $(<0.01)$, indicating that the more complex model (M2) is the better alternative. The fitted trend for model M1 (fig. 14) consisted of a highly significant downtrend $(-37$ percent, $p$-value $=0.00025$ ) from 1975 to 1985 , followed by a mildly significant uptrend
( +26 percent, $p$-value $=0.036$ ) from 1985 to 2000 and another highly significant downtrend ( -31 percent, $p$-value $=0.002$ ) from 2000 to 2015. For model M2 (fig. 15), there was a highly significant step trend for remark code MPCA $(+23$ percent, $p$-value $=0.0038$ ), indicating that concentrations with that remark code tend to be about 23 percent higher, on average, compared to the other two remark codes. Whenever one or more step trends are included in the model, there is an extra page of graphical output showing flow-adjusted concentrations with step trends included (top plot in fig. 15) and with step trends removed (bottom plot). Step trends based on remark codes are assumed to apply to the observations, not the true water-quality conditions, and thus need to be removed before analyzing true trends.

With multiple remark codes, there may be several alternative representations for the step trends that cannot readily be distinguished from one another based on the observations alone and, thus, may require expert judgement or further 

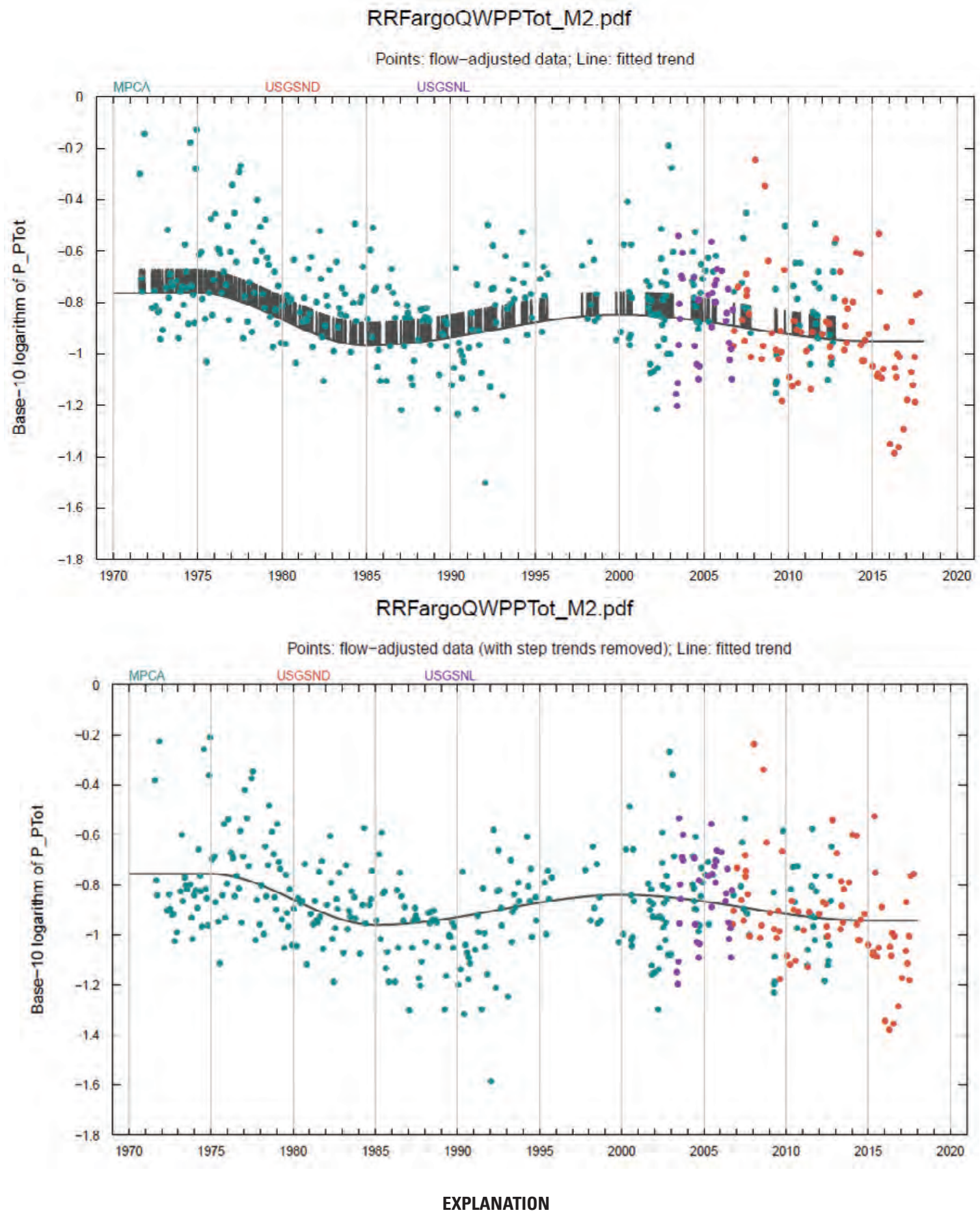

Total phosphorus concentration data

- MPCA-Sample collected and analyzed by Minnesota Pollution Control Agency

- USGSND-Sample collected by U.S. Geological Survey and analyzed by North Dakota Health Department

- USGSNL-Sample collected by U.S. Geological Survey and no outside laboratory specified

Figure 15. Flow-adjusted total phosphorus (PTot) concentration for RRFargoQWP dataset for model with piecewise monotonic trend and step trend for remark code MPCA (model M2). 


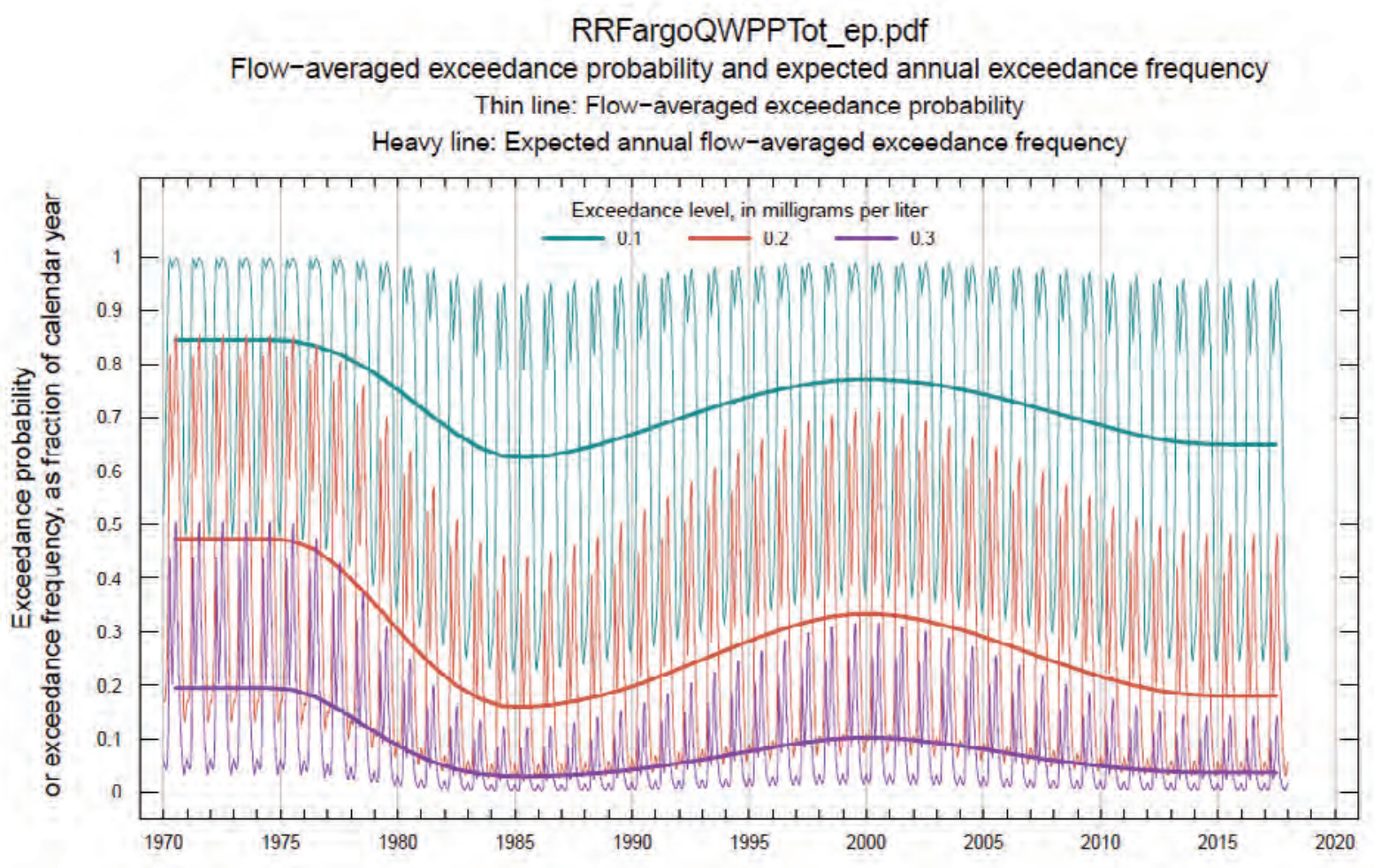

Figure 16. Flow-averaged exceedance probabilities and expected annual exceedance frequencies for total phosphorus (PTot) concentration for RRFargoOWP dataset for model M2.

investigation before accepting the model. In this example, the "true" concentrations were assumed to be represented by the USGSNL and USGSND remark codes and concentrations with remark code "MPCA" were adjusted down by 23 percent to be consistent with the other observations. Another essentially equivalent alternative would be to assume observations with remark code MPCA represent "true" concentrations and adjust concentrations with the other remark codes up to be consistent with the MPCA data. This alternative would be completed by specifying remxx=c("USGSND," "USGSNL"). Deciding which alternative is best may require more investigation into sample collection and preservation methods and laboratory analysis methods used by the various agencies.

Exceedance probabilities for this example can be examined by running line 48 of the script file (fig. 2), which fits the same model used previously (M2) but with three specified exceedance levels of $0.1,0.2$, and 0.3 milligram per liter $(\mathrm{mg} / \mathrm{L})$. Exceedance levels are specified using a numeric vector for the exlev argument, in this case, exlev $=\mathrm{c}(0.1,0.2,0.3)$. After running line 48, examine the graphical output file (RRFargoQWPPTot_ep.pdf) and note the extra page of output (fig. 16) showing the flow-averaged exceedance probabilities (eq. 32) and expected annual flow-averaged exceedance frequencies (eq. 33).

\section{Example 3-Parameter PTot for RRHalstadQWP}

Example 3 is used to reinforce some of the concepts illustrated in the previous examples. In addition, generic dataframes with detailed numerical output are described and the methodology for including user-defined ancillary trend variables is illustrated.

Run lines 51 and 52 of the script (fig. 2) to fit the same trend models used in the previous example for this dataset and examine the parameter estimation results from the text files RRHalstadQWPPTot_M1.txt and RRHalstadQWPPTot_ M2.txt (fig. 17). Similar to the previous example, there was a highly significant step trend $(p$-value $<0.001)$ for remark code MPCA, with those observations about 45-percent higher, on average, compared to the other remark codes. A comparison of the piecewise monotonic trends with and without the step trend (fig. 18) indicates substantial differences in the two fitted trends. In particular, with the step trend included, the fitted trend line was shifted down overall and the monotonic trends were smaller and less significant compared to the model without the step trend. Compared with example 2 (see fig. 15), for this site there was an earlier time interval from 1978 through 1995 during which Minnesota Pollution Control Agency and USGS data were collected, which resulted in an even larger and more significant step trend for this site. With no step trend, the standardized PARMA model residuals for this site (fig. 19, top plot) clearly indicated two distinct populations of residuals, especially during the earlier period, with a much higher 


\begin{tabular}{|c|c|c|c|c|}
\hline ****************** & \multicolumn{4}{|c|}{$-2 \operatorname{lnLik}=-408.54$} \\
\hline \multicolumn{5}{|c|}{$A I C=-360.54$} \\
\hline \multicolumn{5}{|c|}{ ecode $=1$} \\
\hline \multicolumn{5}{|l|}{ modnum $=3$} \\
\hline \multicolumn{5}{|c|}{ Parameter estimates } \\
\hline Variable & $\mathrm{CV}(\log )$ & $\mathrm{SE}(\log )$ & Pvalue & $C V(p c t)$ \\
\hline int & -0.4904 & 0.0135 & 0.00000 & NA \\
\hline$x \cos 1$ & -0.2126 & 0.0188 & 0.00000 & -38.71 \\
\hline$x \sin 1$ & -0.0777 & 0.0170 & 0.00053 & -16.38 \\
\hline$x \cos 2$ & 0.0096 & 0.0131 & 0.47388 & 2.24 \\
\hline$x \sin 2$ & -0.0246 & 0.0145 & 0.11416 & -5.51 \\
\hline falt & -0.1291 & 0.0405 & 0.00714 & -9.08 \\
\hline famt & -0.1584 & 0.0339 & 0.00044 & -13.48 \\
\hline famtsq & 0.1818 & 0.0434 & 0.00106 & 29.17 \\
\hline fast & 0.3152 & 0.0382 & 0.00000 & 21.03 \\
\hline fastxmt & -0.1826 & 0.0822 & 0.04468 & -10.14 \\
\hline m1975x1985 & -0.1783 & 0.0321 & 0.00009 & -33.67 \\
\hline$m 1985 \times 2000$ & 0.1776 & 0.0371 & 0.00036 & 50.52 \\
\hline$m 2000 \times 2015$ & -0.1363 & 0.0406 & 0.00519 & -26.94 \\
\hline
\end{tabular}

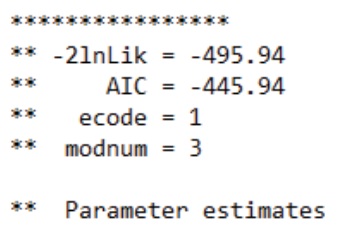

$\begin{array}{rrllr}\text { Variable } & \text { CV(log) } & \text { SE(log) } & \text { Pvalue } & \text { CV(pct) } \\ \text { int } & -0.5821 & 0.0158 & 0.00000 & N A \\ \text { xcos1 } & -0.1893 & 0.0178 & 0.00000 & -35.33 \\ \text { xsin1 } & -0.0775 & 0.0162 & 0.00028 & -16.34 \\ \text { xcos2 } & 0.0079 & 0.0120 & 0.52172 & 1.84 \\ \text { xsin2 } & -0.0241 & 0.0134 & 0.09327 & -5.40 \\ \text { falt } & -0.1336 & 0.0372 & 0.00297 & -9.39 \\ \text { famt } & -0.1459 & 0.0320 & 0.00044 & -12.49 \\ \text { famtsq } & 0.1836 & 0.0401 & 0.00043 & 29.50 \\ \text { fast } & 0.2952 & 0.0345 & 0.00000 & 19.57 \\ \text { fastxmt } & -0.1373 & 0.0734 & 0.08255 & -7.72 \\ \text { rMPCA } & 0.1606 & 0.0160 & 0.00000 & 44.74 \\ \text { m1975x1985 } & -0.1062 & 0.0304 & 0.00354 & -21.69 \\ \text { m1985x2000 } & 0.1119 & 0.0344 & 0.00580 & 29.39 \\ \text { m2000x2015 } & -0.0690 & 0.0378 & 0.08953 & -14.69\end{array}$

\section{EXPLANATION}

[MPCA, sample collected and analyzed by Minnesota Pollution Control Agency]

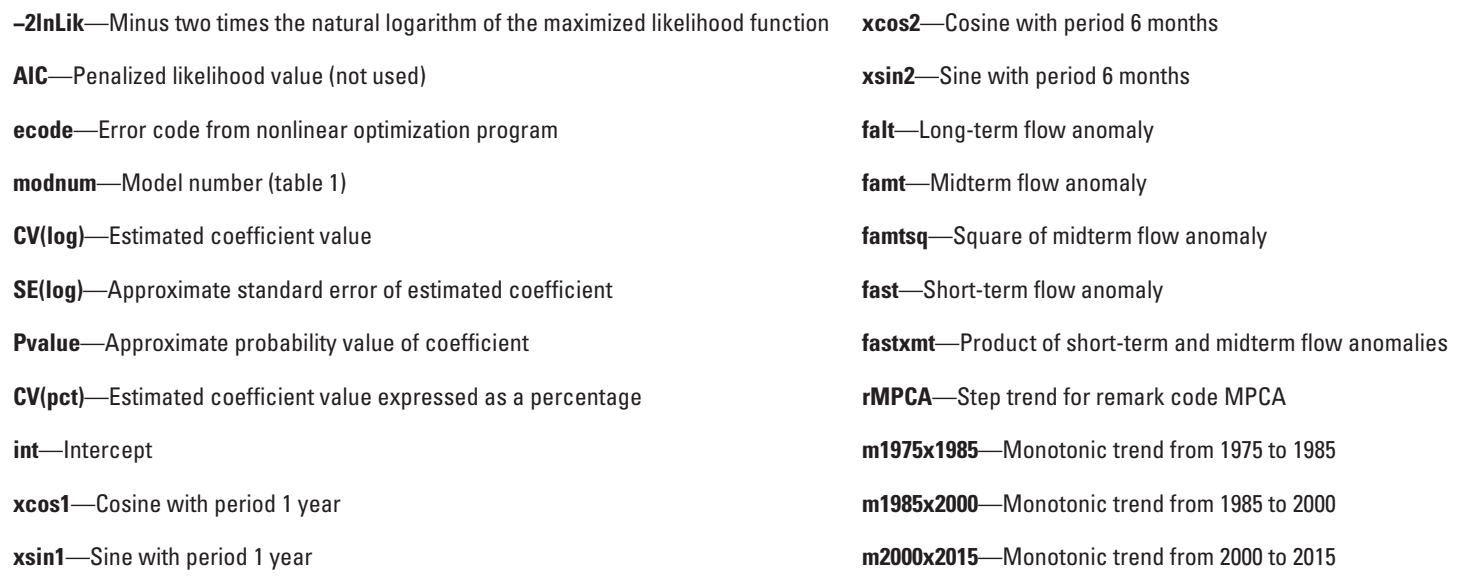

Figure 17. Parameter estimation results for total phosphorus concentration for RRHalstadQWP dataset for piecewise monotonic trend model with no step trends (left) and with step trend for remark code MPCA (right).

proportion of negative residuals for remark code USGSNL and positive residuals for remark code MPCA. With the step trend included (fig. 19, bottom plot), the residual are much more homogeneous. In this case, further examination of the data for this site indicated that the step trend was likely related to a difference between the water-quality sampling locations for the Minnesota Pollution Control Agency data versus the USGS data.

In addition to the graphical output and parameter estimation files produced by runQWmodel, several generic dataframes are produced with detailed numerical information that can be used for custom applications. These dataframes are named QWMODOUT5D (5-day model output), QWMODOUTANN (annual model output), QWFLUXOUT5D (5-day flux output), and QWEXPROBOUT5D (5-day exceedance probabilities, produced only if argument exlev is specified). These are overwritten each time a new model run is completed, so the user needs to rename or save the dataframes if they are needed for custom applications. For the most recent run completed (line 52, fig. 2), the first few lines of these dataframes are shown in figures $20 A-D$.

The generic dataframe QWMODOUT5D (fig. 20A) contains the input data used to fit the model (in this case, these data are from RRHalstadQWP) along with model output for each 5-day time step. Columns include the flow-related variability (frvar), flow-adjusted concentration data (fadat), concentration trend (tnd), flow-adjusted concentration data with step trends removed (fadat2, same as fadat if there are no step trends), concentration trend with step trends removed (tnd2, same as tnd if there are no step trends), and the standardized 

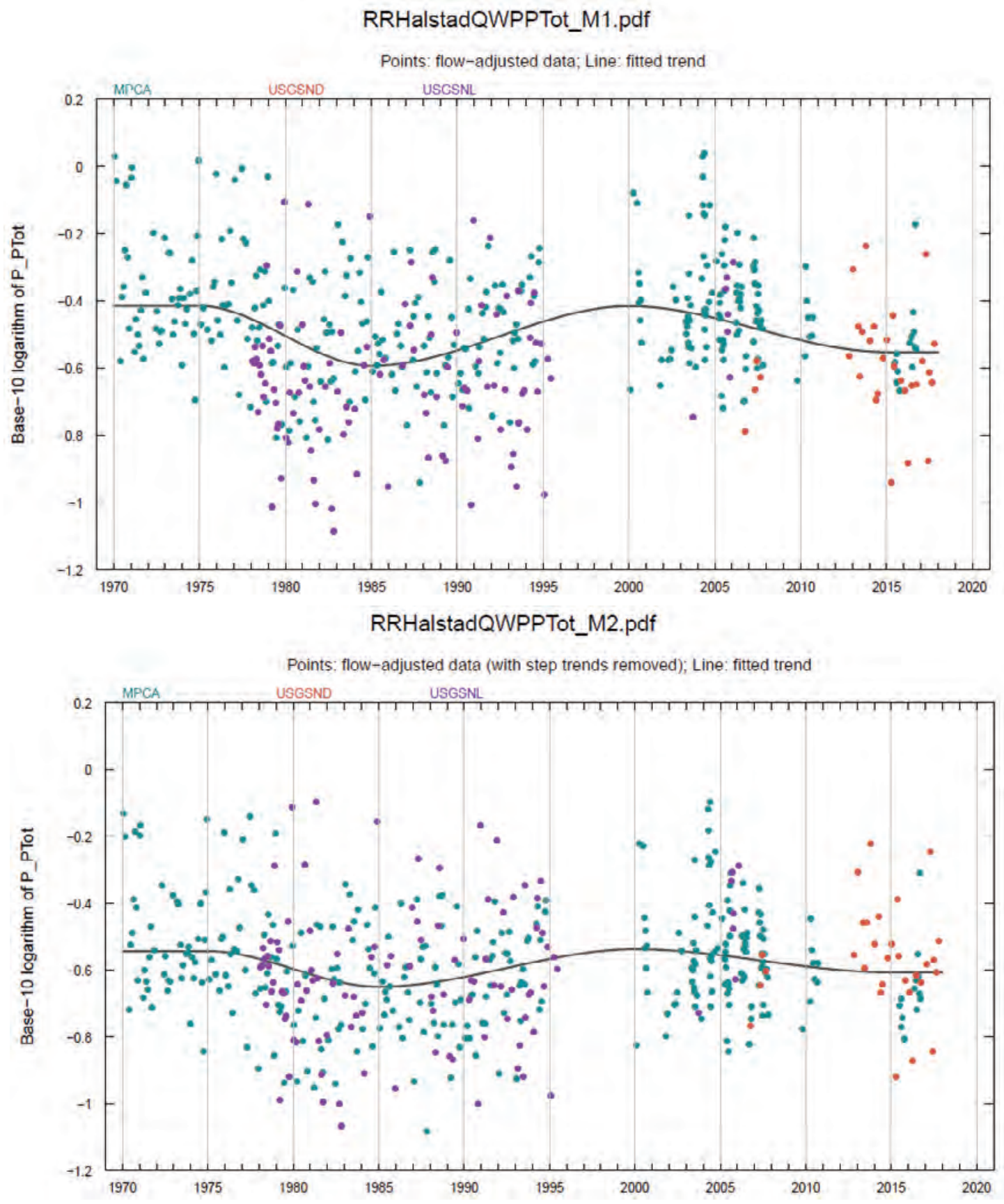

EXPLANATION

Total phosphorus concentration data

- MPCA-Sample collected and analyzed by

Minnesota Pollution Control Agency

- USGSND-Sample collected by U.S. Geological Survey and analyzed by North Dakota Health Department

- USGSNL-Sample collected by U.S. Geological Survey and no outside laboratory specified

Figure 18. Flow-adjusted total phosphorus (PTot) concentration for RRHalstadQWP dataset for piecewise monotonic trend model with no step trends (model M1, top) and with step trend for remark code MPCA (model M2, bottom). 

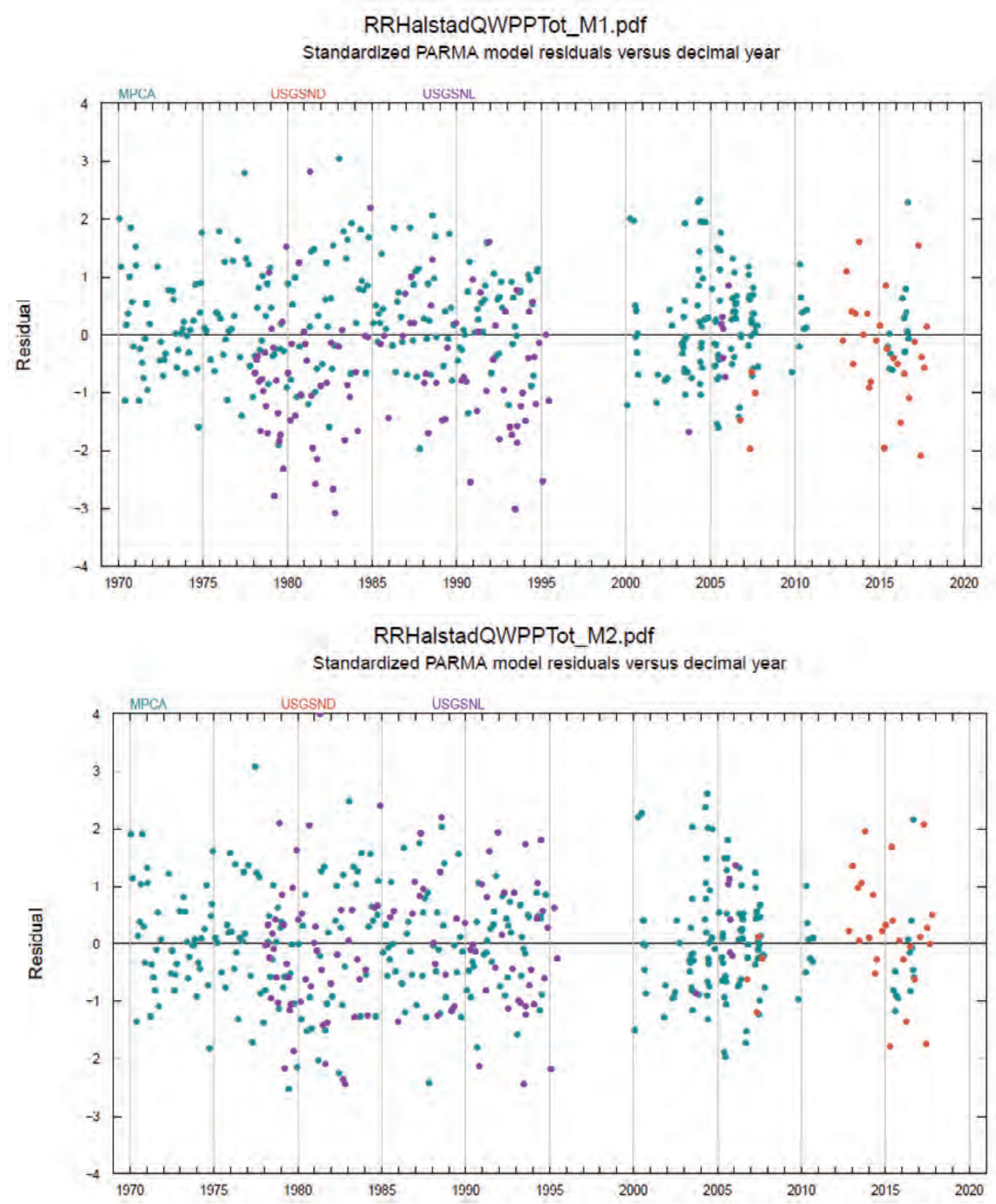

EXPLANATION

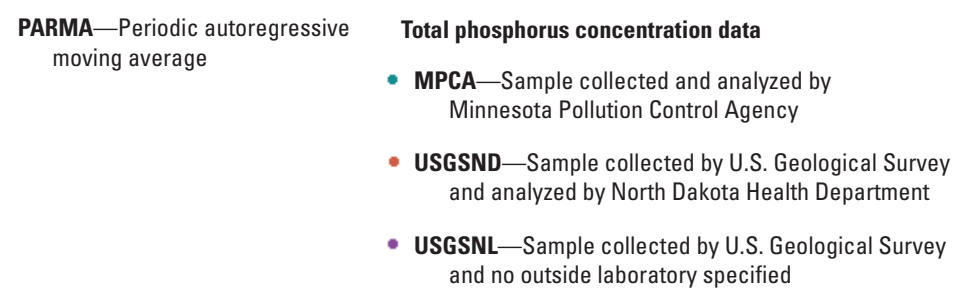

Figure 19. Standardized periodic autoregressive moving average (PARMA) model residuals for total phosphorus (PTot) concentration for RRHalstadQWP dataset for piecewise monotonic trend model with no step trends (model M1, top) and with step trend for remark code MPCA (model M2, bottom). 


\begin{tabular}{|c|c|c|c|c|c|c|c|c|c|c|c|c|c|c|c|c|c|}
\hline \multicolumn{3}{|c|}{ StartQWTrendV4.R* $x$} & \multicolumn{4}{|c|}{ QWMODOUT5D $\times$} & \multicolumn{2}{|c|}{ QWMODOUTANN $x$} & \multicolumn{3}{|c|}{ QWFLUXOUT5D $\times$} & \multicolumn{2}{|c|}{ QWEXPROBOUTSD $\times$} & & & & \\
\hline \multicolumn{18}{|c|}{$\checkmark \quad \mid$ a } \\
\hline 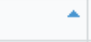 & yr $\quad$ & mo & 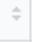 & da & 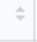 & flow $\hat{*}$ & P_PTot $\neq$ & R_PTot $\hat{\gamma}$ & dyr $=$ & $\log c=$ & frvar & fadat $\hat{\gamma}$ & tnd & fadat2 & tnd2 & 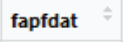 & spmres \\
\hline 3457 & 1970 & & 1 & & 3 & 295.0 & NA & NA & 1970.007 & NA & -0.686 & NA & -0.558 & NA & -0.558 & NA & NA \\
\hline 3458 & 1970 & & 1 & & 8 & 310.0 & NA & NA & 1970.021 & NA & -0.690 & NA & -0.558 & NA & -0.558 & NA & NA \\
\hline 3459 & 1970 & & 1 & & 13 & 343.0 & NA & NA & 1970.035 & NA & -0.684 & NA & -0.558 & NA & -0.558 & NA & NA \\
\hline 3460 & 1970 & & 1 & & 18 & 364.0 & 0.82 & $M P C A=$ & 1970.049 & -0.086 & -0.682 & 0.014 & -0.397 & -0.147 & -0.558 & -0.248 & 1.898 \\
\hline 3461 & 1970 & & 1 & & 23 & 357.0 & NA & NA & 1970.062 & NA & -0.691 & NA & -0.558 & NA & -0.558 & NA & NA \\
\hline 3462 & 1970 & & 1 & & 28 & 348.3 & NA & NA & 1970.076 & NA & -0.699 & NA & -0.558 & NA & -0.558 & NA & NA \\
\hline 3463 & 1970 & & 2 & & 3 & 336.6 & $N A$ & NA & 1970.090 & NA & -0.706 & NA & -0.558 & NA & -0.558 & NA & NA \\
\hline
\end{tabular}

\section{EXPLANATION}

[PARMA, periodic autoregressive moving average]

yr-Calendar year
mo-Month
da_-Day
flow_Streamflow, in cubic feet per second
P_PTot-Concentration data for parameter PTot
R_PTot-Remark code for parameter PTot
dyr-Decimal year for midpoint of 5-day time interval
logc-Logarithmically transformed concentration
(base-10 logarithm)

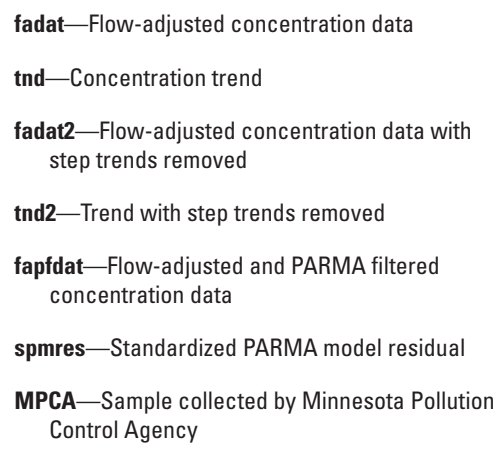

Figure 20. Generic numerical model output for total phosphorus (PTot) concentration for RRHalstadQWP dataset for model M2. $A$, model output for 5-day time step, OWMODOUT5D; $B$, model output for annual time step, OWMODOUTANN; $C$, flux estimates for 5-day time step, OWFLUXOUT5D; $D$, exceedance probabilities for 5-day time step, OWEXPROBOUT5D.

\begin{tabular}{|c|c|c|c|c|c|c|c|c|c|c|}
\hline \multicolumn{3}{|c|}{ (2) StartQWTrendV4.R* $\times$} & \multicolumn{2}{|c|}{ QWMODOUT5D $\times$} & \multicolumn{2}{|c|}{ QWMODOUTANN $\times$} & \multicolumn{2}{|c|}{ QWFLUXOUT5D $\times$} & \multicolumn{2}{|c|}{ QWEXPROBOUTSD } \\
\hline \multicolumn{11}{|c|}{\begin{tabular}{l|l|l|l|}
$\nabla$ & Filter
\end{tabular}} \\
\hline$\Delta$ & 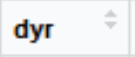 & agmc $\Rightarrow$ & tagmc & frvP10 & frvP90 & amflow & afwac $\Rightarrow$ & tafwac & aflux & taflux \\
\hline 1 & 1970.49 & 0.335 & 0.297 & 0.218 & 0.477 & 1499.487 & 0.436 & 0.381 & 1.600 & 2.591 \\
\hline 2 & 1971.49 & 0.321 & 0.297 & 0.222 & 0.466 & 1197.911 & 0.384 & 0.381 & 1.125 & 2.591 \\
\hline 3 & 1972.49 & 0.282 & 0.297 & 0.168 & 0.374 & 2282.244 & 0.338 & 0.381 & 1.889 & 2.591 \\
\hline 4 & 1973.49 & 0.318 & 0.297 & 0.220 & 0.515 & 995.699 & 0.359 & 0.381 & 0.876 & 2.591 \\
\hline 5 & 1974.49 & 0.295 & 0.297 & 0.177 & 0.421 & 1856.283 & 0.366 & 0.381 & 1.661 & 2.591 \\
\hline
\end{tabular}

\section{EXPLANATION}

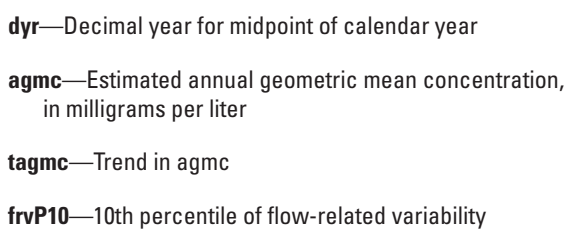

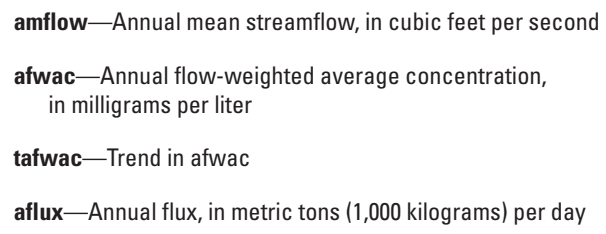

Figure 20. Generic numerical model output for total phosphorus (PTot) concentration for RRHalstadQWP dataset for model M2. $A$, model output for 5-day time step, QWMODOUT5D; $B$, model output for annual time step, OWMODOUTANN; $C$, flux estimates for 5-day time step, QWFLUXOUT5D; $D$, exceedance probabilities for 5-day time step, OWEXPROBOUT5D.-Continued 
$c$

\begin{tabular}{|c|c|c|c|c|c|c|}
\hline \multicolumn{3}{|c|}{ Q StartQWTrendV4.R* $\times$} & QWMODOUT5D $\times$ & QWMODOUTANN $\times$ & \multirow[t]{2}{*}{ QWFLUXOUT5D $\times$} & \multirow[t]{2}{*}{ QWEXPROBOUT5D $\times$} \\
\hline$\leftrightarrow \square$ & 201 & Filter & & & & \\
\hline $\boldsymbol{\Delta}$ & dyr $5 d \quad \hat{~}$ & flow $5 \mathrm{~d} \neq$ & flux $5 \mathrm{~d} \rightleftharpoons$ & & & \\
\hline 1 & 1970.007 & 295.0 & 0.18621 & & & \\
\hline 2 & 1970.021 & 310.0 & 0.19130 & & & \\
\hline 3 & 1970.035 & 343.0 & 0.21130 & & & \\
\hline 4 & 1970.049 & 364.0 & 0.22192 & & & \\
\hline 5 & 1970.062 & 357.0 & 0.20994 & & & \\
\hline
\end{tabular}

\title{
EXPLANATION
}

\author{
dyr5d-Decimal year for midpoint of 5-day time interval \\ flow5d-Streamflow, in cubic feet per second \\ flux5d-Flux, in metric tons (1,000 kilograms)
}

Figure 20. Generic numerical model output for total phosphorus (PTot) concentration for RRHalstadQWP dataset for model M2. $A$, model output for 5 -day time step, OWMODOUT5D; $B$, model output for annual time step, OWMODOUTANN; $C$, flux estimates for 5-day time step, OWFLUXOUT5D; $D$, exceedance probabilities for 5-day time step, OWEXPROBOUT5D.-Continued

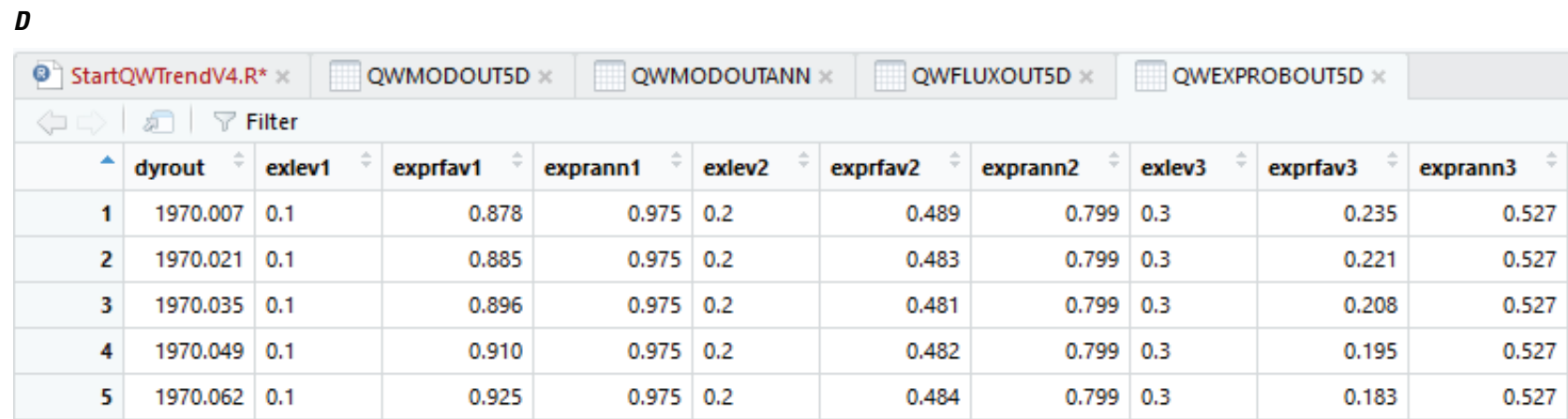

\section{EXPLANATION}

[Trailing integers $(1,2,3)$ for column names designate three different specified exceedance levels]

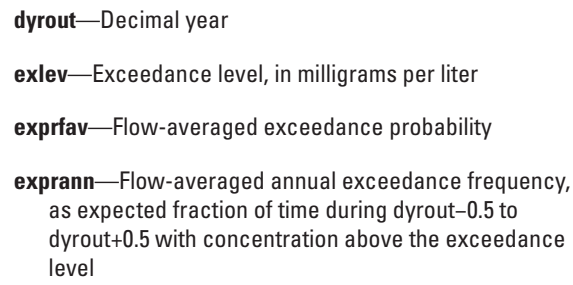

Figure 20. Generic numerical model output for total phosphorus (PTot) concentration for RRHalstadQWP dataset for model M2. $A$, model output for 5 -day time step, OWMODOUT5D; $B$, model output for annual time step, OWMODOUTANN; $C$, flux estimates for 5-day time step, OWFLUXOUT5D; $D$, exceedance probabilities for 5-day time step, OWEXPROBOUT5D.-Continued 
PARMA model residuals (spmres). For example, the bottom plot in figure 18 can be reproduced by plotting the decimal year versus fadat2 (points) and the decimal year versus tnd2 (line) and the bottom plot in figure 19 can be reproduced by plotting the decimal year versus spmres.

The dataframe QWMODOUTANN (fig. 20B) contains annual model output used for producing plots such as those shown in figure $12 \mathrm{H}-\mathrm{J}$. Columns include the estimated annual geometric mean concentration (agmc, the points in fig. 12H) and associated trend (tagmc, the line in fig. 12H), the estimated annual flow-weighted average concentration (afwac, the points in fig. 12I) and associated trend (tafwac, the line in fig. 12I), and the estimated annual flux (aflux, the points in fig. 12J) and associated trend (taflux, the line in fig. 12J).

The dataframe QWFLUXOUT5D (fig. 20C) contains flux estimates for each 5-day time step and can be used for custom applications that require more detained flux estimates than the annual values provided in QWMODOUTANN. Variables include streamflow (flow5d, in cubic feet per second) and estimated flux (flux 5d, in metric tons).

The dataframe QWEXPROBOUT5D (fig. 20D) contains information on exceedance probabilities used to produce plots such as figure 16. Variables include, for each specified exceedance level, the flow-averaged exceedance probability (exprfav, used to produce the thin lines in fig. 16) and the flow-averaged annual exceedance frequency (exprann, used to produce the heavy lines in fig. 16, where the annual values are plotted for the midpoint of each decimal year).

The next part of this example shows how to include userspecified trend variables using the optional argument userxx in the runQWmodel() function:

userxx $=\operatorname{list}(\mathrm{nu}$, ancxx, vnms)

where

nu is the number of user-specified trends,

ancxx is a dataframe with a row dimension identical to the input dataframe (XXXQWP) and one or more columns with user-specified ancillary trend variables, and

vnms the column names of the trend variables to select from ancxx.

The columns of ancxx corresponding to ancillary trend variables must be numeric and have no missing values, and the dates of the rows must correspond to the "date" column of XXXQWP.

Run lines 55-56 of the script file (fig. 2) to create a dataframe called ancxx with 8 columns, where the first column is the decimal year and the remaining 7 columns are basis functions for a cubic spline with the specified knots. Then, run line 57 to fit a trend model with user-specified trend variables consisting of the seven basis functions and step trend for remark code MPCA (model M3). The graphical output for model M3 (see RRHalstadQWPPTot_M3.pdf, fig. 21) was similar to the output for model M2 (fig. 18, bottom plot) and the value of $-2 \ln L i k$ for model M3 (-497.56, see RRHalstadWQWPPTot_M3.txt) was less than the value for M2 $(-495.94)$. However, using the GLR principal, the $p$-value for judging if the more complicated model (M3) is better than the less complicated model (M2) is $P=1-p c h i s q(1.62$, $d f=4)=0.805$. The large $p$-value indicates that the less complicated model (M2) is preferred over M3.

Occasionally, when runQWmodel() is computing the maximum likelihood parameter estimates, a runtime error can occur. The most likely cause for the error is a misspecified trend model; for example, in line 59 of the script file (fig. 2), there are 3 monotonic trends specified, but the first two are identical. When running this command, an error window will appear (fig. 22). When this happens, simply close the error window, correct the trend model, and continue. On rare occasions, a similar error window may appear even if the trend model is not misspecified. This usually means that either the trend model, PARMA model, or both are too complicated to allow the maximum likelihood estimates to be computed. If the error cannot be avoided by either simplifying the trend model or lowering the PARMA model number (for example, trying modnum $=2$ or modnum $=1$ rather than the default, modnum=3), the data cannot be analyzed using R-QWTREND. 


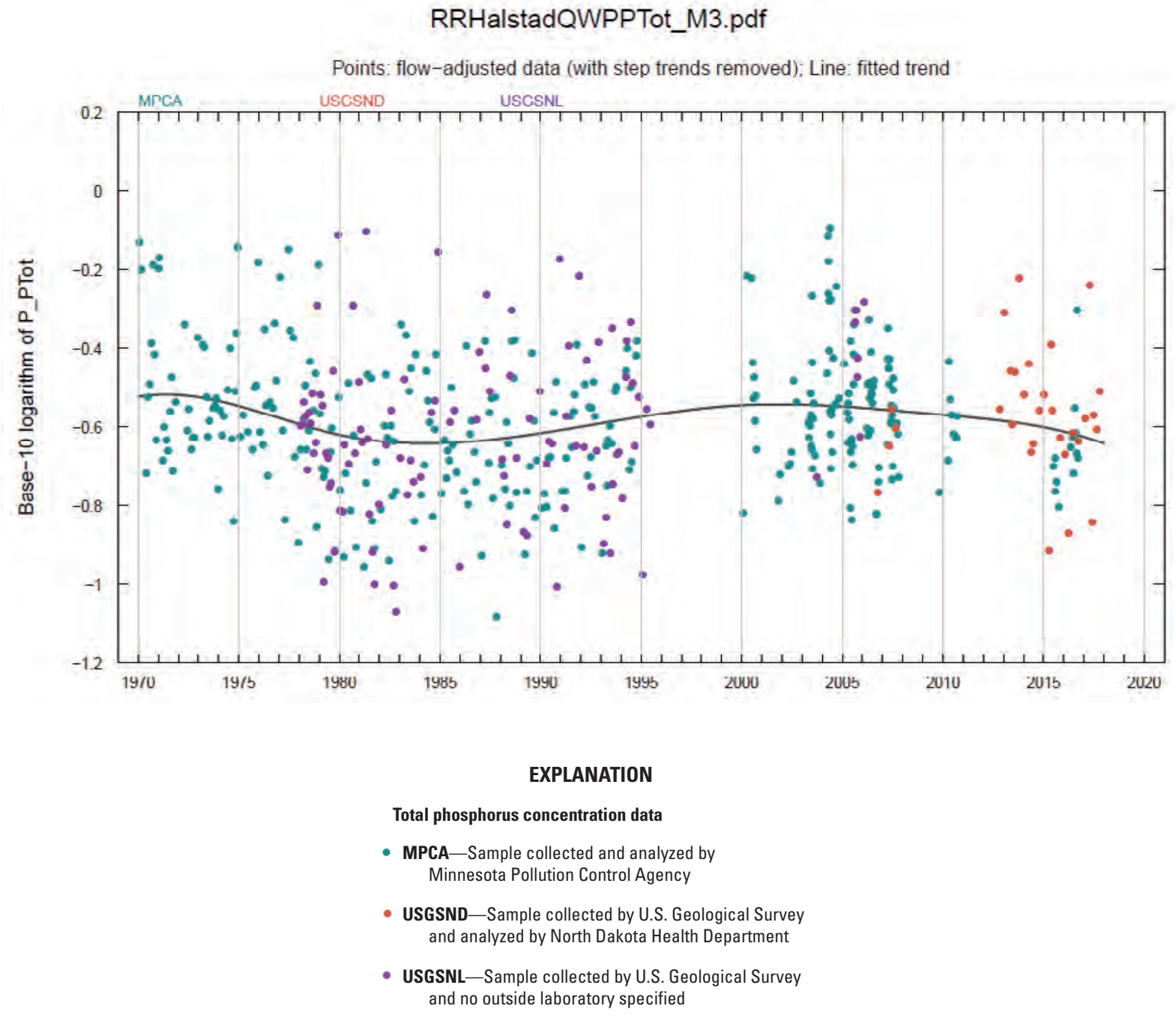

Figure 21. Graphical output for total phosphorus (PTot) concentration for RRHalstadQWP dataset for model with user-specified trend (model M3).

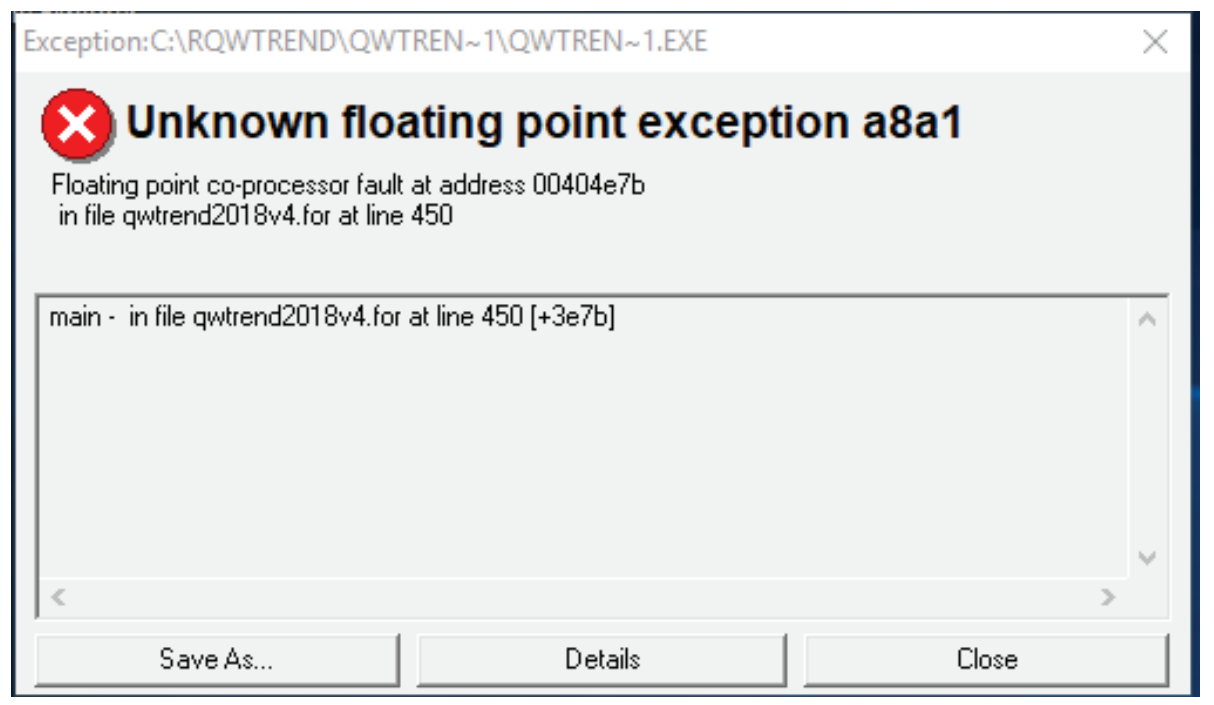

Figure 22. Runtime error window produced by run 0 Wmodel when an error is detected during the maximum likelihood estimation. 


\section{Summary}

As part of a U.S. Geological Survey water-quality study started in 2018, in cooperation with the International Joint Commission, North Dakota Department of Environmental Quality, and Minnesota Pollution Control Agency, a publicly available software package called R-QWTREND was developed for analyzing trends in stream-water quality. The R-QWTREND package is a collection of functions written in $\mathrm{R}$, an open source language and a general environment for statistical computing and graphics. The package uses a parametric time-series model to express logarithmically transformed concentration in terms of flow-related variability, trend, and serially correlated model errors. Flow-related variability captures natural variability in concentration on the basis of concurrent and antecedent streamflow. The trend identifies systematic changes in concentration in terms of potential step trends, piecewise monotonic trends, or user-specified trends. Maximum likelihood estimation is used to estimate model parameters and determine the best-fit trend model.

This report describes the time-series model and statistical methodology behind R-QWTREND and provides formal documentation for installing and using the package. This report, along with the accompanying software package, practice datasets, and examples, provides all of the necessary materials and documentation for using R-QWTREND to analyze and interpret trends in stream-water quality based on long-term (10 or more years) datasets on constituent concentration from discrete stream-water samples collected multiple times per year (quarterly or more frequent sampling) and for which the stream-water sampling location is colocated with a streamflow-gaging station from which a complete record of daily mean streamflow is available.

\section{References Cited}

Cohn, T.A., DeLong, L.L., Gilroy, E.J., Hirsch, R.M., and Wells, D.K., 1989, Estimating constituent loads: Water Resources Research, v. 25, no. 5, p. 937-942. [Also available at https://doi.org/10.1029/WR025i005p00937.]

Dennis, J.E., Jr., and Schnabel, R.B., 1996, Numerical methods for unconstrained optimization of nonlinear equations: Englewood Cliffs, N.J., Society for Industrial and Applied Mathematics, 378 p. [Also available at https://doi.org/ 10.1137/1.9781611971200.]

Galloway, J.M., Vecchia, A.V., Vining, K.C., Densmore, B.K., and Lundgren, R.F., 2012, Evaluation of water-quality characteristics and sampling design for streams in North Dakota, 1970-2008: U.S. Geological Survey Scientific Investigations Report 2012-5216, 304 p. [Also available at https://doi.org/10.3133/sir20125216.]
Giorgino, M.J., Cuffney, T.F., Harden, S.L., and Feaster, T.D., 2018 , Trends in water quality of selected streams and reservoirs used for water supply in the Triangle area of North Carolina, 1989-2013: U.S. Geological Survey Scientific Investigations Report 2018-5077, 67 p., accessed June 2019 at https://doi.org/10.3133/sir20185077.

Graybill, F.A., 1976, Theory and application of the linear model: Duxbury Press, 704 p.

Helsel, D.R., and Hirsch, R.M., 1992, Statistical methods in water resources: Elsevier, 529 p.

Jimenez, C., McLeod, A.I., and Hipel, K.W., 1989, Kalman filter estimation for periodic autoregressive moving average models: Stochastic Hydrology and Hydraulics, v. 3, no. 3, p. 227-240. [Also available at https://doi.org/10.1007/ BF01543862.]

Johnson, H.O., Gupta, S.C., Vecchia, A.V., and Zvomuya, F., 2009, Assessment of water quality trends in the Minnesota River using non-parametric and parametric methods: Journal of Environmental Quality, v. 38, no. 3, p. 1018-1030. [Also available at https://doi.org/10.2134/ jeq2008.0250.]

Jones, G., and Armstrong, N., 2001, Long-term trends in total nitrogen and total phosphorus concentrations in Manitoba streams: Environment Manitoba, Manitoba Conservation Report no. 2001-07, 175 p.

Metropolitan Council, 2014, Comprehensive water quality assessment of selected metropolitan area streamsIntroduction and methodologies: St. Paul, Minn., Metropolitan Council, 46 p., accessed November 7, 2019, at https://metrocouncil.org/Wastewater-Water/Services/ Water-Quality-Management/Stream-Monitoring-Analysis/ Introduction-and-Methodologies.aspx.

National Water Quality Monitoring Council, 2019, Water quality portal: National Water Quality Monitoring Council web page, accessed October 31, 2019, at https://www.waterqualitydata.us.

Paquette, C., 2011, Statistical analysis of trends in the Red River over a 45-year period: University of Manitoba, UM Project 33898, 126 p.

R Development Core Team, 2019, R-A language and environment for statistical computing: Vienna, Austria, R Foundation for Statistical Computing, accessed June 12, 2019, at https://www.r-project.org.

Risch, M.R., Bunch, A.R., Vecchia, A.V., Martin, J.D., and Baker, N.T., 2014, Water quality in Indiana-Trends in concentrations of selected nutrients, metals, and ions in streams, 2000-10: U.S. Geological Survey Scientific Investigations Report 2014-5205, 47 p. [Also available at https://doi.org/10.3133/sir20145205.] 
Salas, J.D., Tabios, G.Q., III, and Bartolini, P., 1985, Approaches to multivariate modeling of water resources time series: Water Resources Bulletin, v. 21, no. 4, p. 683-708. [Also available at https://doi.org/10.1111/ j.1752-1688.1985.tb05383.x.]

Sando, S.K., Clark, M.L., Cleasby, T.E., and Barnhart, E.P., 2015, Water-quality trends for selected sites in the Boulder River and Tenmile Creek watersheds, Montana, based on data collected during water years 1997-2013: U.S. Geological Survey Scientific Investigations Report 2015-5008, 46 p., accessed June 2019 at https://doi.org/10.3133/sir20155008.

Sando, S.K., Vecchia, A.V., Lorenz, D.L., and Barnhart, E.P., 2014a, Water-quality trends for selected sampling sites in the upper Clark Fork Basin, Montana, water years 1996-2010: U.S. Geological Survey Scientific Investigations Report 2013-5217, 162 p., with appendixes, accessed June 2019 at http://dx.doi.org/ 10.3133/sir20135217.

Sando, S.K., Vecchia, A.V., Barnhart, E.P., Sando, T.R., Clark, M.L., and Lorenz, D.L., 2014b, Trends in majorion constituents and properties for selected sampling sites in the Tongue and Powder River watersheds, Montana and Wyoming, based on data collected during water years 1980-2010: U.S. Geological Survey Scientific Investigations Report 2013-5179, 123 p., accessed June 2019 at https://doi.org/10.3133/sir20135179.
Therneau, T.M., 2019, survival-A package for survival analysis in S: R package version 3.5.1, accessed June 12, 2019, at https://cran.r-project.org/web/packages/survival/ index.html.

U.S. Geological Survey, 2019, USGS water data for the Nation: U.S. Geological Survey National Water Information System database, accessed October 31, 2019, at https://nwis.waterdata.usgs.gov/nwis. [Also available at https://doi.org/10.5066/F7P55KJN.]

Vecchia, A.V., 1985, Periodic autoregressive moving average (PARMA) modeling with applications to water resources: Water Resources Bulletin, v. 21, no. 5, p. 721-730. [Also available at https://doi.org/10.1111/j.17521688.1985.tb00167.x.]

Vecchia, A.V., 2000, Water-quality trend analysis and sampling design for the Souris River, Saskatchewan, North Dakota and Manitoba: U.S. Geological Survey WaterResources Investigation Report 2000-4019, 77 p. [Also available at https://doi.org/10.3133/wri004019.]

Vecchia, A.V., 2003, Water-quality trend analysis and sampling design for streams in North Dakota: U.S. Geological Survey Water-Resources Investigation Report 2003-4094, 73 p. [Also available at https://doi.org/10.3133/wri034094.]

Vecchia, A.V., 2005, Water-quality trend analysis and sampling design for streams in the Red River of the North Basin, Minnesota, North Dakota, and South Dakota, 1970-2001: U.S. Geological Survey Scientific Investigations Report 2005-5224, 54 p. [Also available at https://doi.org/10.3133/ sir20055224.] 


\section{Appendix 1 R-OWTREND Software Package}

A folder, QWTREND2018V4, can be downloaded at https://doi.org/10.3133/ofr20201014. The folder contains the files described in table 1.1.

Although the files and data have been processed successfully on a computer system at the U.S. Geological Survey (USGS), no warranty expressed or implied is made regarding the display or utility of the data for other purposes, nor on all computer systems, nor shall the act of distribution constitute any such warranty. The USGS or the U.S. Government shall not be held liable for improper or incorrect use of the data and files described and (or) contained herein.
This software has been approved for release by the USGS. Although the software has been subjected to rigorous review, the USGS reserves the right to update the software as needed pursuant to further analysis and review. No warranty, expressed or implied, is made by the USGS or the U.S. Government as to the functionality of the software and related material nor shall the fact of release constitute any such warranty. Furthermore, the software is released on condition that neither the USGS nor the U.S. Government shall be held liable for any damages resulting from its authorized or unauthorized use.

Table 1.1. Name and description of files in OWTREND2018V4 folder.

\begin{tabular}{ll}
\hline \multicolumn{1}{c}{ File name } & \multicolumn{1}{c}{ Description } \\
\hline Readme.doc & Word document with instructions for using R-QWTREND. \\
prepQWdataV4.txt & Text file containing R code for creating function prepQWdata(). \\
runQWmodelV4.txt & Text file containing R code for creating function runQWmodel(). \\
plotQWtrendV4.txt & Text file containing R code for creating function plotQWtrend(). \\
qwtrend2018v4.exe & Windows executable file used for computing maximum likelihood parameter estimates. \\
salflibc.dll & Dynamic link library required by qutrend2018v4.exe. \\
QWTrendV4_practice.RData & R workspace with example datasets. \\
StartQWTrendV4.R & R script for installing and running R-QWTREND. \\
\hline
\end{tabular}


For more information about this publication, contact: Director, USGS Dakota Water Science Center 821 East Interstate Avenue, Bismarck, ND 58503 1608 Mountain View Road, Rapid City, SD 57702

605-394-3200

For additional information, visit: https://www.usgs.gov/centers/dakota-water

Publishing support provided by the Rolla Publishing Service Center 
